\title{
WestVirginiaUniversity
}

THE RESEARCH REPOSITORY @ WVU

Graduate Theses, Dissertations, and Problem Reports

2020

\section{Shaping Urban spaces to fit into Religious Boundaries through Landscape}

Niharika Alahari

na0056@mix.wvu.edu

Follow this and additional works at: https://researchrepository.wvu.edu/etd

Part of the Landscape Architecture Commons

\section{Recommended Citation}

Alahari, Niharika, "Shaping Urban spaces to fit into Religious Boundaries through Landscape" (2020). Graduate Theses, Dissertations, and Problem Reports. 7676.

https://researchrepository.wvu.edu/etd/7676

This Thesis is protected by copyright and/or related rights. It has been brought to you by the The Research Repository @ WVU with permission from the rights-holder(s). You are free to use this Thesis in any way that is permitted by the copyright and related rights legislation that applies to your use. For other uses you must obtain permission from the rights-holder(s) directly, unless additional rights are indicated by a Creative Commons license in the record and/ or on the work itself. This Thesis has been accepted for inclusion in WVU Graduate Theses, Dissertations, and Problem Reports collection by an authorized administrator of The Research Repository @ WVU. For more information, please contact researchrepository@mail.wvu.edu. 


\section{Shaping urban spaces to fit into religious boundaries through landscape. \\ Niharika Alahari}

Thesis submitted to

Davis College of Agriculture, Natural Resources and Design at West Virginia University

In partial fulfillment of the requirements for the degree of

Masters in Landscape Architecture

Peter Butler, MLA, Committee Chairperson

Dr. Stefania Staniscia

Dr. James Anderson

Department of Landscape Architecture

School of Design and Community Development

Morgantown, West Virginia

May 2020

Keywords: Vijayawada, Religion, Urban context, Pushkaraalu, Ghats

Copyright 2020 Niharika Alahari 
Shaping urban spaces to fit into religious boundaries through landscape.

\author{
Niharika Alahari
}

In India, rivers are considered a sacred entity for Hindus and temples on the banks of rivers are a common sight in Indian architectural character. Devotees come to worship and perform small ceremonies on ghats, banks of the river, to the gods and ancestors. This is considered a part of an important ritual prior to entering the temple associated with the river. One such river in South India where this practice occurs, is the Krishna river in Vijayawada, an important pilgrimage center for devotees and the location for this study. Although this practice is a daily occurrence and one hundred thousand devotees visit the temple on average, Pushkaraalu is the main event that happens once every 12 years and observed for a period of 12 days. 2016 was the latest when the river hosted 35 million devotees. Performing ceremonies on the riverbank often led to stampedes and devotees fainting due to exhaustion. This study looks at creating a spiritual experience through landscape design along the corridor that connects the ghats to the temple. Also, on design alternatives that helps people to carry out required rituals in a protective environment on the ghats and alleviate further degeneration of the river. Further this project develops a design template that could be adopted at various other ghats along the river, as needed. The speed of the river during monsoons and the amount of water in the river during summer are principle considerations along with existing integrity and emotional connection of people with this sacred location.

\section{SHAPING URBAN SPACES TO FIT INTO RELIGIOUS BOUNDARIES \\ THROUGH LANDSCAPE.}

\author{
NIHARIKA ALAHARI \\ నిహరిక అలహరి
}




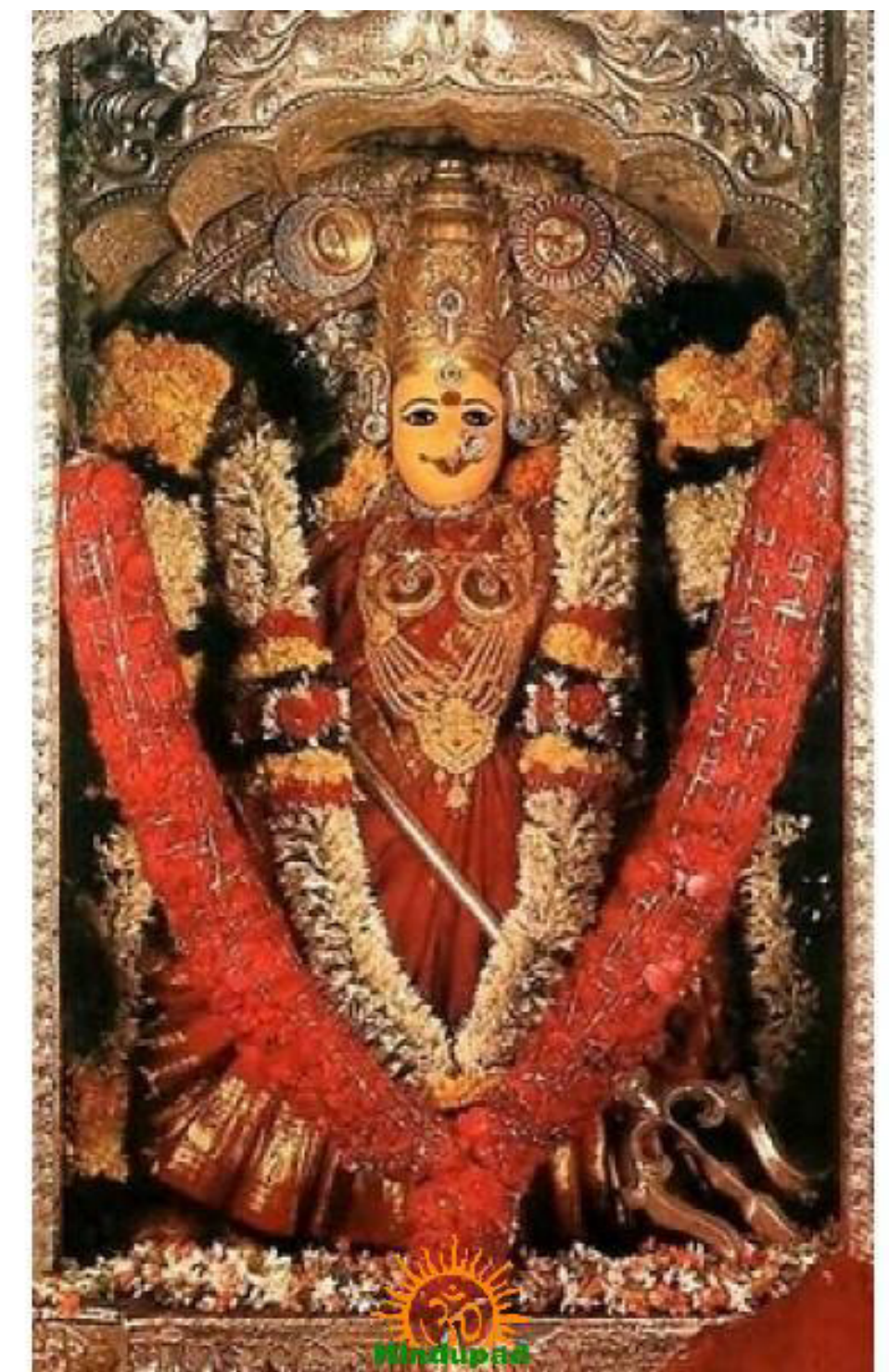

GODDESS KANAKA DURGA, VIJAYAWADA, INDIA

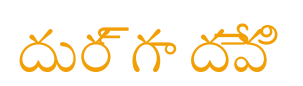

\section{AEKNBWLEBEEMENTS}

To my grandparents, with whom I had the motivation and perseverance to finish my master's degree. My forever best friend and my brother who is emotional support during days when it felt like the end of the world. A huge gratitude to my uncle and parents for supporting me all through my life and friends like family who have made my living in this alien world, a home.

My deepest gratitude to Prof. Peter Butler, for the encouragement he has given me over the years and fostering a positive and learning environment. Also, Dr. Stefania Staniscia and Dr. James Anderson for being patient guides and advisors for my thesis. My sincere thanks to all the professors and staff of Landscape Architecture Dept. and my fellow master's students who have been a great source of knowledge.

Thank you all. 


\section{E8NFENFS}

INTRODUCTION

SOUTH INDIA

CASE STUDIES

URBAN SETTLEMENTS 32

SITE STUDY

THEORY

FESTIVALS

ACTIVITY MAPPING

CONCEPT SKETCHES

AIM \& OBJECTIVE
56

41

60

73

75

82

\section{E8NFENT§}

MASTER PLAN 85

DETAIL PLAN 90

PERSPECTIVES 91

SECTIONS

97

PLANTING LIST 103

CANAL STUDY 109

CONCLUSION 127

REFERENCES 129 


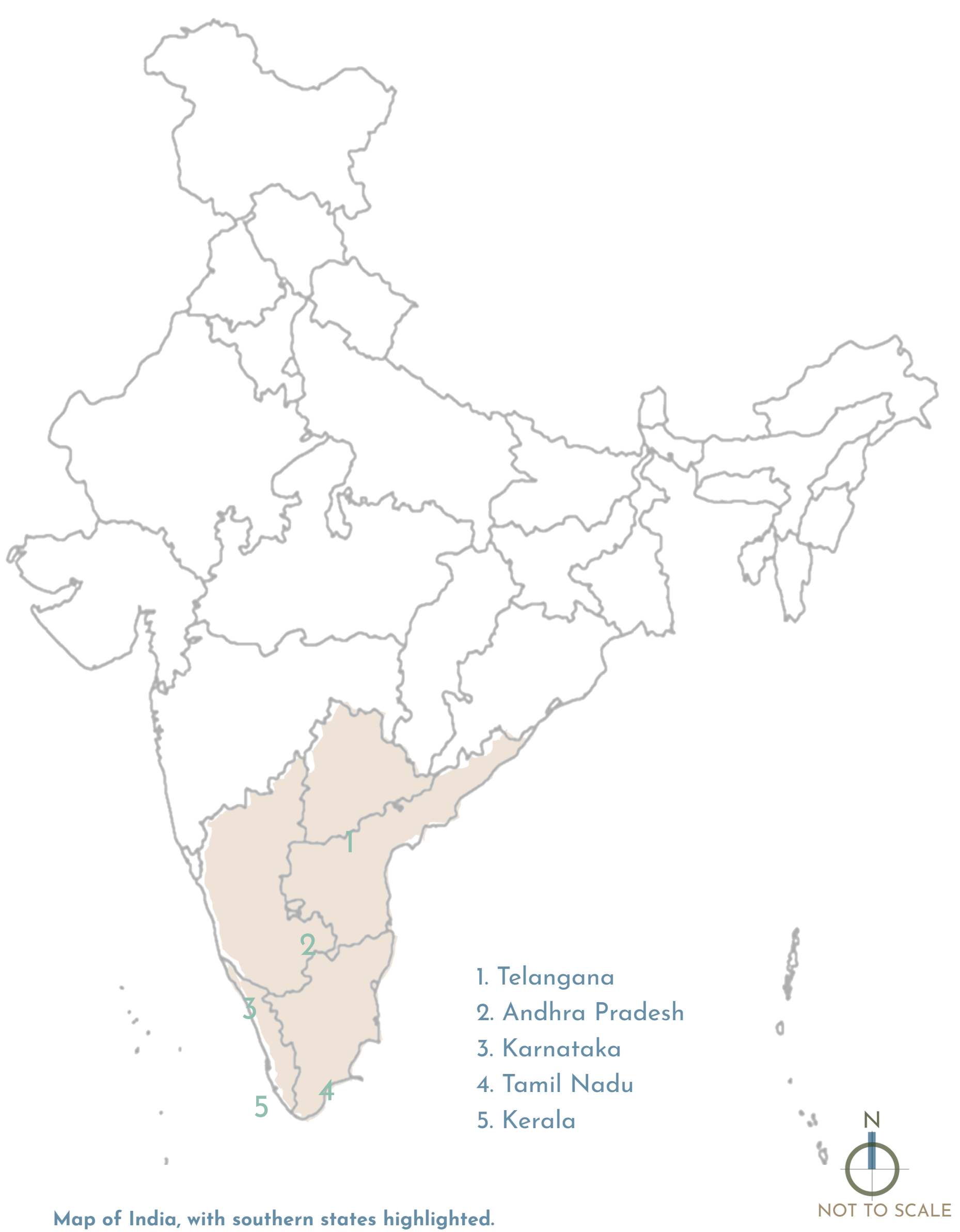

\title{
INFR8BUE干|8N
}

\author{
"India rarely changes and rarely forgets" - F.Yeats Brown
}

Religion in India is diverse, with varied religious beliefs and practises. The second most populous country in the world, 78.35\%[1] of Indian population are considered Hindus (people who follow Hinduism), $14.2 \%$ are Muslims (people who follow Islam), $2.34 \%$ are Christians and the rest fall under the categories of Jainism, Sikhism, Buddhism, among other religious which are unaffiliated. Religious structures like temples, mosques, gurdwaras, etc. are scattered within the urban fabric of densely distributed country. Social gatherings in the premises of temples, for example, is a common sight which coexists with everyday life of diverse activities.

Temples host religious events based on the Hindu Lunar Calendar[2], attracting crowds containing thousands of devotees, waiting for a chance to glimpse at the idol of the deity. Furthermore, the guidelines and sacred scriptures of Hinduism, describes the importance of nature and often seen are teachings that consider the earth as the ultimate God and offer prayers to all the natural elements. 


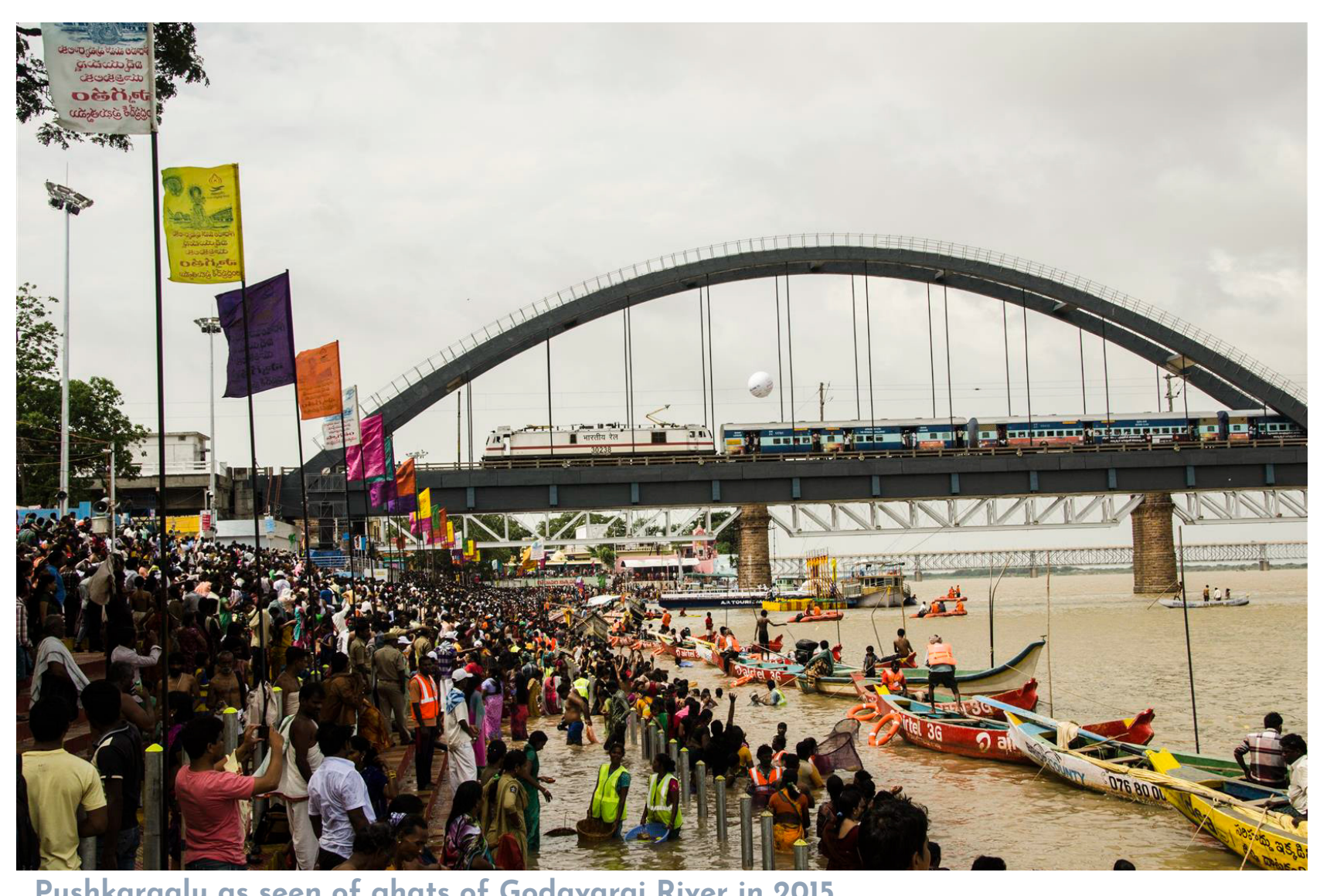

The earth - Devi - is a goddess and our mother and deserves our devotion and protection. Many Hindu rituals recognize that human beings benefit from the earth, and offer gratitude and protection in response Many Hindus touch the floor before getting out of bed every morning and ask Devi to forgive them for trampling on her body.

Pankaj JainAssociate Professor of Indic Studies

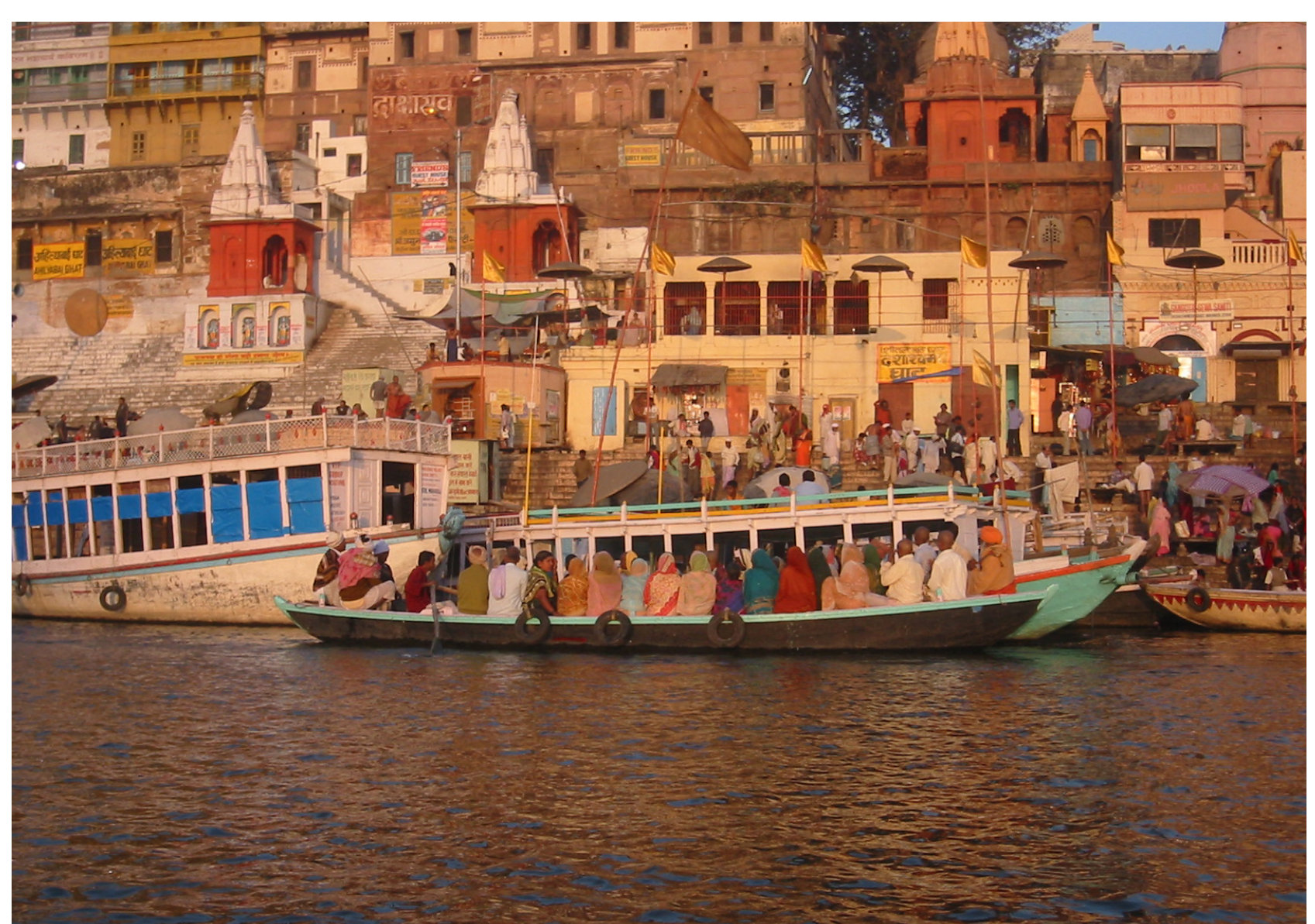

Water, in the form of rivers, is one of the elements of nature that is worshipped in Hindu religion. A devotee reaches the bank of the river to complete assigned religious hrituals before entering the temple. The banks of the river, with a series of steps leading to the river is called a 'ghat' and along with its religious importance, adds an essential architectural character to the urban context.

There are specific "shmashana" [3] or "cremation" ghats where bodies are cremated on the banks, allowing ashes to be washed away by rivers. 


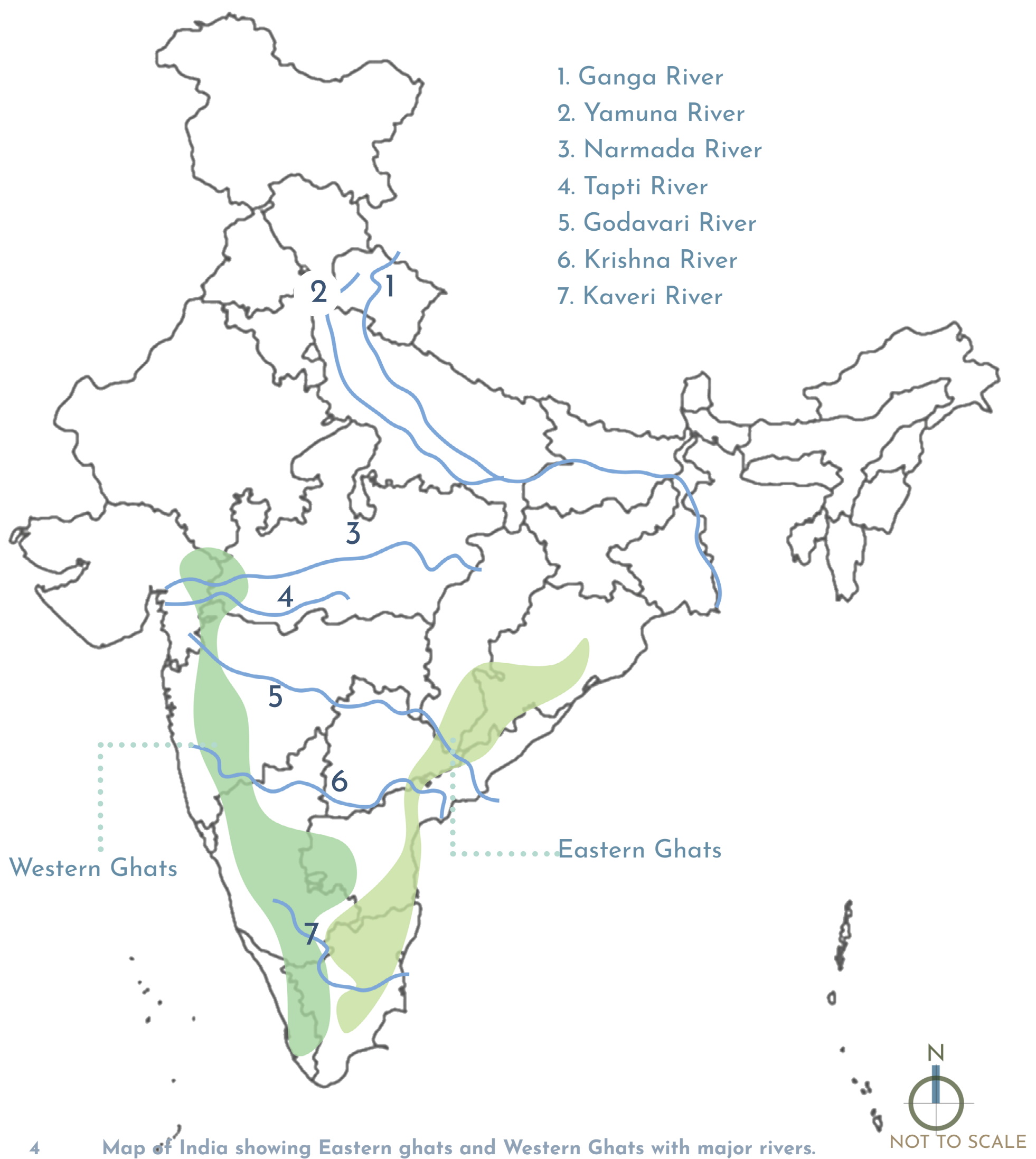

Additionally, India lies on the Indian Plate, the northern part of the Indo-Australian Plate [4], whose continental crust forms the Indian subcontinent. The country is situated north of the equator. On the south, India projects into and is bounded by the Indian Ocean-in particular, by the Arabian Sea on the west, the Lakshadweep Sea to the southwest, the Bay of Bengal on the east, and the Indian Ocean proper to the south.

Topographically the Western Ghats [5] are a mountain range that covers an area of 140,000 square kilometres $(54,000 \mathrm{sq} \mathrm{mi})$ in a stretch of 1,600 kilometres $(990 \mathrm{mi})$ parallel to the western coast of the Indian peninsula. It is a UNESCO World Heritage Site and is one of the eight hot-spots of biological diversity in the world. It is sometimes called the Great Escarpment of India.It contains a large proportion of the country's flora and fauna, many of which are only found in India.

Also, the eastern ghats are a discontinuous range of mountains along India's eastern coast. They are eroded and cut through by four major rivers of peninsular India which are the Godavari, Mahanadi, Krishna, and Kaveri. 


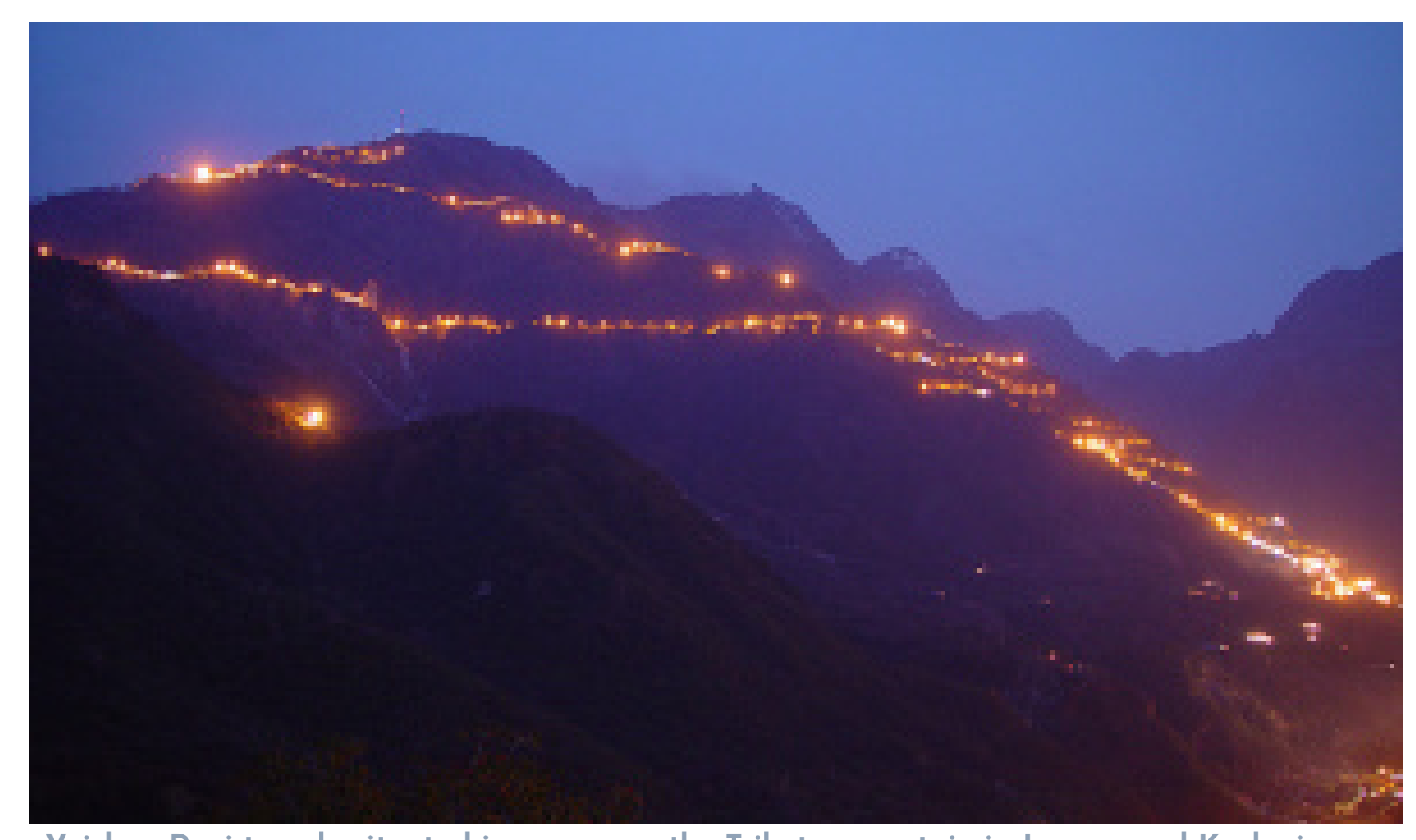

While both type of ghats along with rivers, play an important role in Hindu religion, this thesis looks at one particular river and temple/ goddess associated with it.

\begin{tabular}{|c|c|c|c|}
\hline $\begin{array}{l}\text { Hindu } \\
\text { Zodiac }\end{array}$ & $\begin{array}{l}\text { Western } \\
\text { Zodiac }\end{array}$ & River & $\begin{array}{l}\text { Next } \\
\text { Pushkaraalu }\end{array}$ \\
\hline Mesha & Aries & Ganga & 2023 \\
\hline Vrishabha & Taurus & Narmada & 2024 \\
\hline Mithuna & Gemini & Saraswati & 2025 \\
\hline Karkataka & Cancer & Yamuna & 2026 \\
\hline Simha & Leo & Godavari & 2027 \\
\hline Kanya & Virgo & Krishna & 2028 \\
\hline Tula & Libra & Kaveri & 2029 \\
\hline Vrishchika & Scorpio & Bhima & 2030 \\
\hline Dhanus & Sagittarius & Tapti & 2031 \\
\hline Makara & Capricorn & Tungabhadra & 2020 \\
\hline Kumbha & Aquarius & Singhu & 2021 \\
\hline Mina & Pisces & Pranahita & 2022 \\
\hline
\end{tabular}

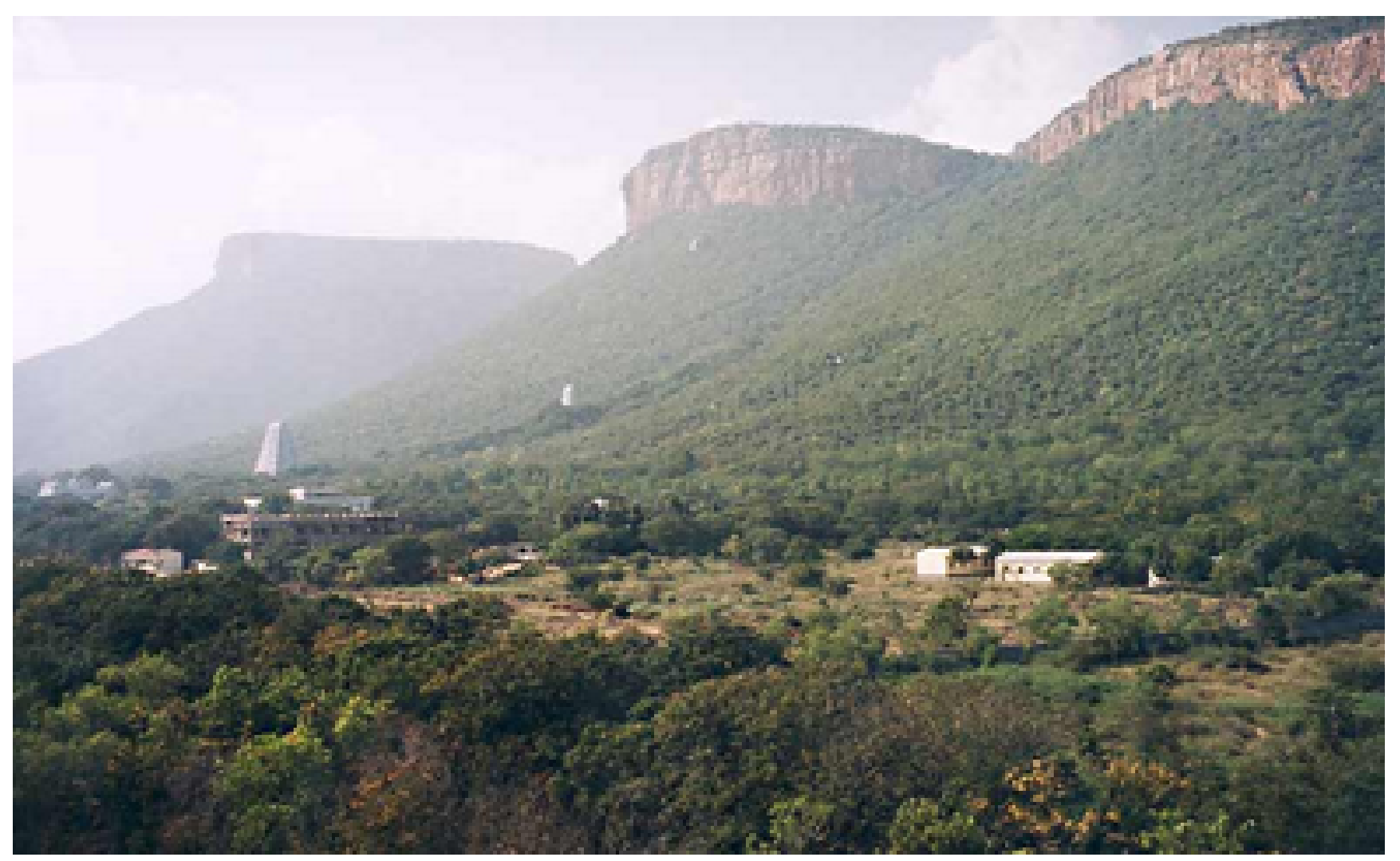




\section{§В U干月 INBIA}

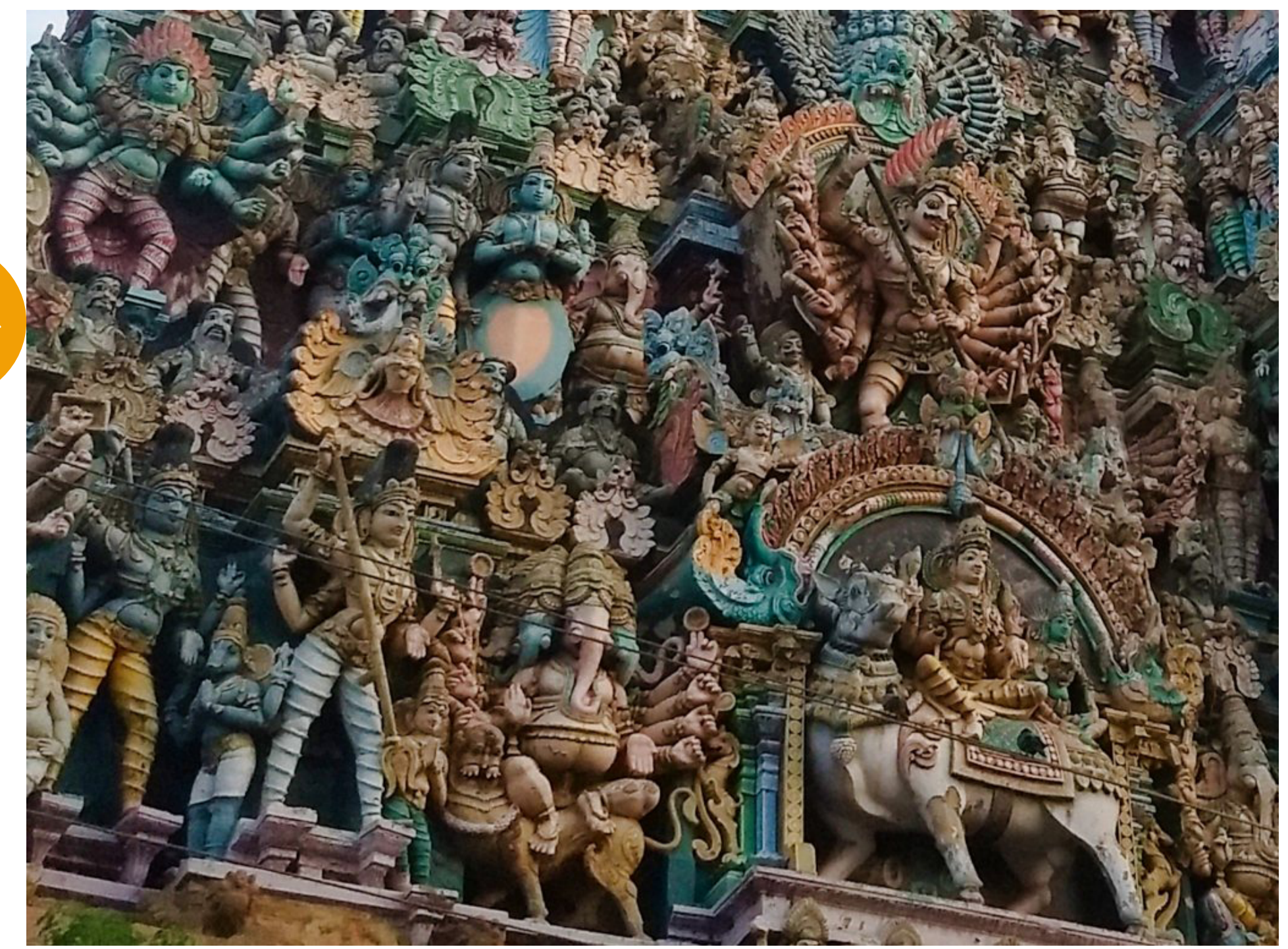

Intricate sculpture work on the 'gopuram' of Meenakshi temple, Madurai.
The numerous religions in India represent one of the important aspects of Indian culture and at the same time significant influences contributing to the differentiation of Indian society

South India mainly consists of 5 states who take pride in their rich heritage, culture and religion. The celebration of eternal universe through the celebration of the beauty of the body and feminity, exemplified through dance, clothing, art, crafts among various others summarizes the culture of South India[6]. The use of intricate and abstract sculptures with inspiration from religious deities is a common sight in all the temples. Although India is predominantly Hindu, other religious groups have their own place in the society and social order. These include Muslims, Christians, Jains, Sikhs, Parsee, Buddhists, Jews, and various other tribal people. Religion finds its way into every aspect of life. 

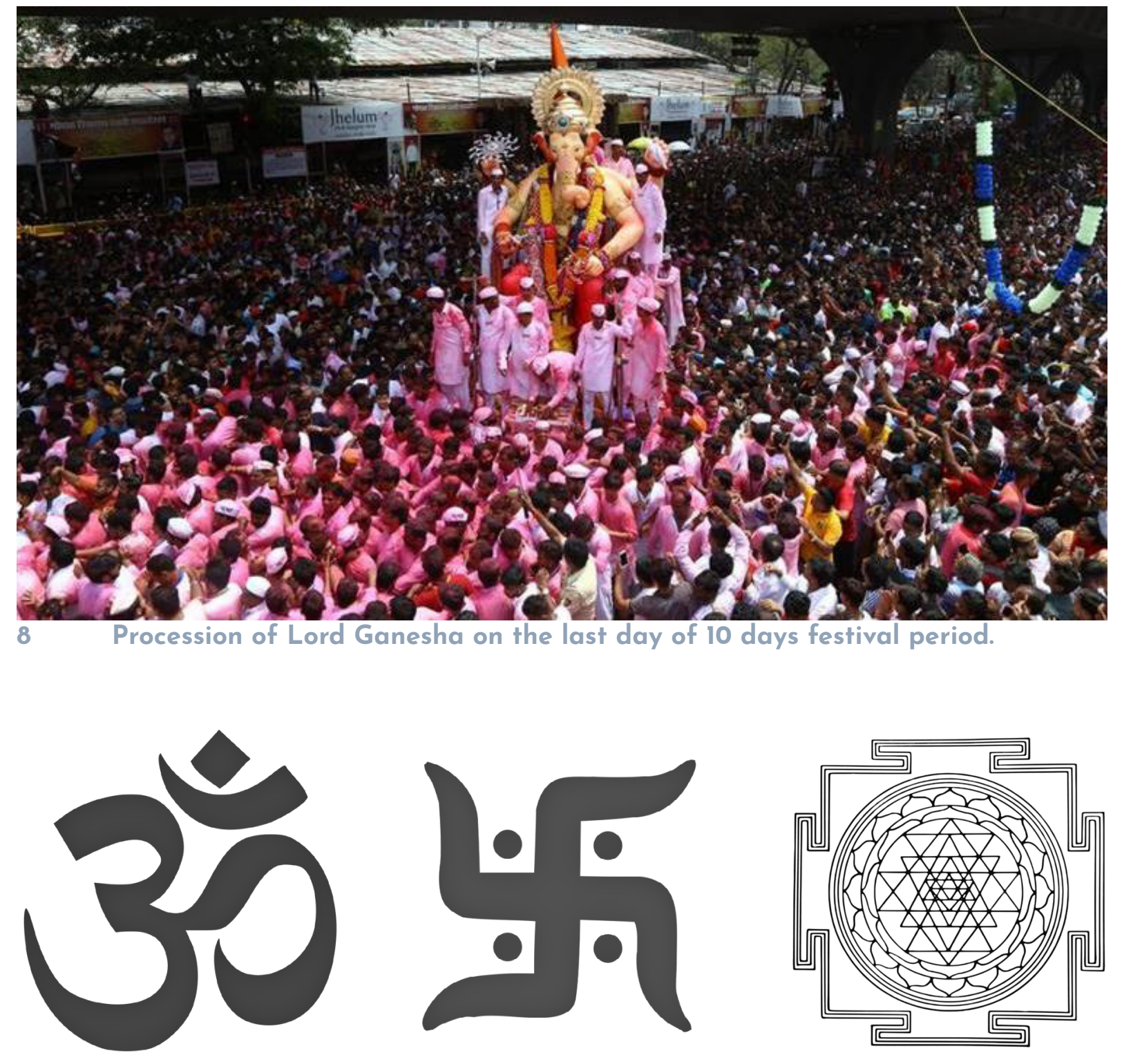

There are two primary symbols associated with Hinduism, the om and the swastika. The word swastika means "good fortune" or "being happy" in Sanskrit, and the symbol represents good luck. The om symbol is composed of three Sanskrit letters and represents three sounds ( $a, u$ and $m$ ), which when combined are considered a sacred sound. The om symbol is often found at family shrines and in Hindu temples. It refers to Atman (soul, self within) and Brahman (ultimate reality, entirety of the universe, truth, divine, supreme spirit, cosmic principles, knowledge). It is a sacred spiritual incantation made before and during the recitation of spiritual texts, during puja and private prayers, in ceremonies of rites of passages (samskara) such as weddings, and sometimes during meditative and spiritual activities such as Yoga. [7] [8]

Temples were constructed by architects who used a specific system of measurement unique to south india and primarily selected sandstone as the material for construction. Each area in south india had a ruler/ king who was in power at the respective time a temple was built reflecting a period in the history. 


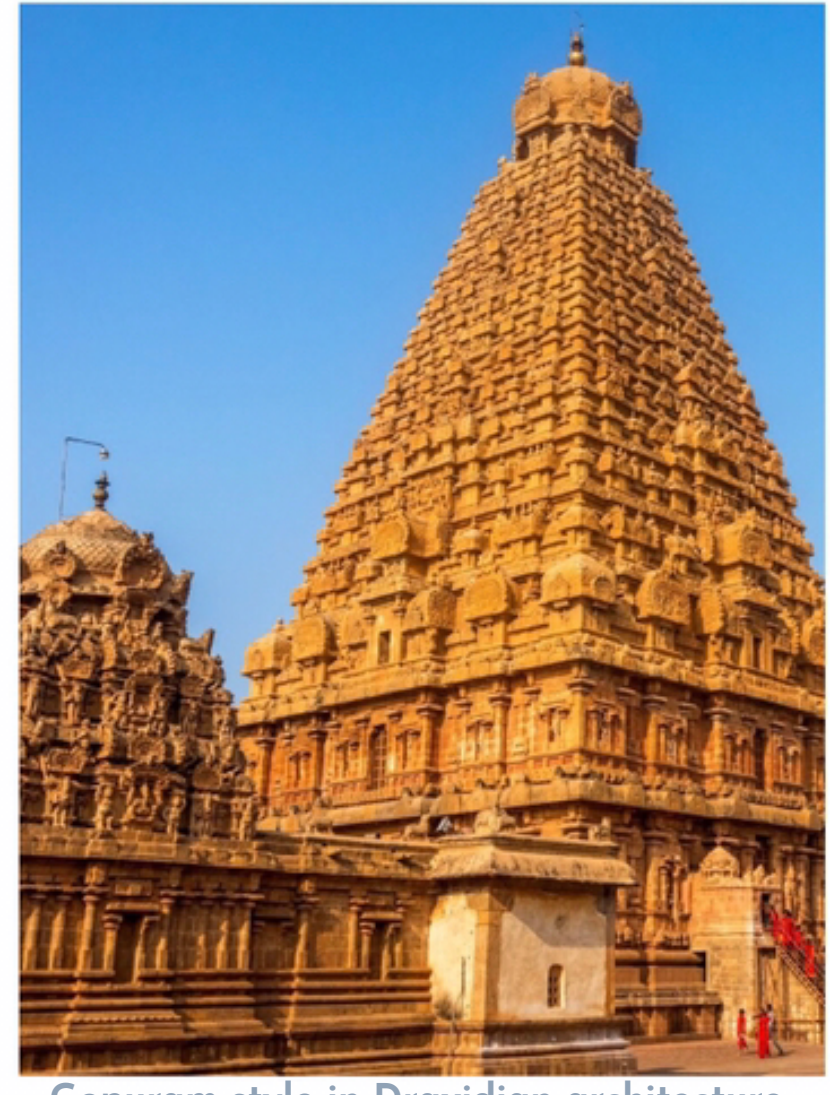

12

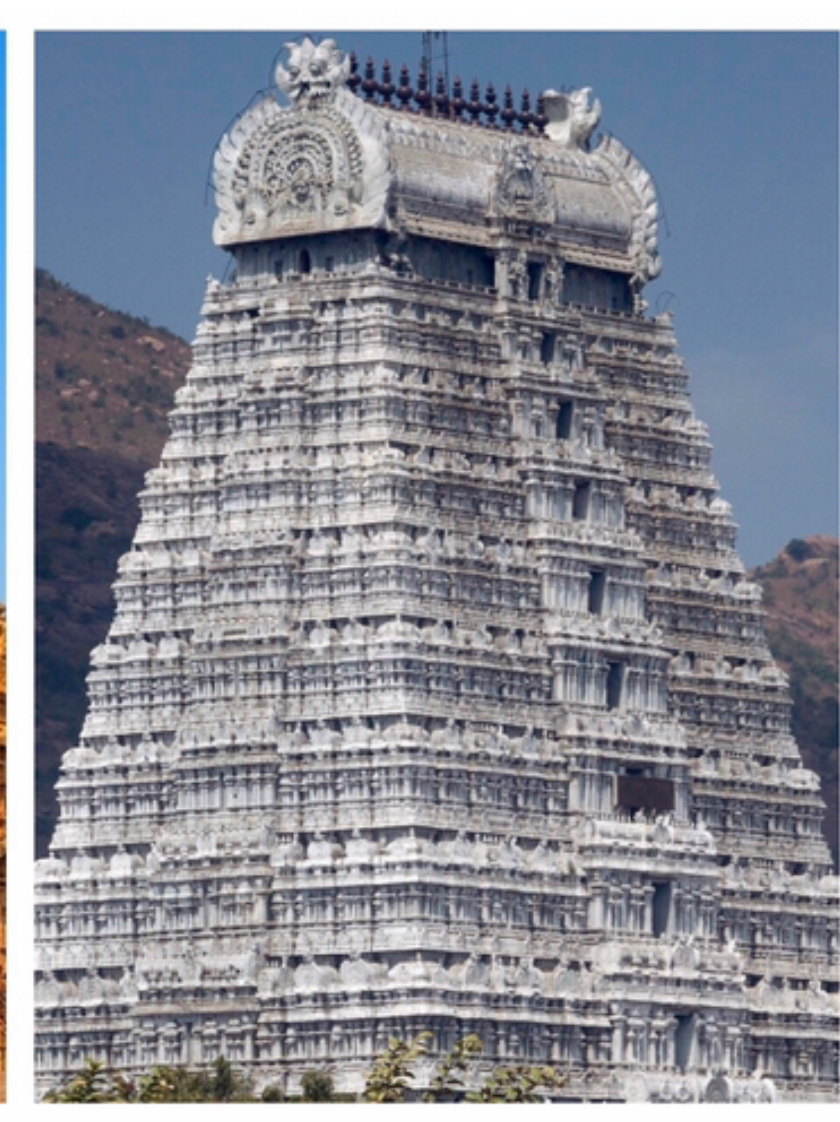

A significant amount of people follow Hinduism, which is a way of life and culture rather than a religion. Hindus follow a series of sacred texts that provide rules for rituals, worship, pilgrimage and everyday life among other things. But, one of the key ideas is about ones 'atma' or the belief in soul. The goal is to achieve "moksha," or salvation, which ends the cycle of rebirths to become part of the absolute soul. With the intent of achieving 'dharma', which is a code of living that emphasizes good conduct and morality. They honor all living creatures and consider the cow a sacred animal. Food, among other elements, is an important aspect and many do not eat meat for the afore mentioned reason. [7] [8]

Dravidian architecture, the idiom given to the type of temple architecture in south india, developed its own form and tradition. Temples were a place of worship, a center for learning, a space to clear one's mind, to clear one's sins. Along with elaborate rituals, festivals, performances of dance dedicated to the god, it is a celebration of its own. When it comes to the prospect of a religious procession, crowds gather in thousands to take a glimpse of the deity. Although each house has its own variation of an altar specifically designated for religious practices, performing puja, visiting a temple and participating in the ceremonies and festivals is the life of the community. Also, it creates a sense of calmness and togetherness among community members. 


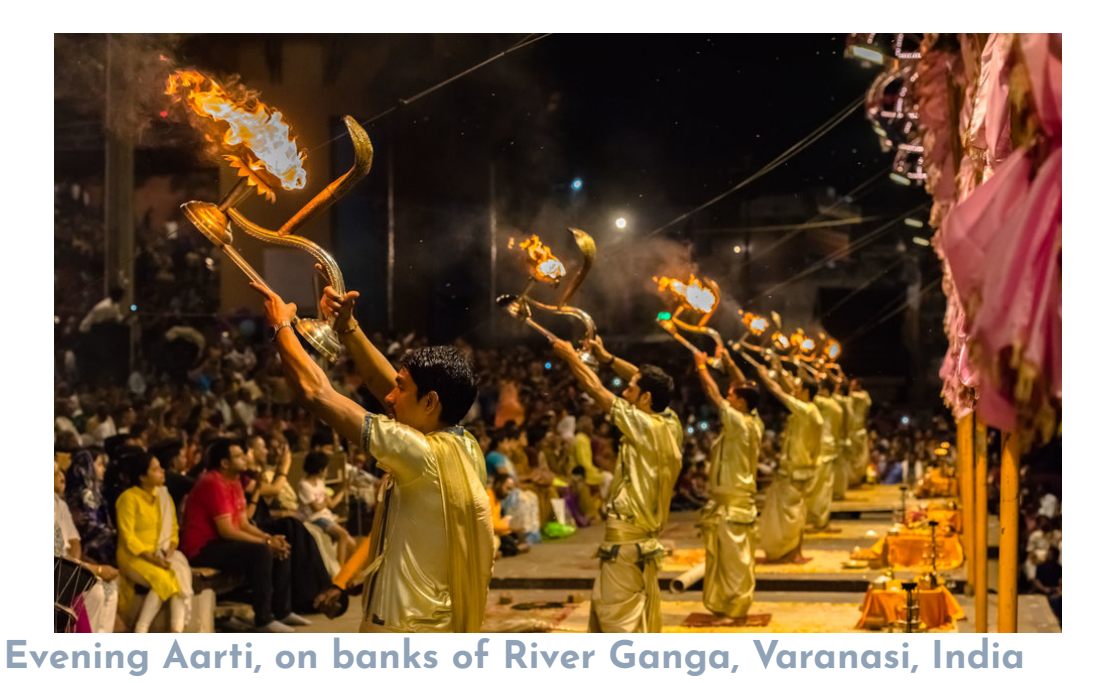

13

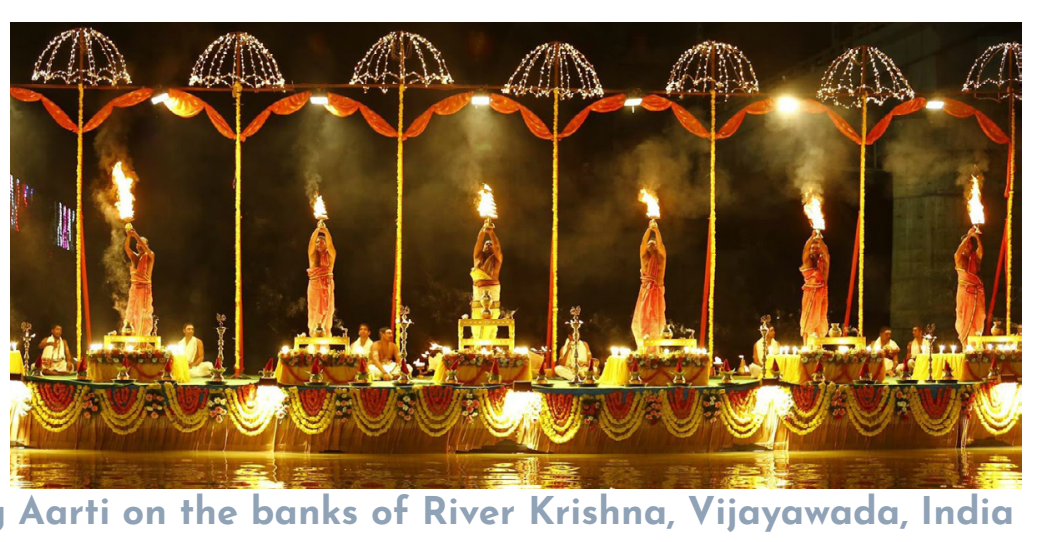

14

Evening Aarti on the banks of River Krishna, Vijayawada, India

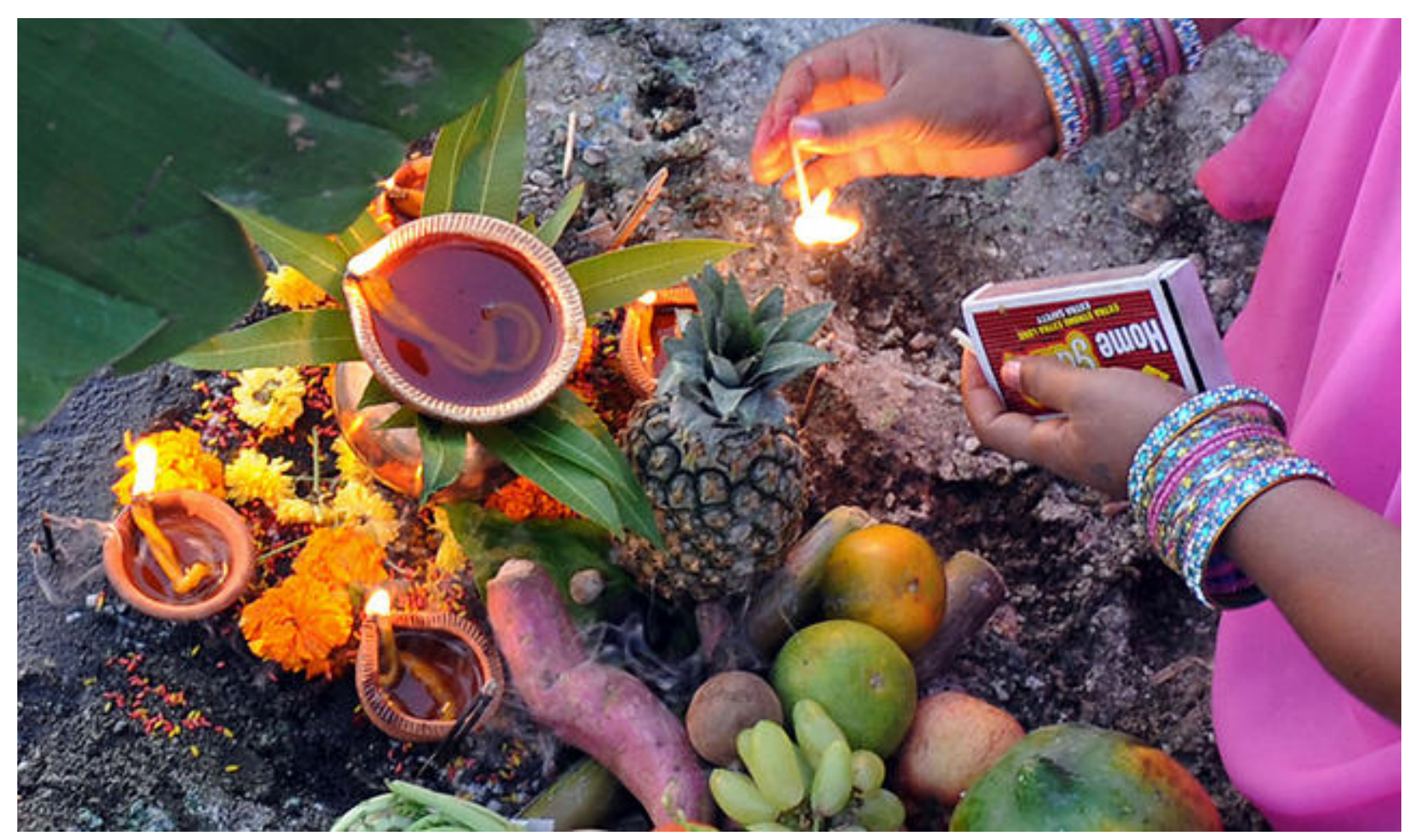

15

Devotee offering light in the form of fire, and fruits as a ritual, part of everyday prayer.
An important part of puja, a ceremonial worship, is the task of offering of light, aarti, which is believed to remove darkness and welcome in light and warmth. Also, offering of flowers, food, water and other natural products is a common practice.

Devotees before entering the temples should make sure they have bathed, put on a fresh set of clothes, fully covered and leave behind their footwear. For the ease of devotees and pilgrims coming from far away distances, architects have placed a huge tank with water, or constructed the temple on the banks of rivers. The tanks also functioned as reservoirs during monsoons and are used during summer drought season.

In addition to the ceremonies that happen inside the temple, few processions take place outside the temple, thus extending the boundaries into the urban context. The parade of the elaborately decorated idols of the deity, happen in a clockwise manner, another opportunity for gathering. [9] 


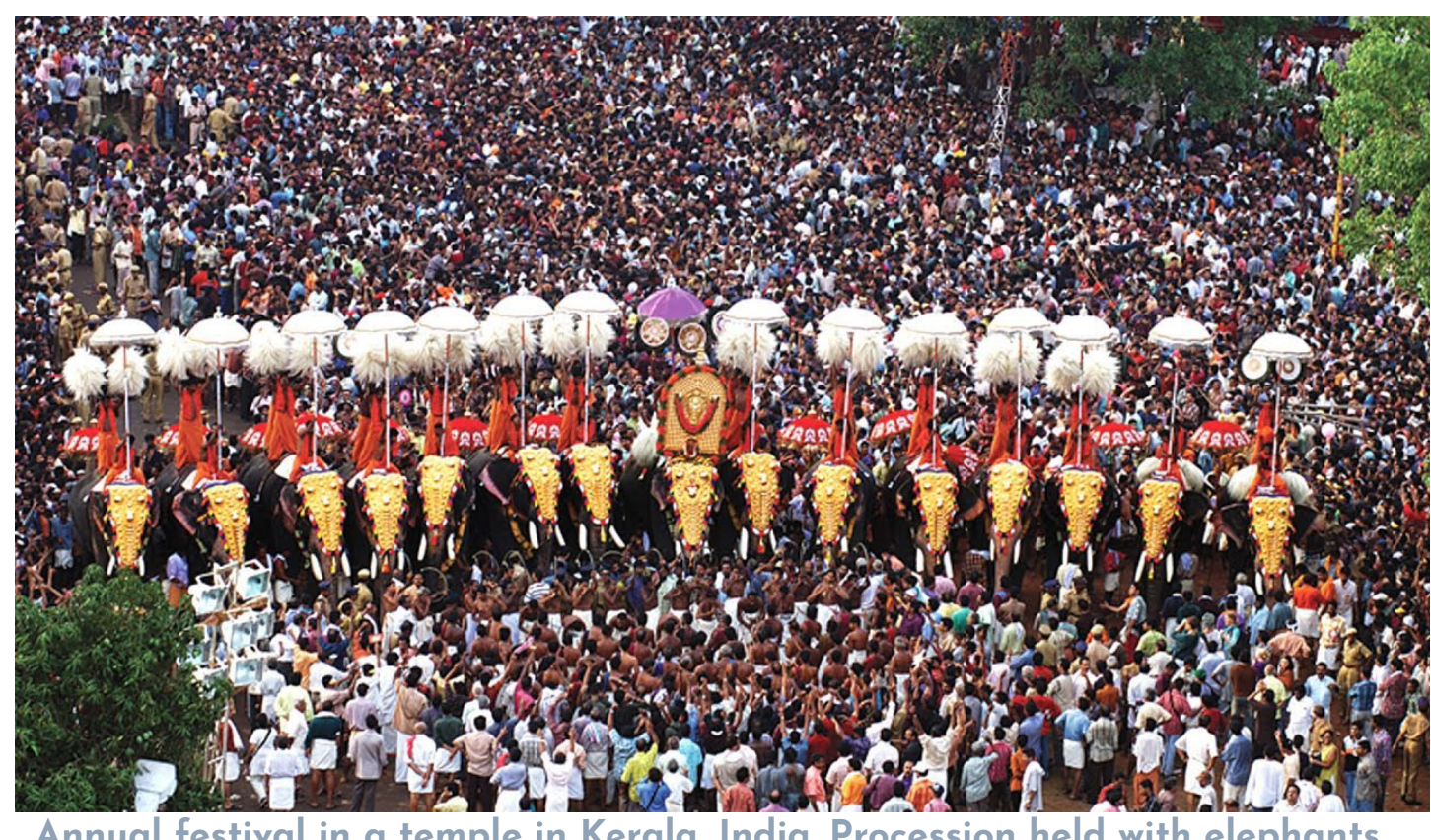

and traditional music

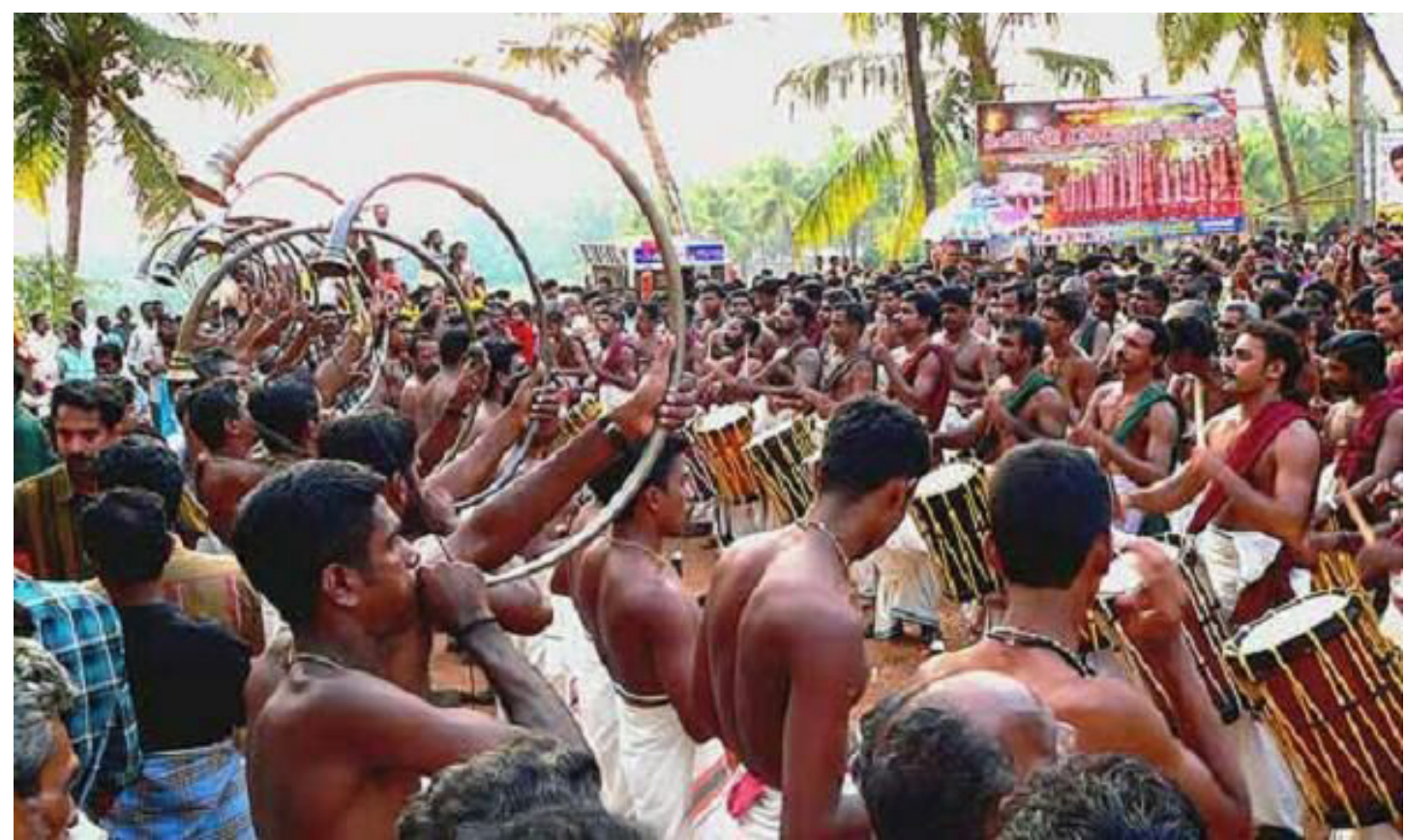

17

Annual festival in a temple in Kerala, India. Procession held with elephants and traditional music
Chants and sounds from musical instruments blow in huge volumes and the scent of flowers and incense sticks exhilarates a person by creating a divine experience that can be compared to nothing. These gatherings are never small, with the given population in India and the density of each city, there are always thousands of people at any communal meet. [10]

While a daily offering witnesses' flowers and fresh fruit, a huge gathering would see the same multiplied by thousands. The fresh fruits/ food are then donated to the needy and the flowers are presented to the god and later used as organic fertilizer along the temple premises. Often seen, vendors on the sides of the roads leading to the temple sell required materials for offerings, also inside the premises of the temple, shaded stalls sell the same. This practice slowly turned into commercial habit of selling crafts, mini idols of the deity, sculptures, art works depicting stories of the god further extending the temple premises into neighboring commercial district, seldom blurring the lines. 


\section{EAASE $\oint 干 \cup B I E S$}
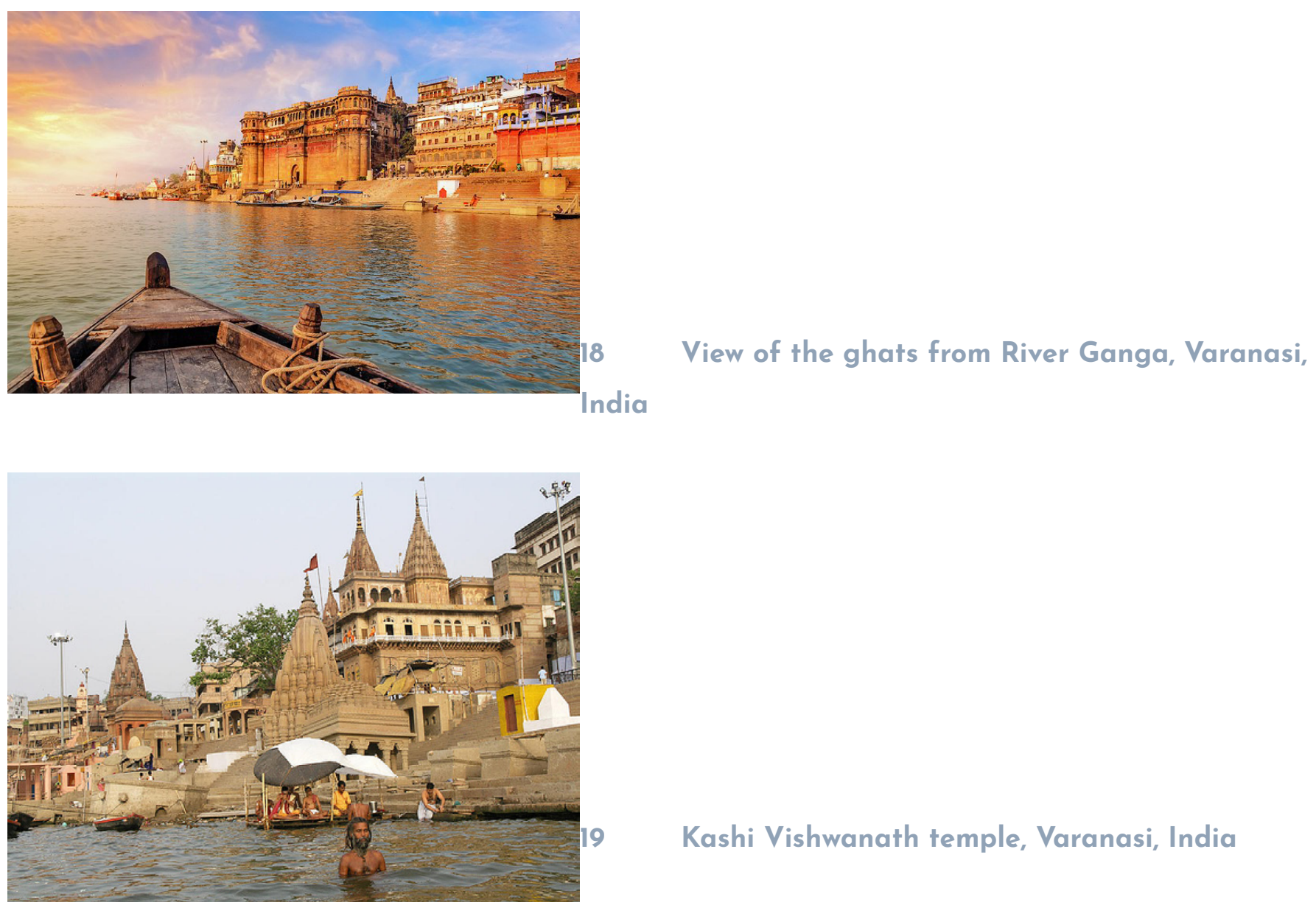

Kashi Vishwanath temple, Varanasi, India

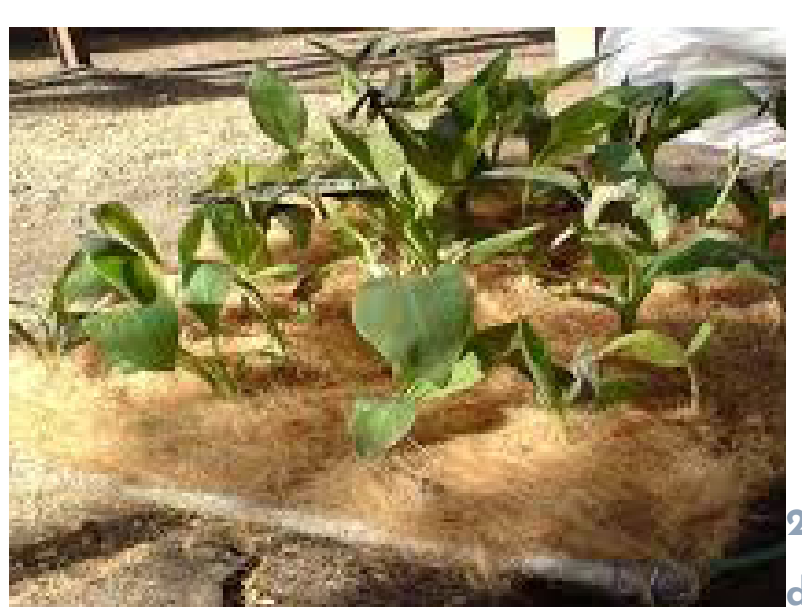

Artificial floating ecosystems to help regenerate
Following case studies concentrate on ghats that are associated with rivers that host "Pushkaraalu", a religious event every 12 years.

1. Varanasi Riverfront Study

2. The Kashi-Vishwanath Corridor Plan

3. Artificial Floating Island, Pune, India.

\section{Varanasi Riverfront Study [11]}

The city of Varanasi, also known as Banaras, is a city on the banks of river Ganges in Uttar Pradesh, India. Spread over an area of 24 sq. kms the city has a population of 1.2 million people. A major religious center in India, it is one of the holiest of the seven sacred cities in Hinduism. The Ghats in Varanasi are world-renowned embankments made in steps of stone slabs along the riverbank where pilgrims perform ritual ablutions. The Ghats are an integral complement to the Hindu concept of divinity represented in physical, metaphysical, and supernatural elements. Varanasi has 88 Ghats, most of which are used for bathing by pilgrims and spiritually significant Hindu puja ceremony, while a few are used exclusively as Hindu cremation sites.

Most Varanasi ghats were rebuilt in the 18th century, when the city came under Maratha rule. Many ghats are associated with legends or mythologies while many ghats are privately owned. Morning boat rides on the Ganges across the ghats is a popular visitor attraction. 


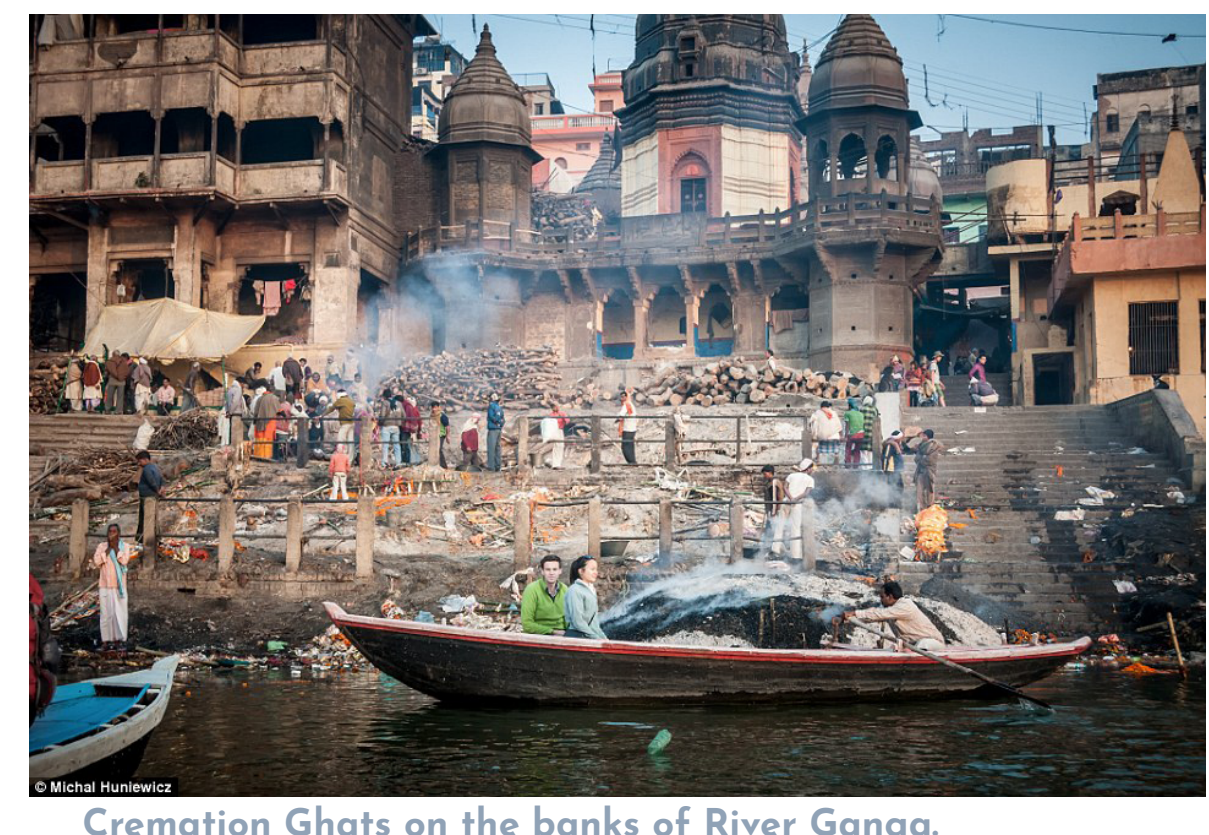

21

Cremation Ghats on the banks of River Ganga.

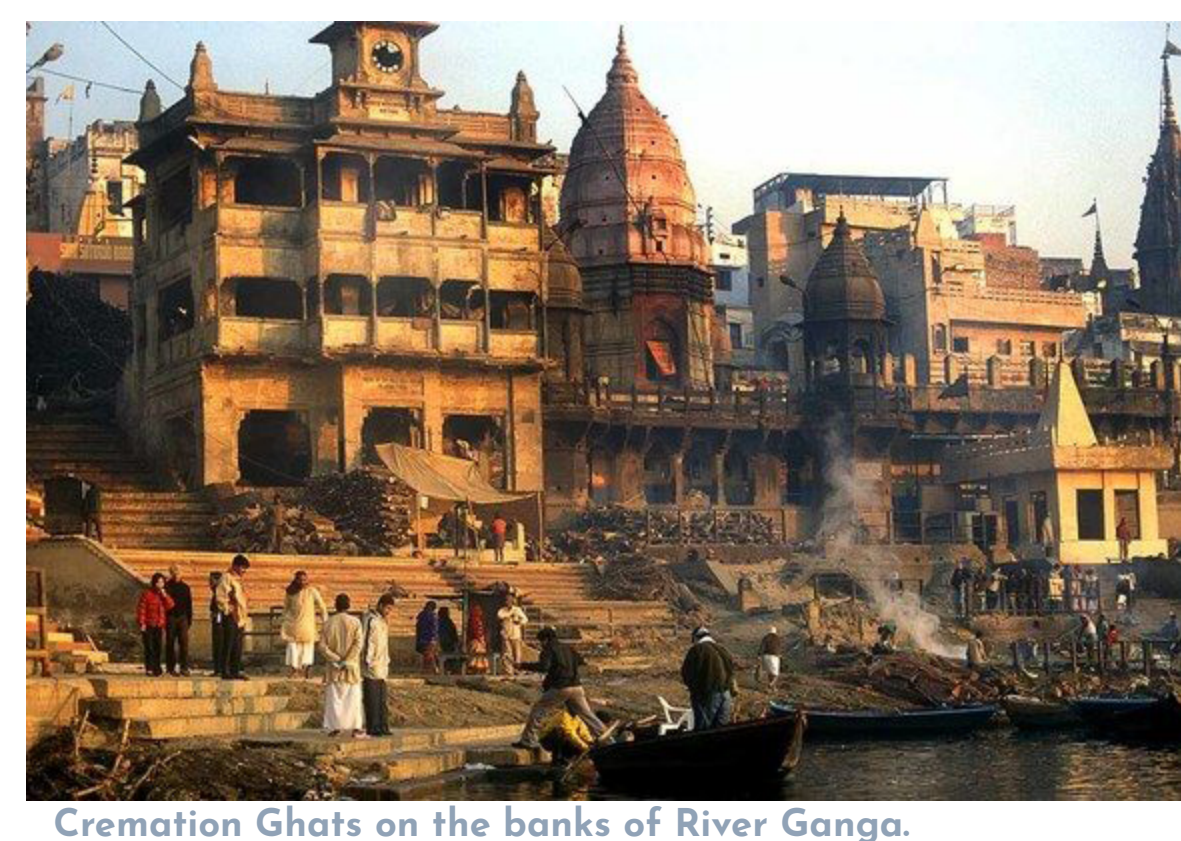

Cremation and pollution: In Hindu traditions, cremation is one of the rites of passage and the Ghats of Varanasi are considered one of the auspicious locations for this ritual. At the time of the cremation or "last rites", a prayer is performed. Hymns and mantras are recited during cremation to mark the ritual. Annually, 25,000 to 30,000 bodies are cremated on various Varanasi Ghats; about an average of 80 per day.

This may sound like a grim and macabre place, but Varanasi is full of life and celebrations. To die and to be cremated in Varanasi is to have the chance to achieve Moksha (the end of the rebirth cycle), a great honor and the goal of earthly existence.

This practice has become controversial for the pollution it causes to the river. In the 1980s, the Government of India funded a Clean Gan ges initiative, to address cremation and other sources of pollution along the Ghats of Varanasi. In many cases, the cremation is done elsewhere and only the ashes are dispersed into the river near these Ghats. Untreated sewage is a pervasive source of the river pollution in India. City municipal waste and untreated sewage is the largest source of pollution of the Ganges river near the Ghats of Varanasi. 


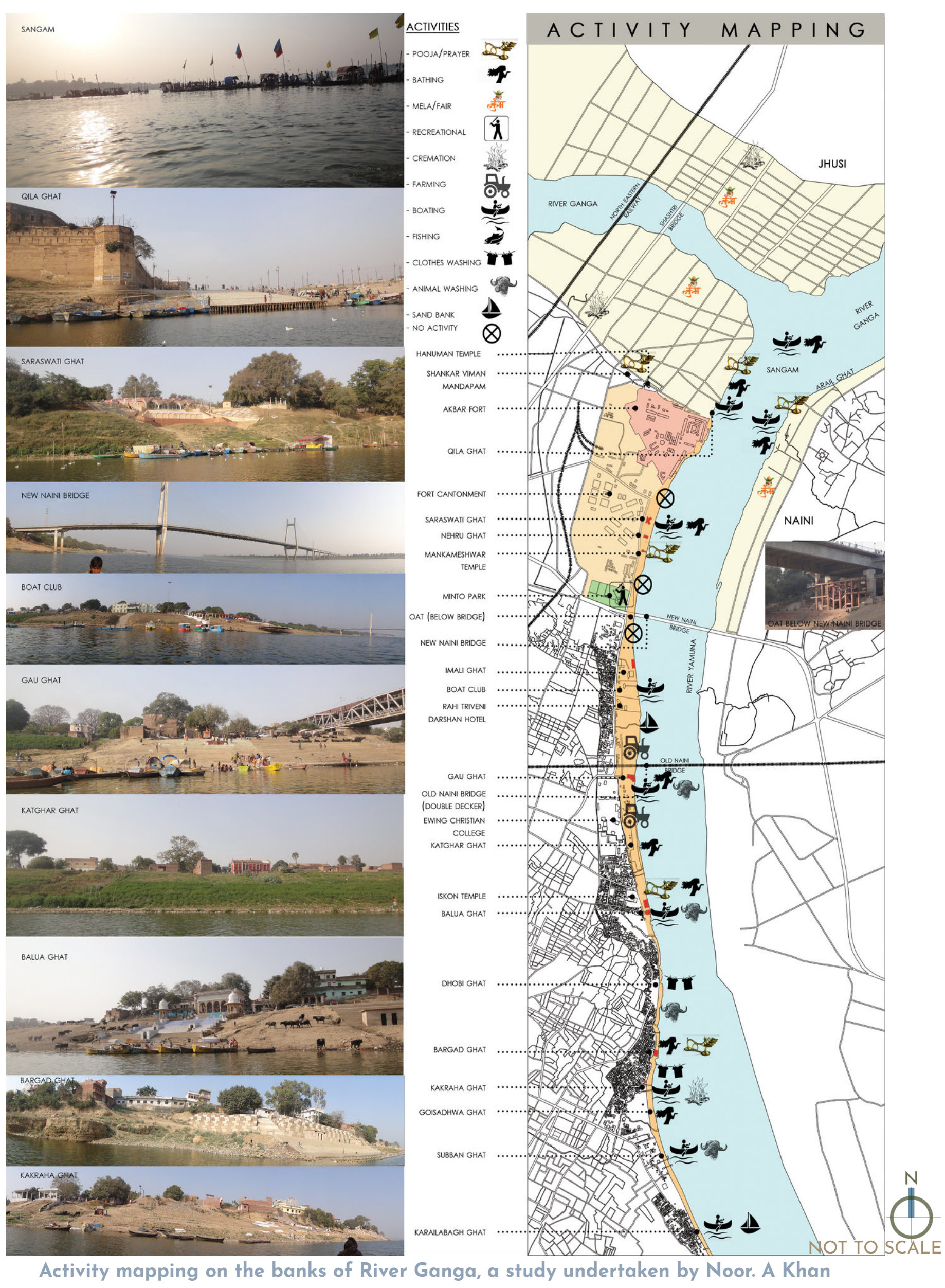

The Ganga Action Plan was launched on 14 Jan. 1986, with the main objective of pollution abatement of the river Ganga, to improve the water quality by interception, diversion, and treatment of domestic sewage, and to identify grossly polluting units to prevent their toxic and industrial chemical wastes from entering the river. The plan has been a dismal failure and a major source of corruption.

Ganga Action Plan has not been completely successful so far in part because it is guided by a top-down planning approach. In this engineering approach, cultural practices, folk beliefs, and local community traditions are ignored. The multiplicity of stakeholders, widespread encroachment of public land, and ineffective and inadequate local ordinances are some of the challenges in conserving the Varanasi ghats. Site planning and management should consider what is today considered non-essential knowledge the esoteric language of myths, hidden meanings of rituals, and sanctity attributed to nature evident in everyday practices so that a new culture specific, participatory model for solving complex problems can emerge. This bottoms-up eco-cultural approach advocates the use of appropriate technology, local materials, and renewable energy sources. Programs such as vending collaborative and on-site composting will engage the local communities and improve the local economy. 

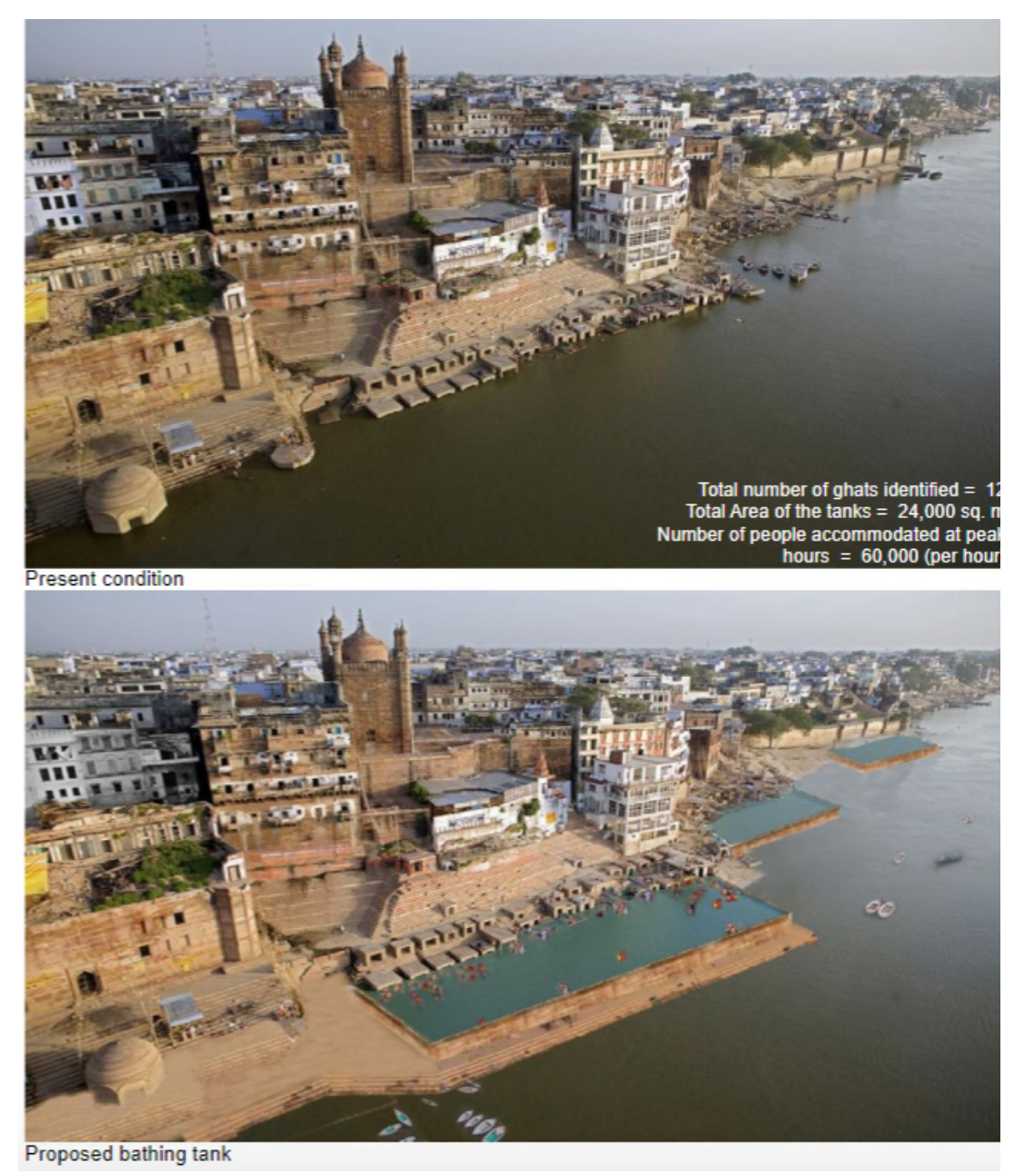

24 Aerial image of ghats showing before and after implementing the design proposal.

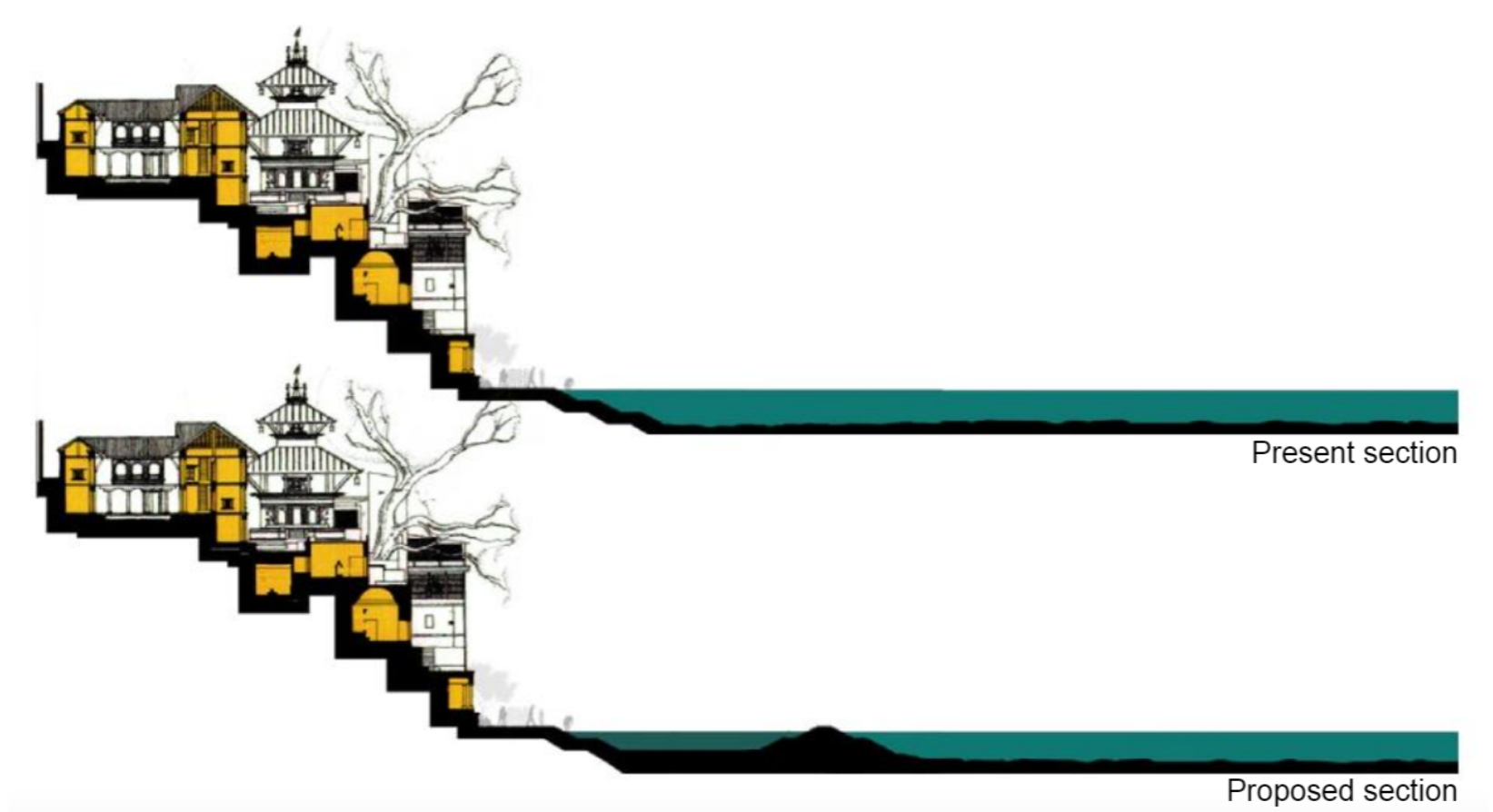

Ghat Re-design: There are many proposals to redesign the ghats of Varanasi, as it being the most popular of all ghats present in India. But, for this study, one of the redesign proposal concepts is considered. In this proposal, sacred tanks are introduced along the holy ghats for bathing purposes.

Recent technological advances help in filtering water in large volumes and help maintain its purity. This tech has 400 sensors per acre which helps in continuous monitoring for bacteria and algae levels. If sensed with an imbalance, the system automatically injects chemicals such as chlorine to disinfect the water and the $\mathrm{pH}$ levels are balanced. The amount of material needed is 100 times lesser than what could be used in an equivalent filtering system.

Also, this project proposes the imporovement of the cultural walk corridor between all the ghats. Existing conditions show a deteriorated pathway with exposed drain channels that are often filled with garbage. All through the riverfront, we can see ghats associated with temples, historically important palaces and illegally encroached residential buildings and miscellaneous businesses. Being a popular tourist attraction, a transport hub with a boarding jetty and parks are designed at various places to upgrade the existing transport utilities. 


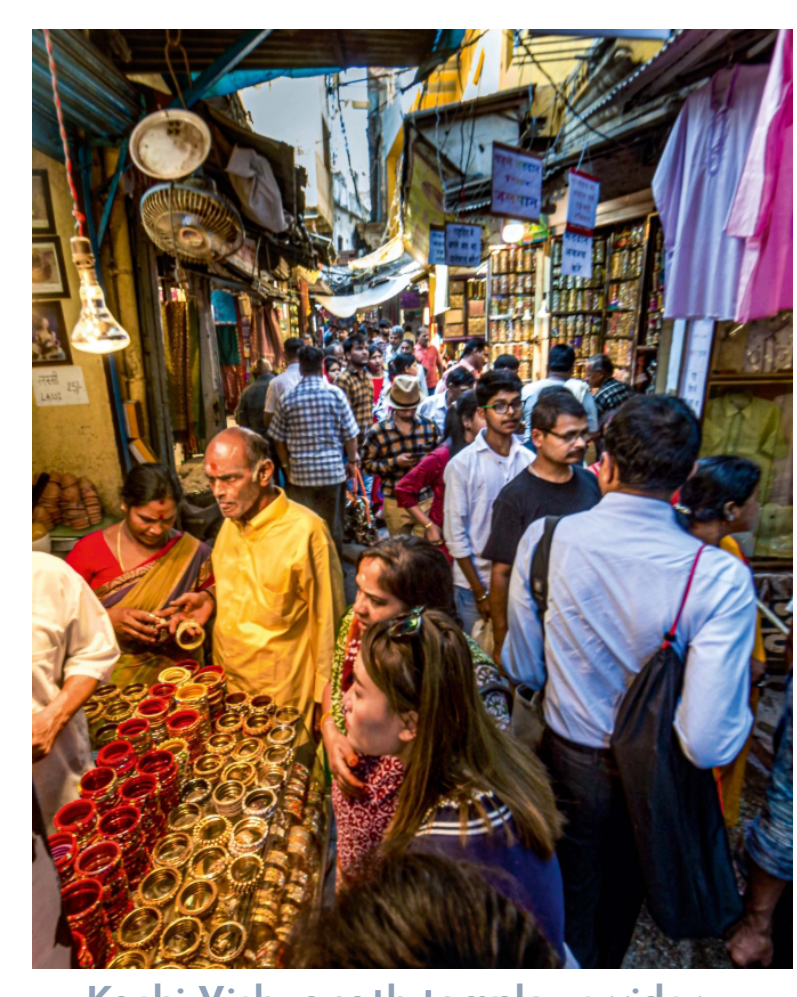

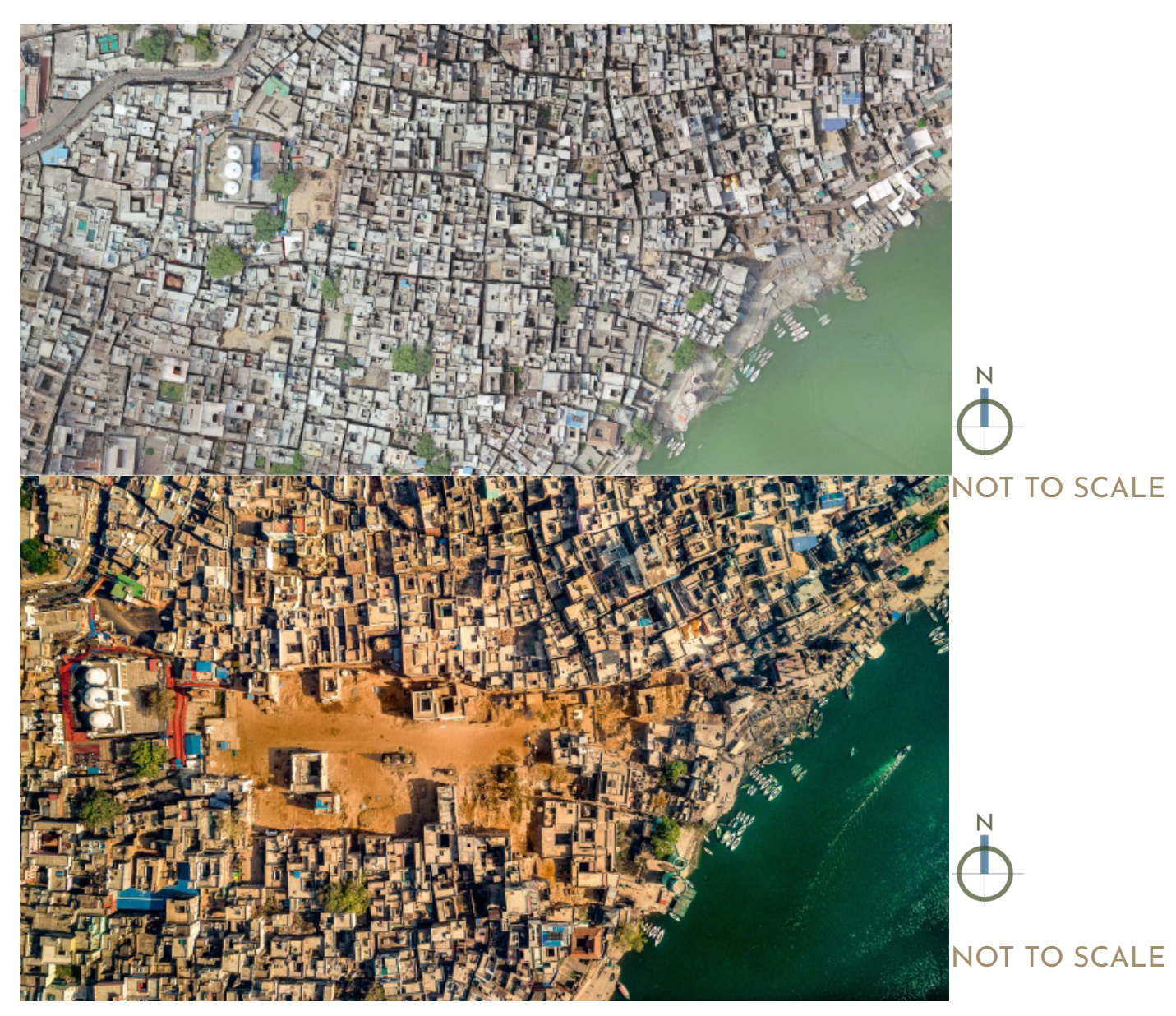

Before and After aerial images of Kashi-Vishwanath corridor plan.
The Kashi-Vishwanath Corridor Plan [12]

Introduction: Kashi Vishwanath Temple is one of the most famous Hindu temples dedicated to Lord Shiva. It is in Varanasi, Uttar Pradesh, India. The Temple stands on the western bank of the holy river Ganga. The temple consists of a series of smaller shrines along a lane that leads to the river Ganga. The Kashi Vishwanath temple receives around 3,000 visitors every day. On certain occasions, the numbers reach $1,000,000$ and more.

Design concept: The blueprint of the highly ambitious Kashi Vishwanath Corridor Project, paves the way for devotees to comfortably access the temple from the ghats. The government had to address the issue of rehabilitation of the tenants and shopkeepers who would be displaced after 166 buildings are demolished, for illegally encroaching. [13] 

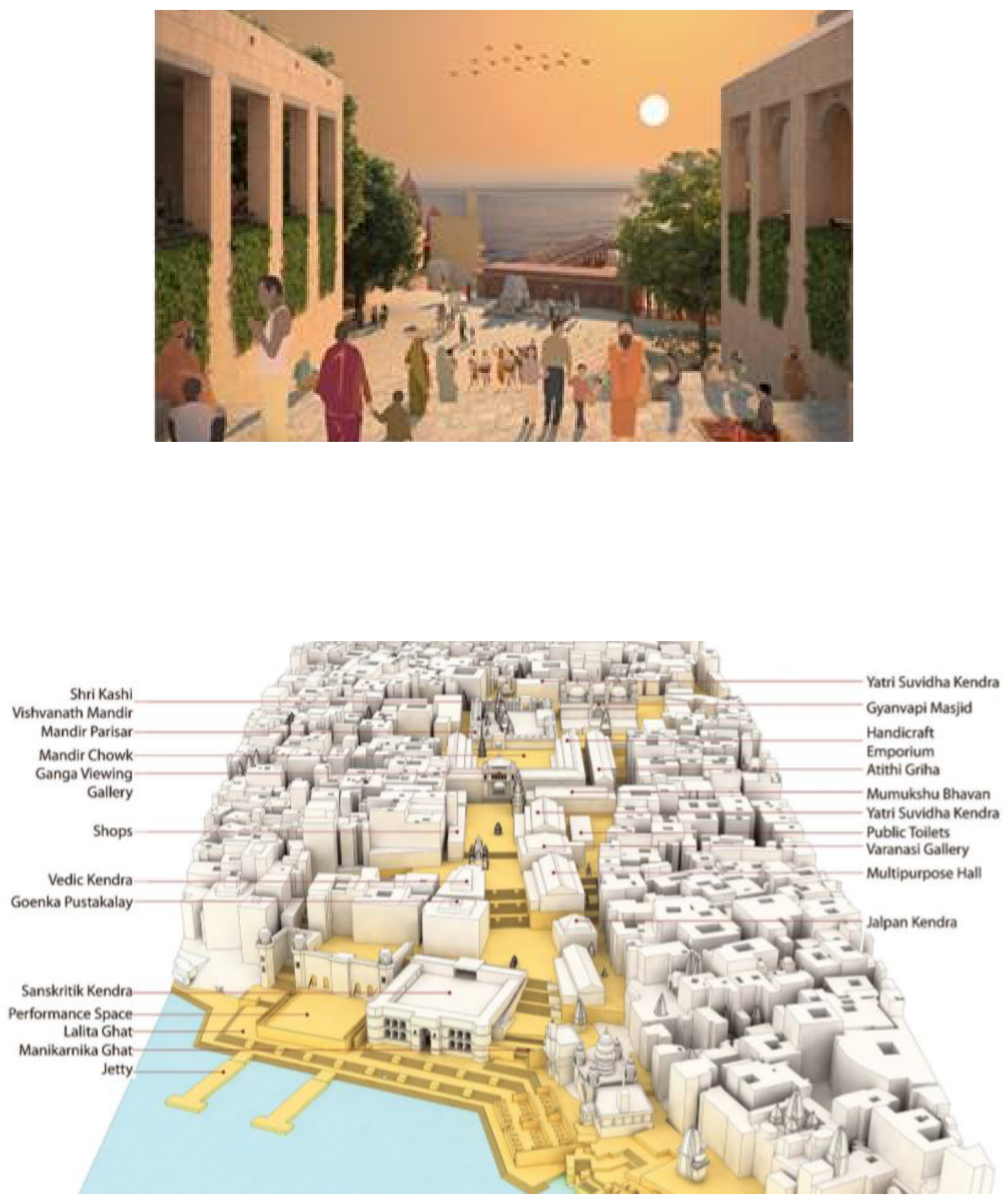

Perspective views of the proposed temple premises.
Also, few of these buildings are left intact, which include temples, libraries and buildings of architectural importance. Forty-six in total were preserved for this project. The corridor is designed to be 56 meters wide and over 300 meters in length. Despite being a prime pilgrimage site, it is surrounded by narrow lanes which are lined with dilapidated buildings which prevented fire-fighting system and other medical facilities to enter in the past. After completion of this project, the temple site would see ease in congestion and would provide people with lanes that are well lit and provide other basic facilities. 


\section{URBRAN SEFTFEEMMENTS}

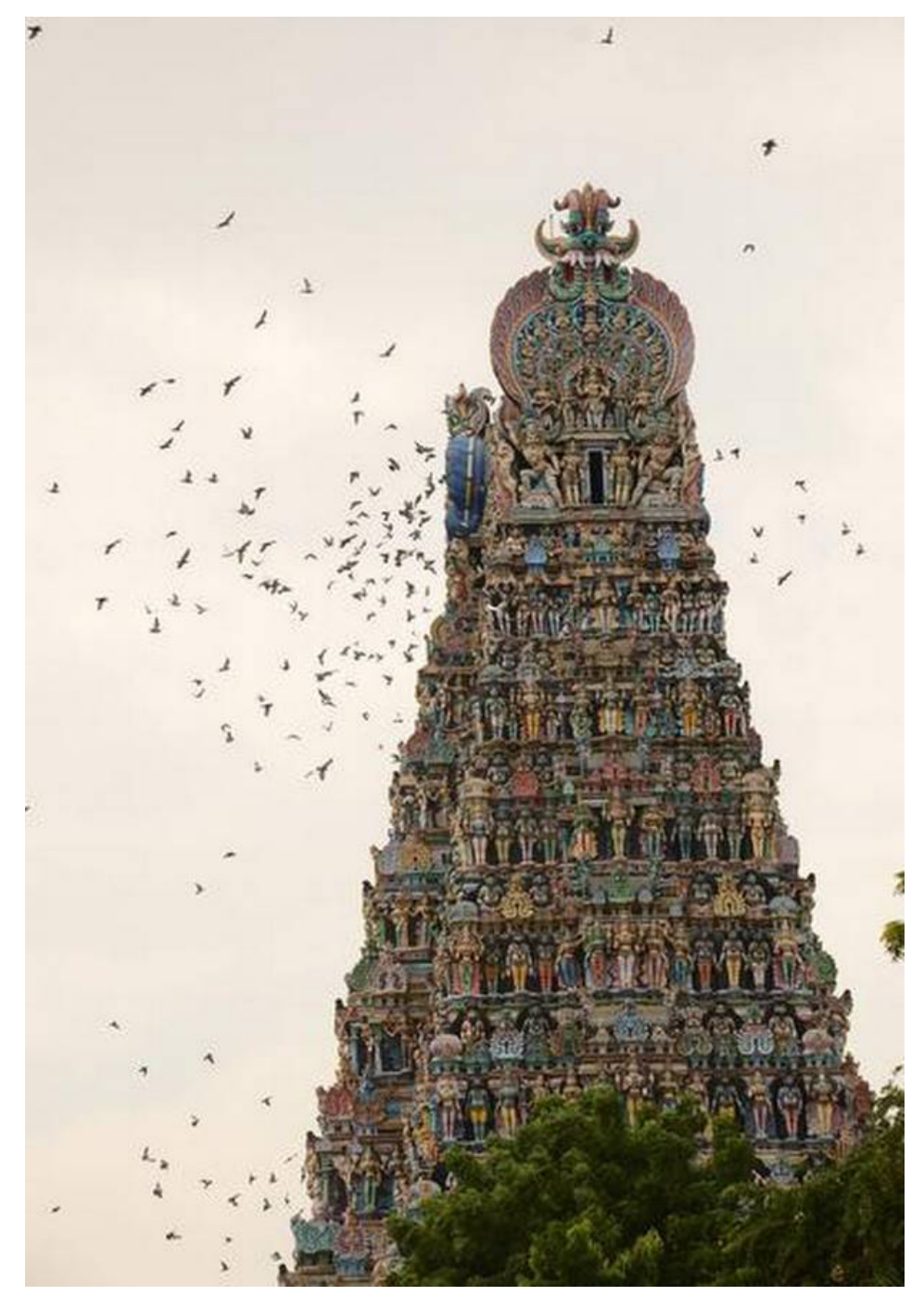

While religion from a Hindu perspective is way more complex than other religions, for the sake of this thesis, only the required amount of information is presented.

Temple towns were an important source of economy and a way to show devotion for a deity by the ruler of the region. They were the main reason for a town to prosper. The kings endowed land and other grants to the priests in return to conduct ceremonies where devotees used to gather, who in turn donated money which was used for trade and banking. Eventually priests, traders and artisans settled near temples to cater to the needs of the devotees.

Vijayawada was one such town which can be labelled as a temple town, but at the same time functioned as a port town. It consisted of the temple and a small community of traders, artisans and priests. This was during the 1800's and with the construction of the bridge in 1855, which also functioned as a dam, it increased the importance of the town and eventually transformed the agricultural economy and the trade and commerce. Rapid urbanization and improper planning executions helped the town developed into a city with multiple nuclei. Transportation, trade and industry, religious infrastructure, cultural art and crafts are among the nuclei that helped the city grow in terms of economy and population. 

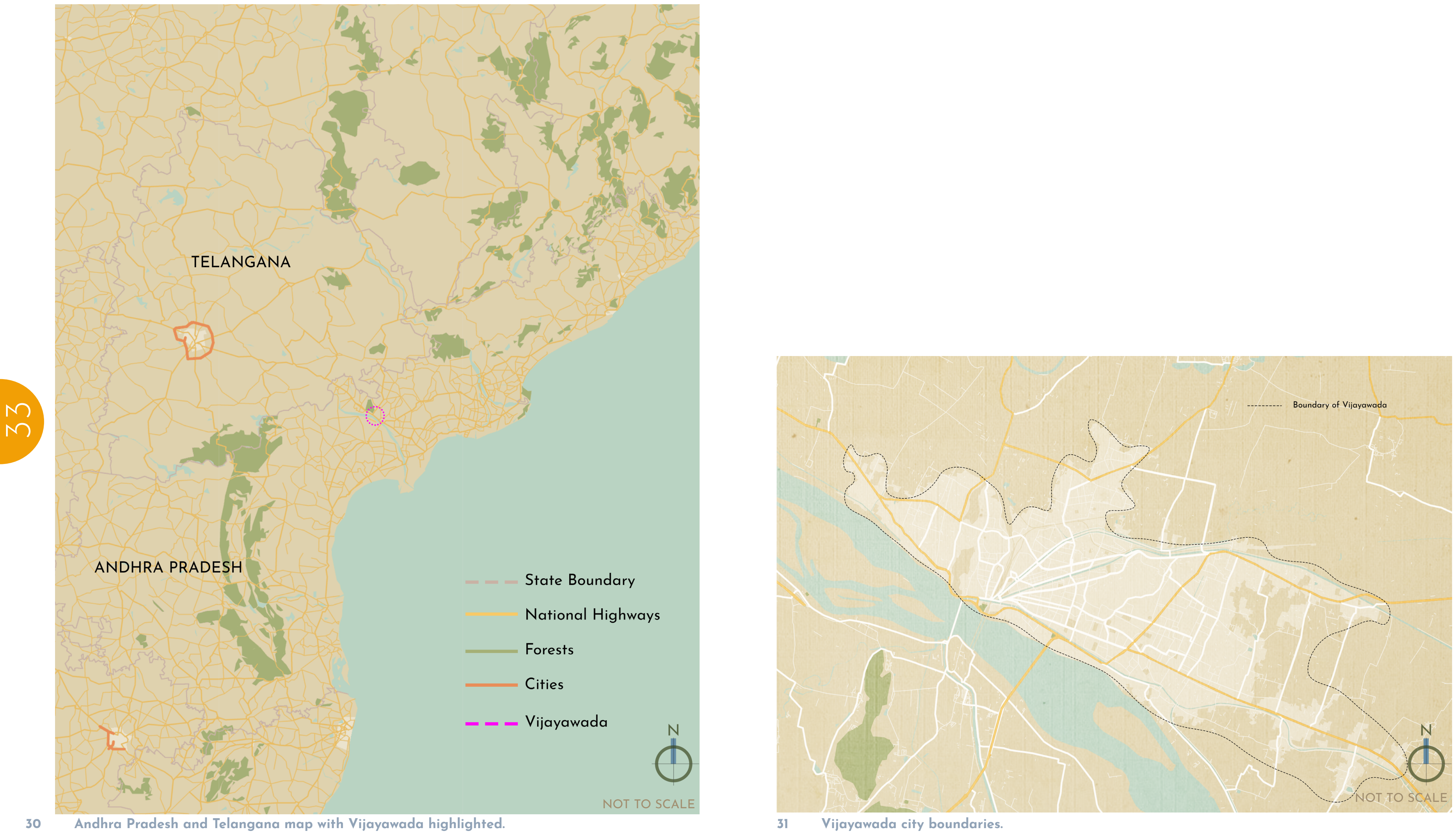


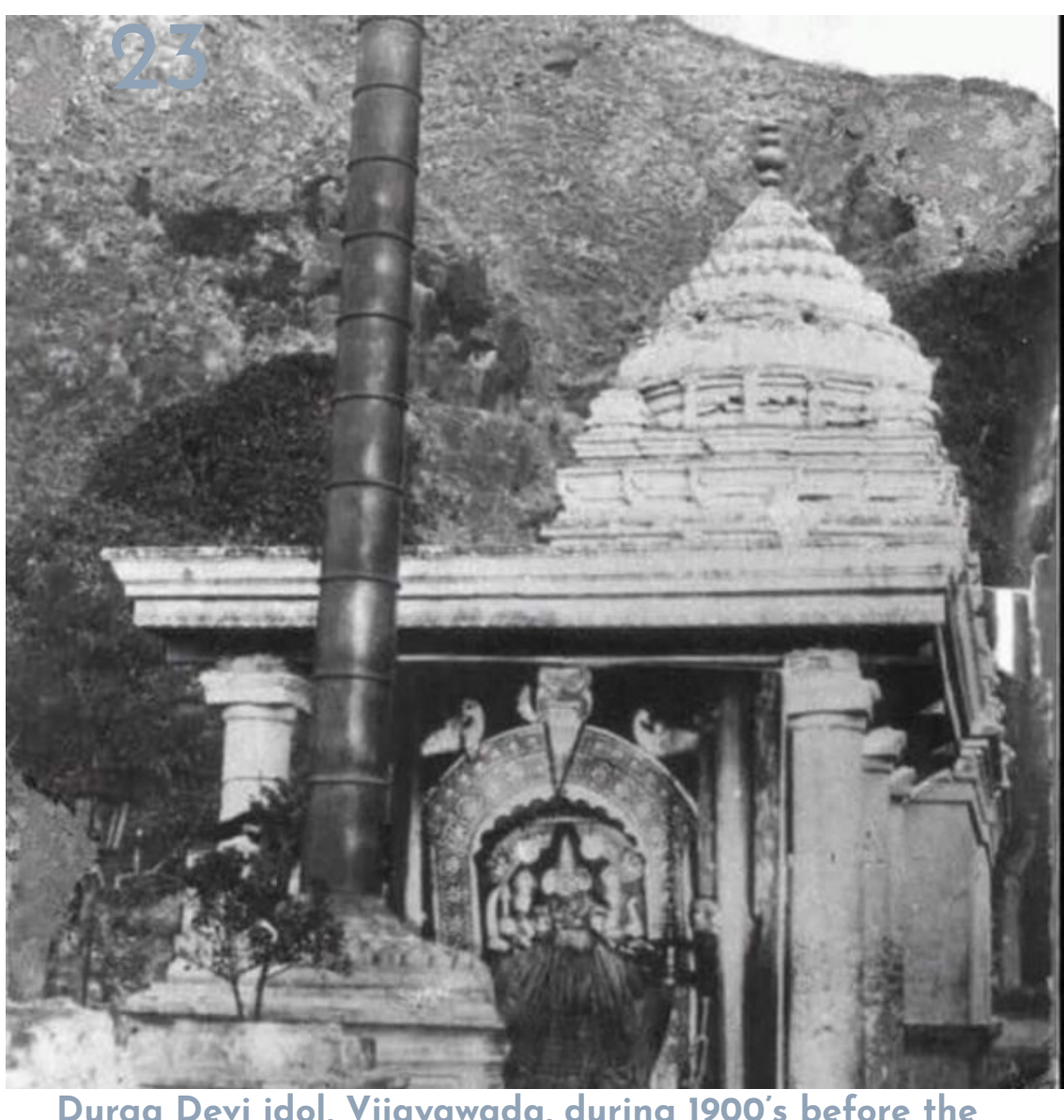

temple complex was built

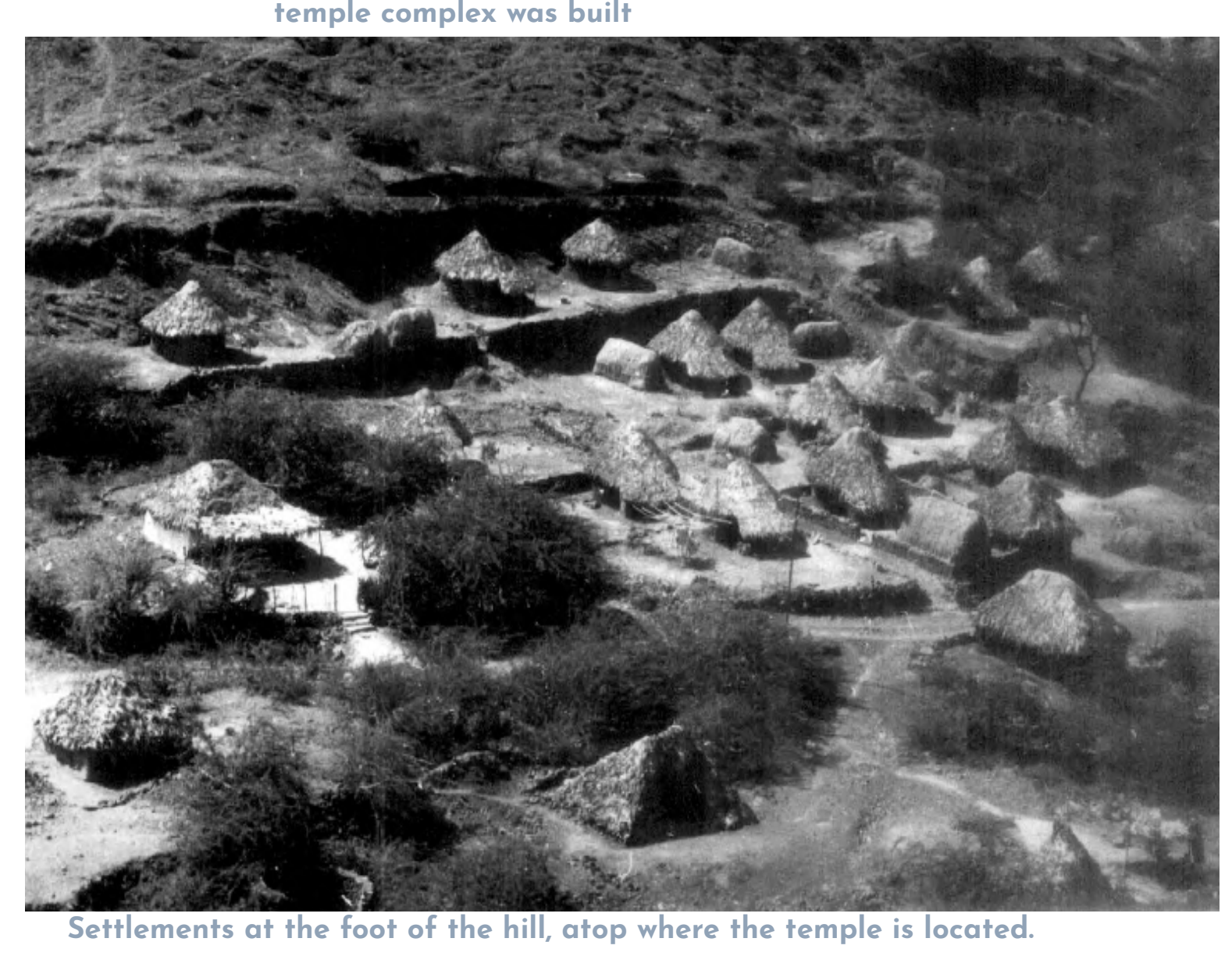

The Krishna River is a dominant part of the geography of the Krishna District(County) and runs through the city. Although the hills here are a continuation of the Eastern Ghat Hills of India, they have a low elevation compared to the rest of the Ghats.

Physiographically Krishna district (County) comprises of Precambrian basement of peninsular Indian shield. General slope of the land is from West to East or South East. The main hill range is of the Eastern Ghats, comprising mostly of charnockite and Khondalites suite of rocks. The Khondalites have been derived from rather high-alumina clays.

There are four types of soils in the area. Black cotton soils (58\%), Sandy clay loams (23\%), Red loamy soils (17\%), and Sandy soils (2\%). The sandy soils form a fringe along the coast. The black cotton soil is most extensive and occurs in Western part. The sandy clay loams are formed along river.

Geomorphologically the area can be divided into four different environments namely, [14]

(i) Hilly and flat upland terrain (granite gneiss, charnockite, khondalite and sandstone),

(ii) Piedmont deposits (colluvium and piedmont fans),

(iii) Rolling plain (sandy, silty gravel and sandy soil),

(iv) level plain (silty clayey sand and sandy silt). 

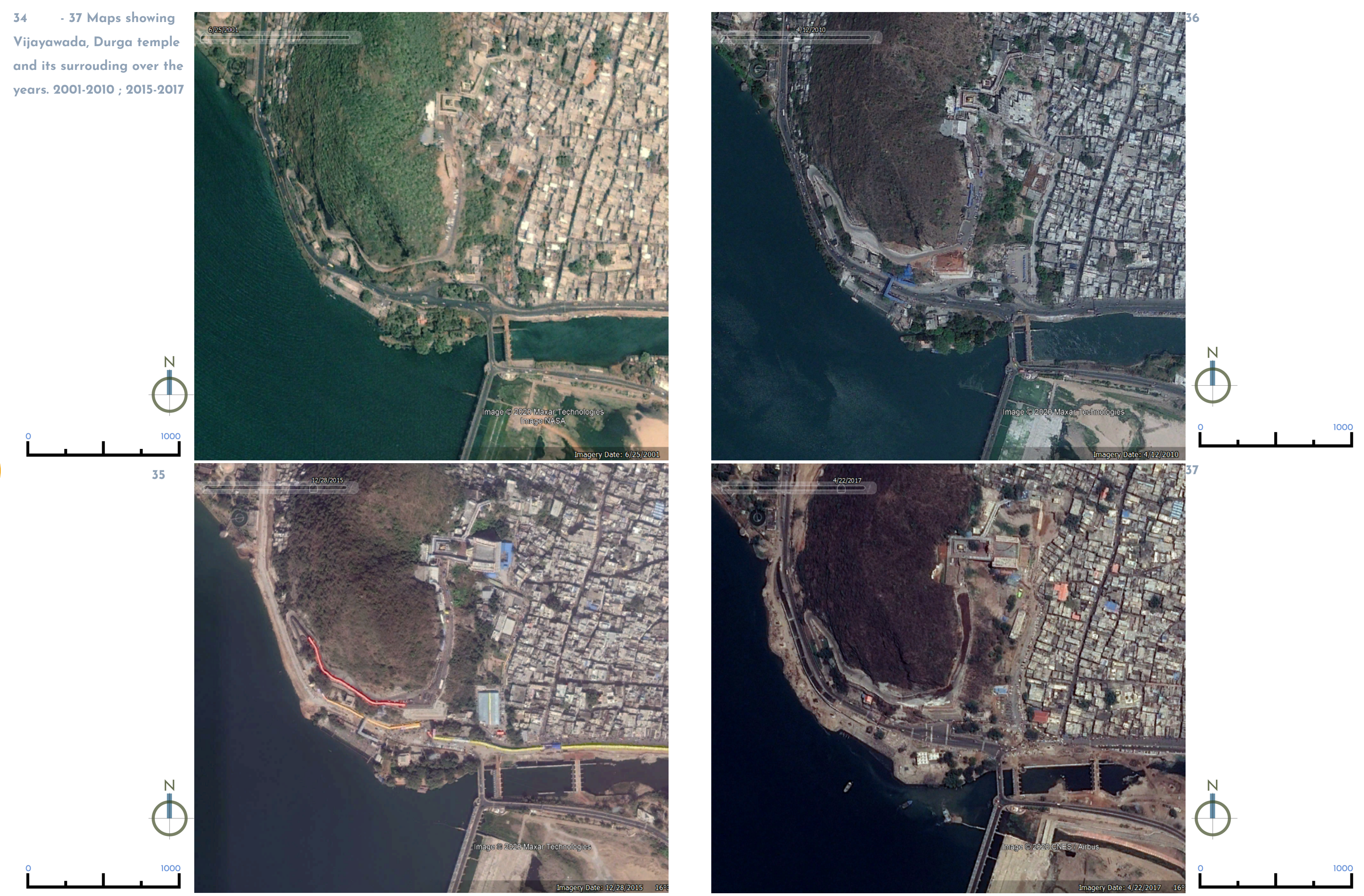


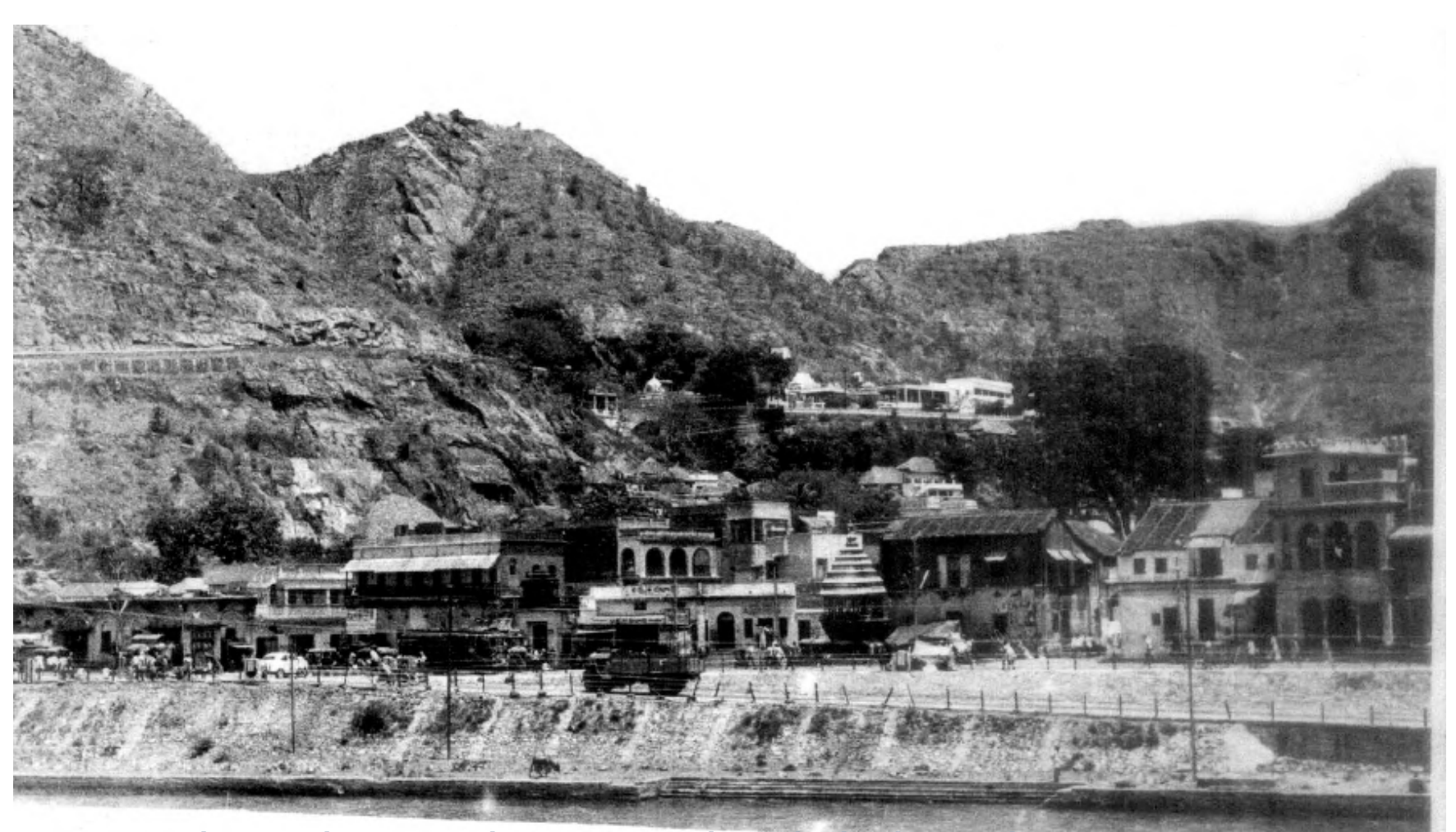

Yiew of ghats and Vijayawada Durga temple in the background.

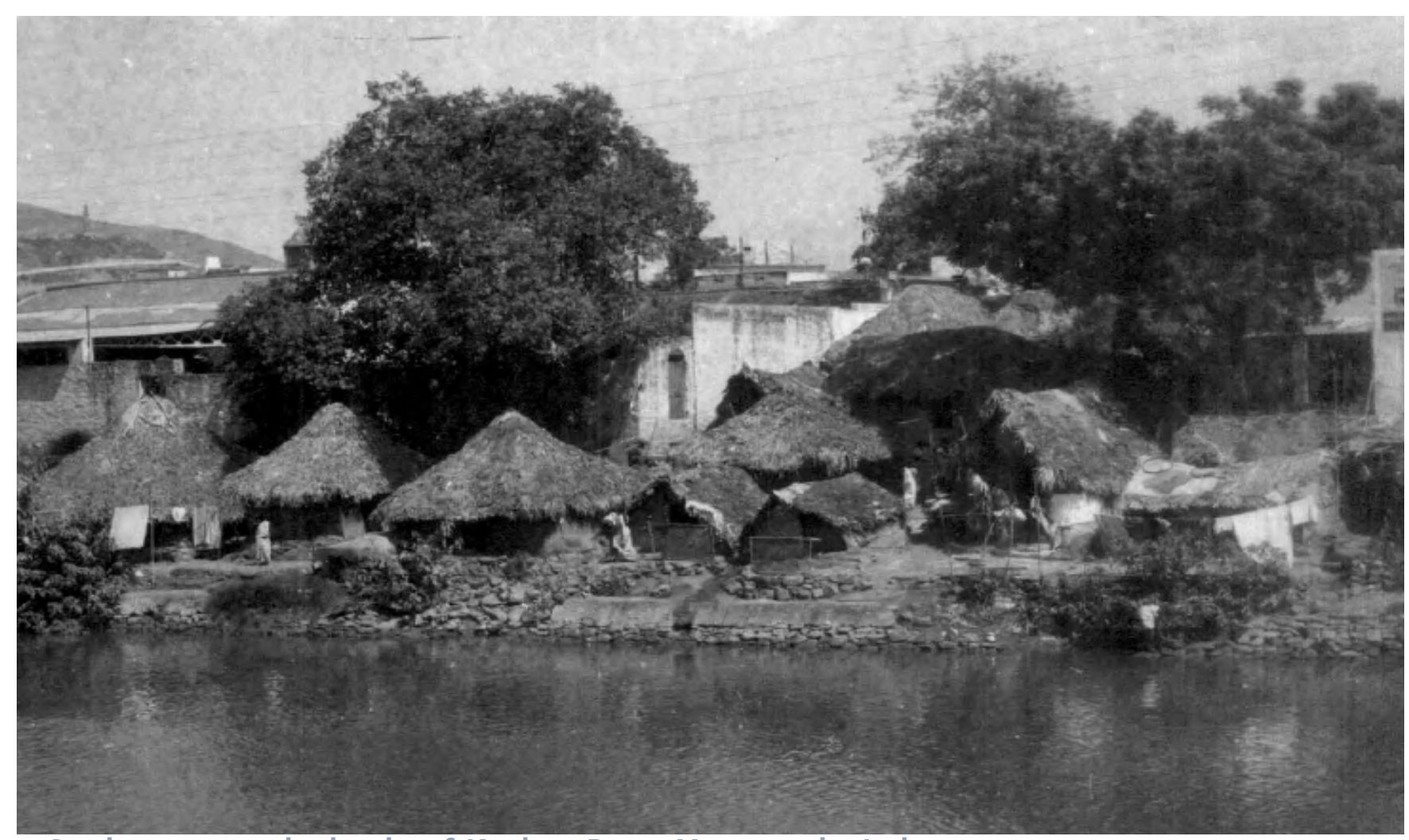

39

Settlements on the banks of Krishna River, Vijayawada, India.
Vijayawada lies on the banks of river Krishna and has three canals supported by the river. Eluru, Bandar and Ryves,

Every year during monsoon, the city experiences flash floods, inundating settlements on the banks and island inhabitants as well.

The temperature in the city surged to a record high touching 44.6 degree Celsius mark. This was the highest temperature recorded in the city this season. - A news article reported in 2017. Summers are infamous in the city for the amout of high temperatures, gaining a nickname for itself. 'Blaze'-wada. [17] 


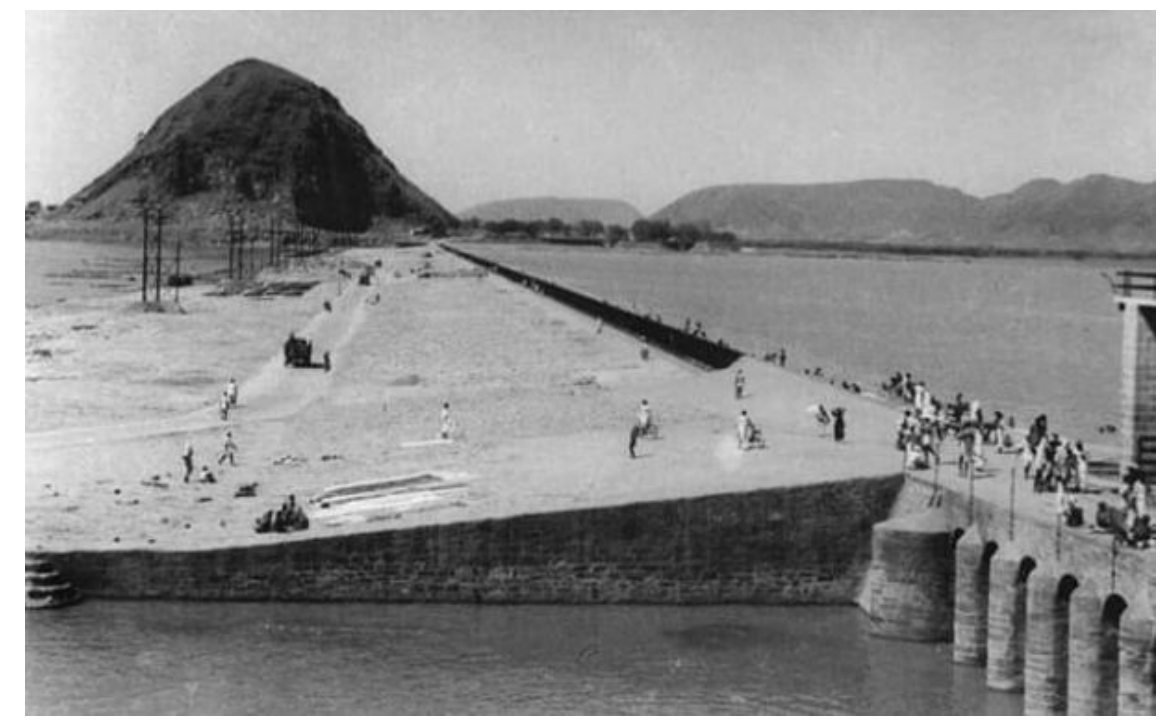

40

Construction of Prakasam Barrage, Vijayawada, India. 1900s

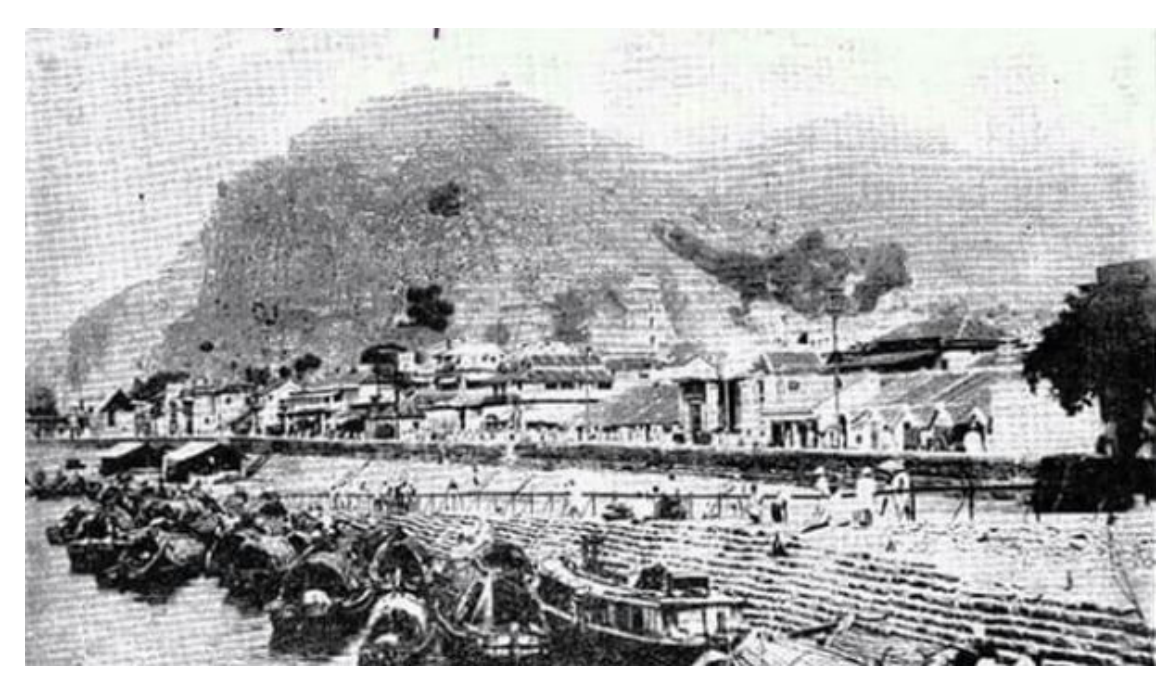

41

Boats used for transportation on banks of Krishna river with Durga temple in the background.
The city has a total road length of $785.56 \mathrm{mi}$. Benz Circle is one of the busiest road junctions in the city with an average of 57,000 vehicles crossing daily, which has the intersection of two national highways of $\mathrm{NH} 16$ and $\mathrm{NH}$ 65. [15]

Bus Transit is the major mode of passenger transport in the city. There are 4 major bus-stations connecting locally and the city to the rest of the country. Additionally, there are close to 8,500 auto rickshaws operating in the city, and the number may be as high as 13,000 by including suburbs. Also to decrease the environmental impact, eco-friendly E-rickshaws were introduced in the city.

Train Transit is the another major mode of affordable transportation. An average of 1.40 lakh passengers are served per day and 50 million annually. More than 250 passenger trains and 150 goods trains utilize the station daily. Vijayawada's internationalairport is located at Gannavaram, suburb of Vijayawada located at a distance of 20 $\mathrm{km}$ from the heart of the city. 
Wind direction is from the SOUTH from January to June, from the WEST from June to October and from the EAST for the remainder.

Every year during October, for a period of 10 days, the city witnesses devotees in high numbers visiting the temple. Barricades would be erected to represent queues for devotees along these roads.

Taking into consideration, average traffic timings, the map illustrates the distances a person can travel by car, bicycle and foot. Whcih are $4 \mathrm{~km}$ $1.2 \mathrm{~km}$ and $0.8 \mathrm{~km}$ respectively

As discussed earlier, settlements in this city started around the temple where artisans set up their houses for ease of travel to temple. Later, as various people started to travel, by ships, during late 1800's and early 1900 's, the boundaries started expanding

Also, since the soil is appropriate for agriculture, farmers settled from early 1950's and with urbanization, agricultural lands kept moving to the outskirts of the built-up areas.

Train Transit is the another major mode of affordable transportation. An average of 1.40 lakh passengers are served per day and 50 million annually. More than 250 passenger trains and 150 goods trains utilize the station daily.

Vijayawada Airport is located at Gannavaram, suburb of Vijayawada located at a distance of $20 \mathrm{~km}$ from the heart of the city. It has been recognized as an international airport.

The city has 20 small parks scattered around, some of which collect garbage. Agricultural lands can be seen at the outskirts of the city on the map. The other green areas/ areas of vegetation are the two hills, one of which is developed for tourism and the other has a religious center atop.

Krishna River along with the three canals that branch out to the northwest are the major waterbodies.
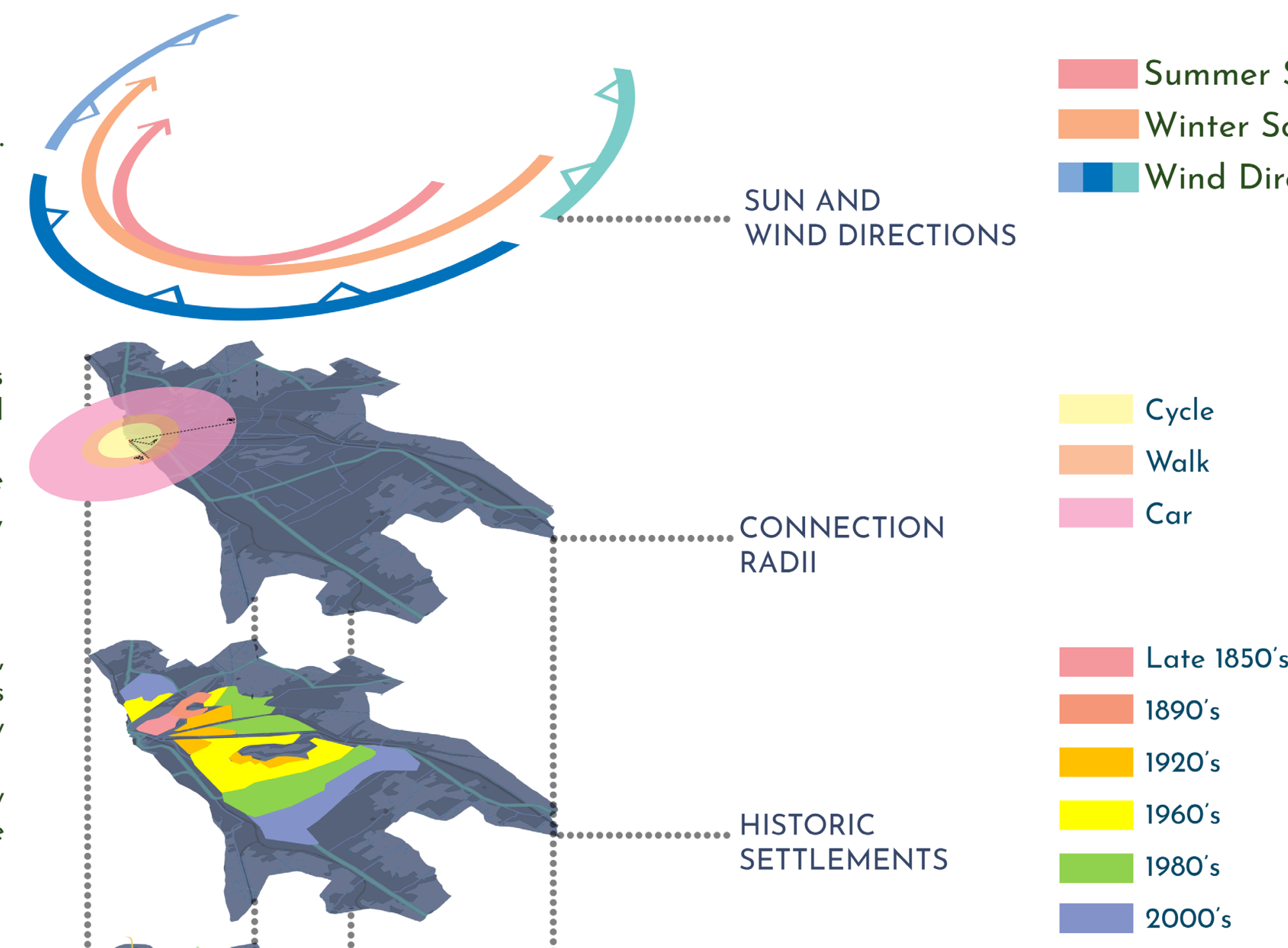

ROADS AND TRAFFIC

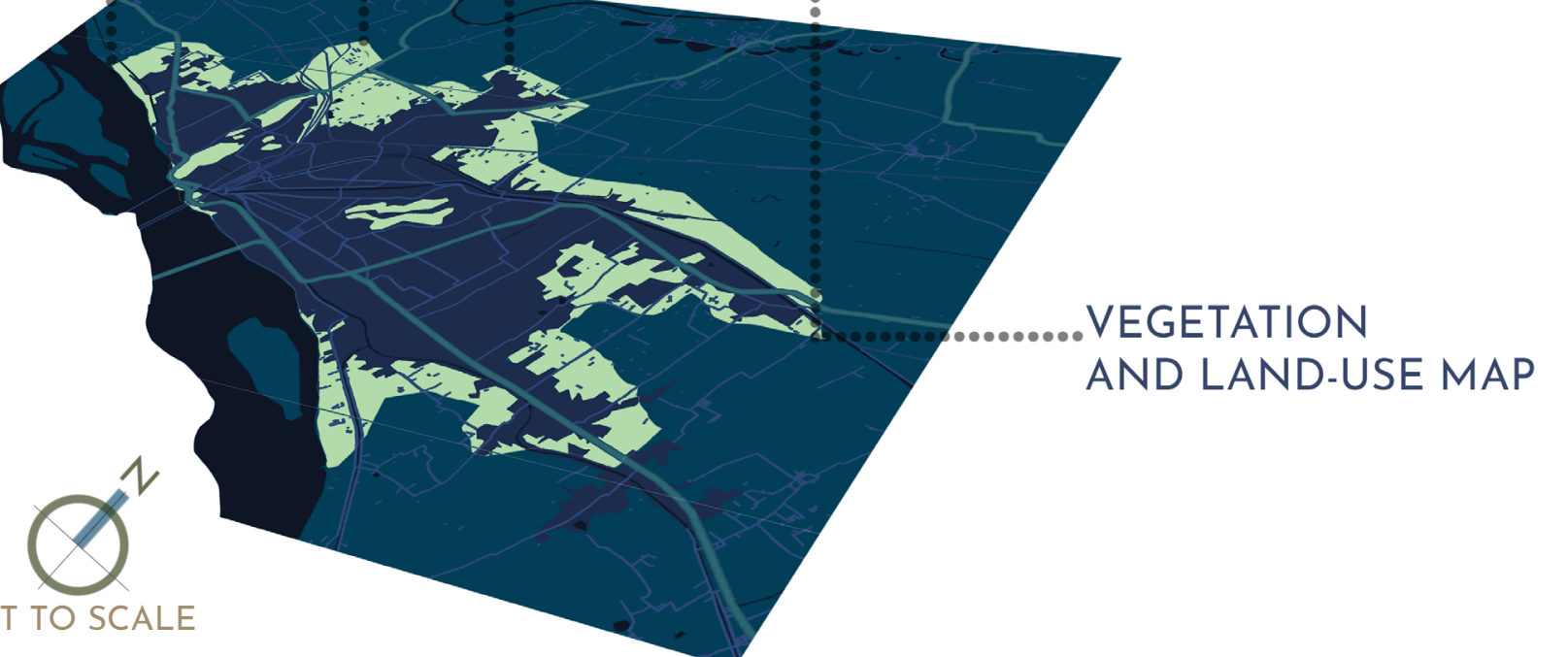

Vegetation/ Agriculture

Waterbodies

Built-up Area

Arterial Roads

Highway 


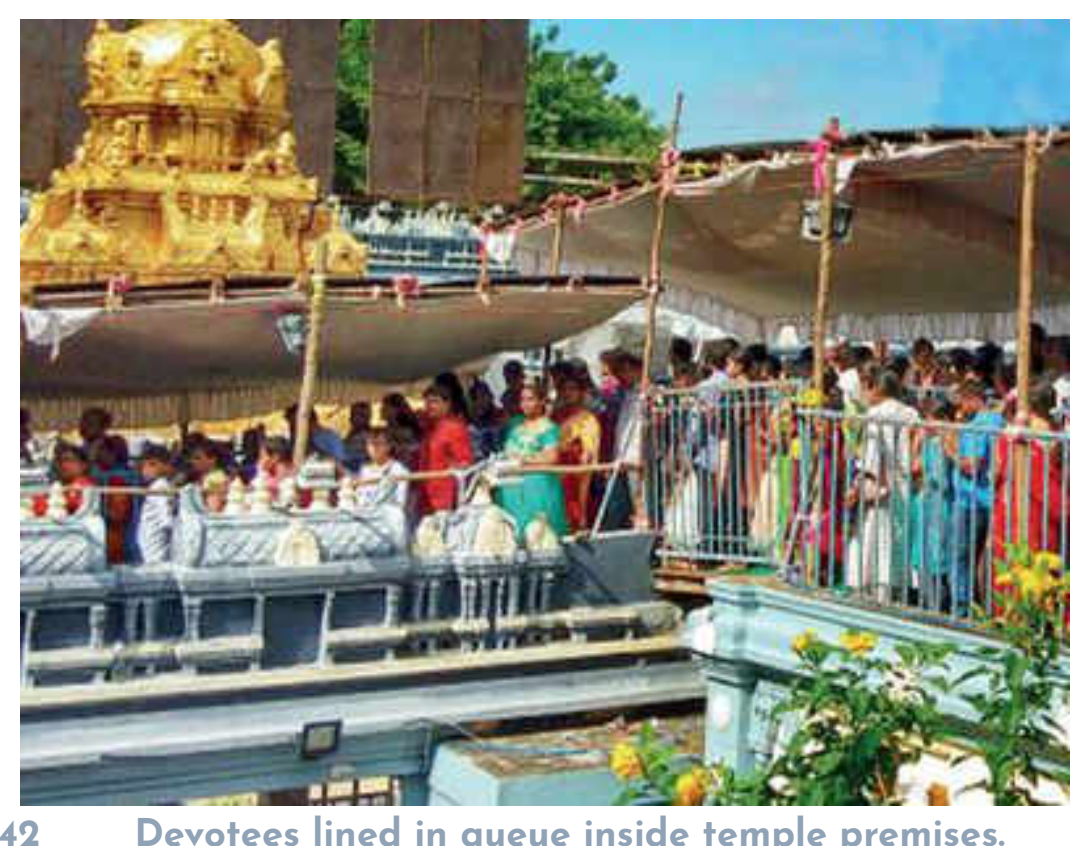

Devotees lined in queue inside temple premises.

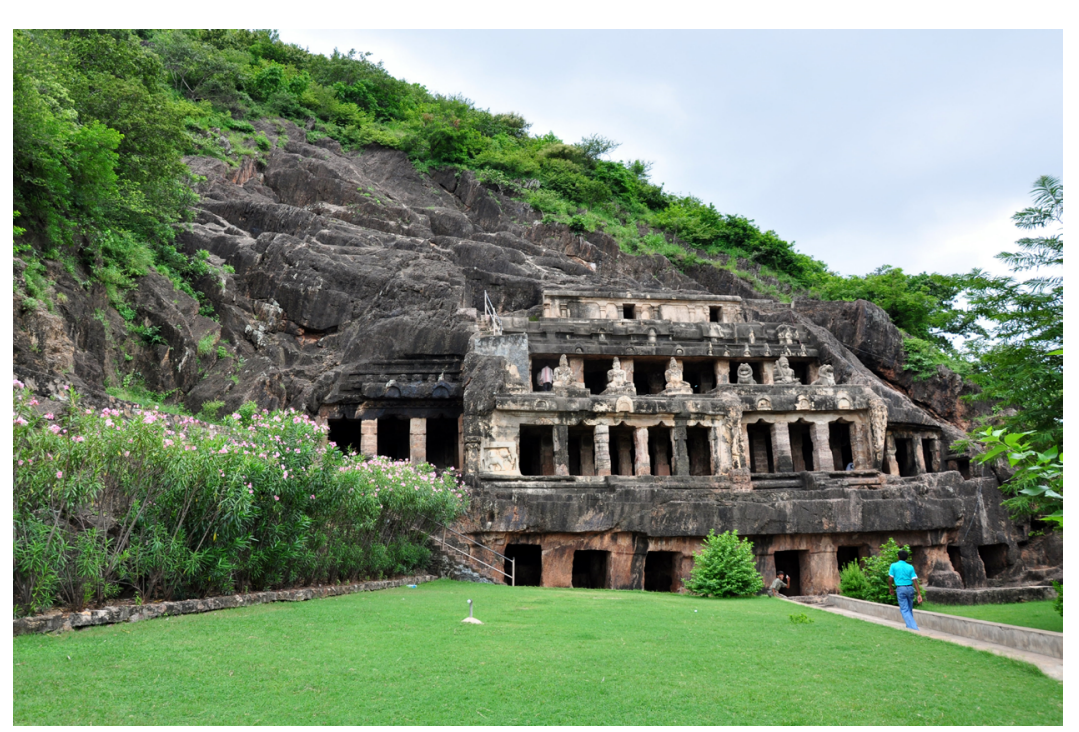

Undavalli Rock-cut caves, Vijayawada, India.

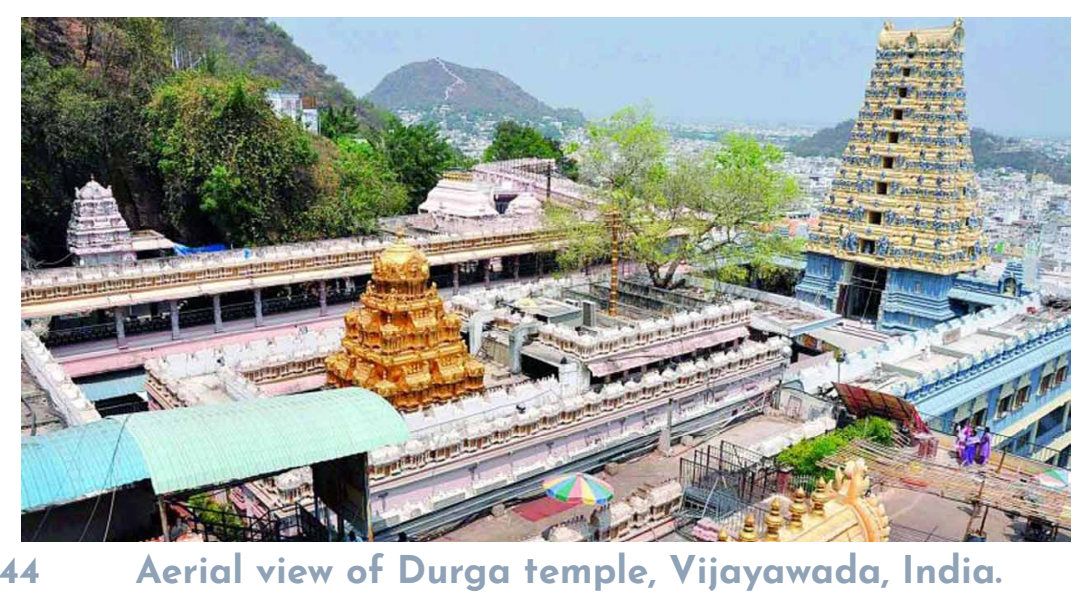

Every year during October, which is the festival month, a period of 10 days, the city sees devotees in high numbers visiting the temple. The lines represented in the map above, indicate the roads being closed off or limiting the number of vehicles. Barricades would be erected to represent queues for devotees along these roads.

Vehicles entering through national highways would be re-directed along other routes.Parking is along the road adjacent to the river, limiting to only 2 -wheeler vehicles.

A mobile phone application that allows users to keep track of their parked vehicle, traffic (especially during this period) and the rush of devotees visiting the temple (to avoid any trampede), was introduced along with a huge police force, exclusively. 


\section{LYNAE BIAAGRAMS}

$45 \quad$ Vijayawada temple ghat, Krish na river during monsoon.
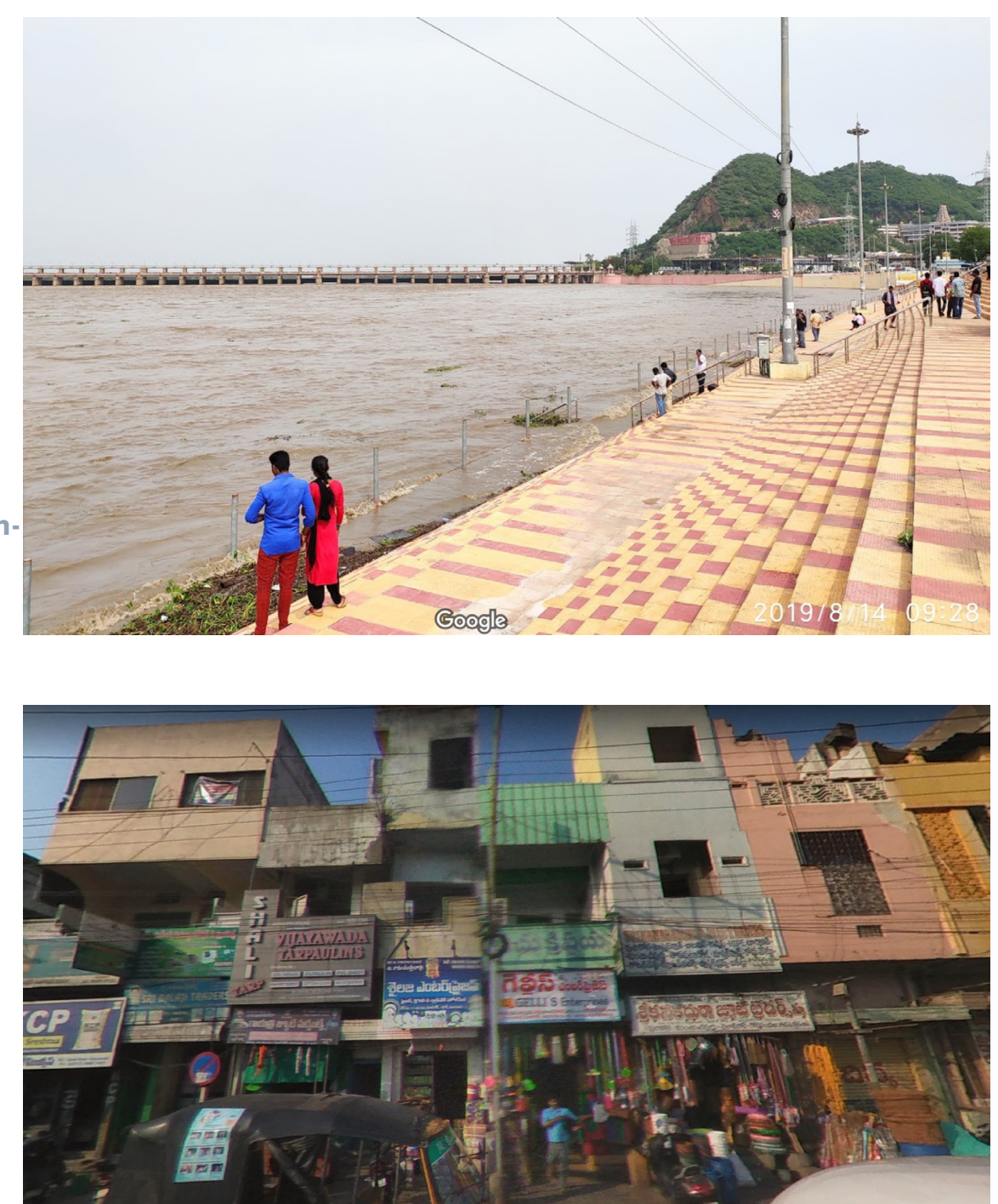

ter of Yijayawada.

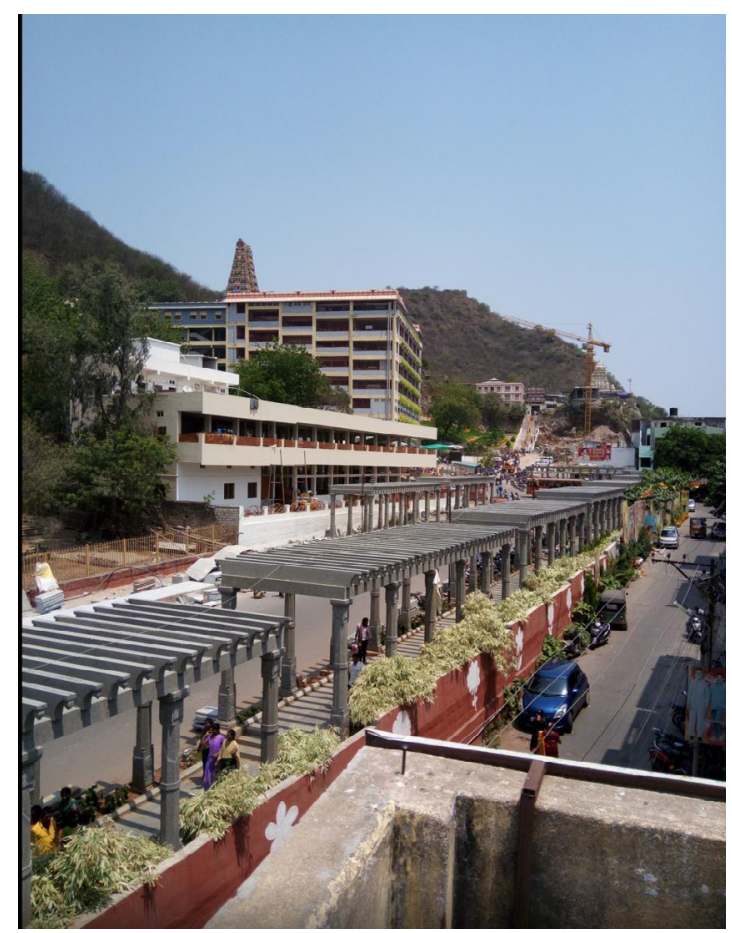

47 Temple premises as seen from neighboring residential area.
The National Highway, Railway lines, path along the foot of the mountain are few of the edges, that bred

One of the important junction of the city is the intersection of the Prakasam Barrage, and the National highway which the temple.

Industrial sector, religious sector, residential sector are various pockets bordered with agricultural fields on the outskirts of the city - can be common characteristics.

The ghat station during monsoon, Durga temple, are scattered around the city.

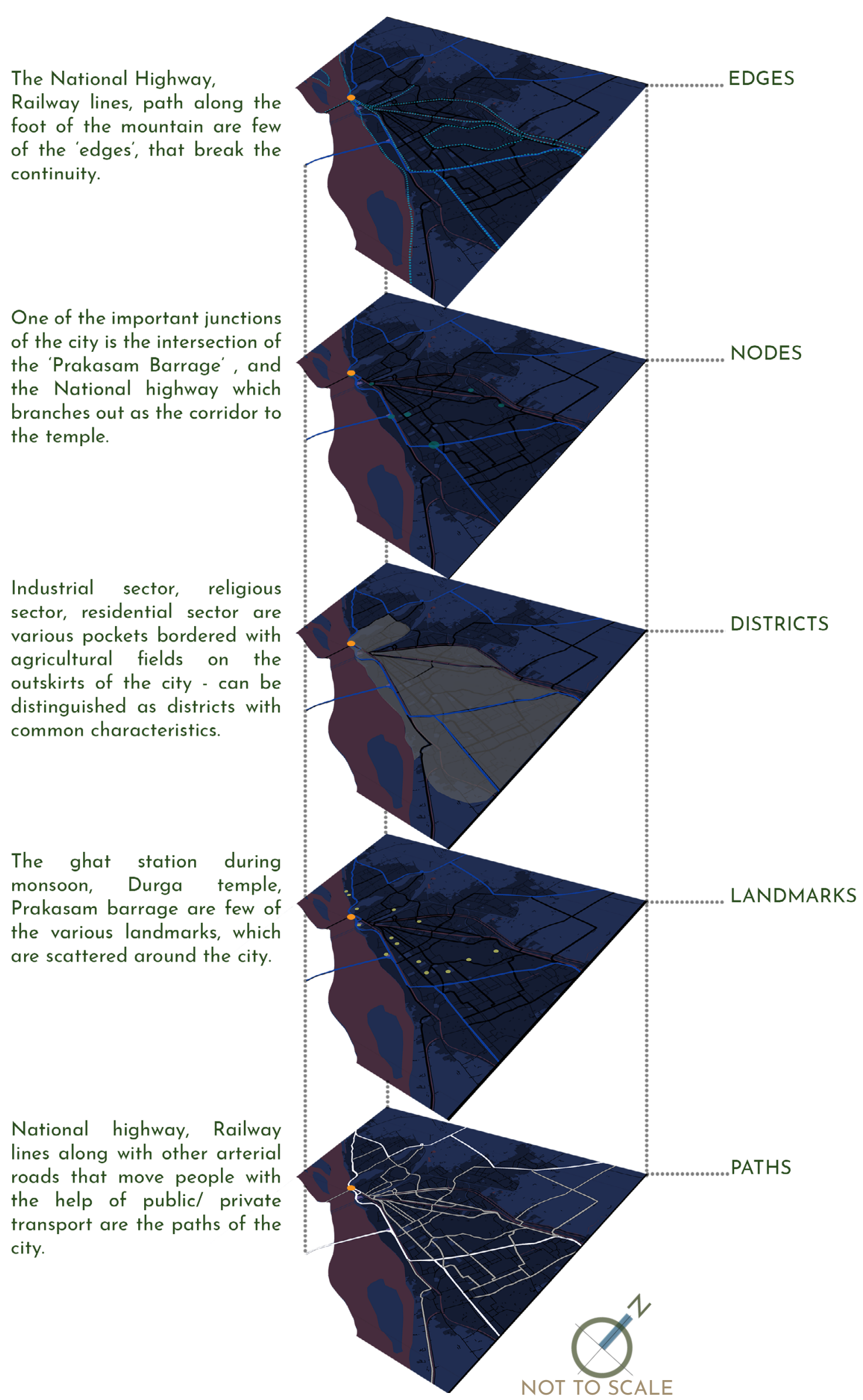




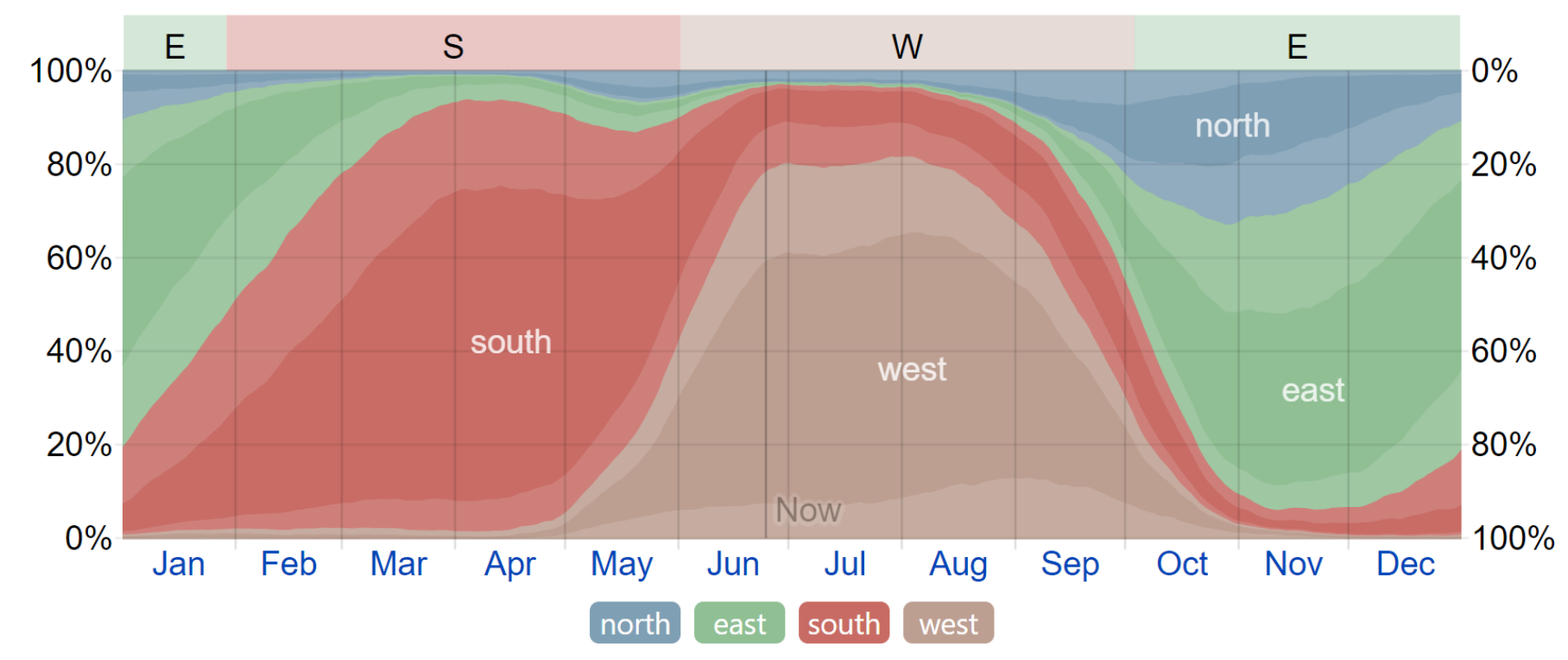

48 Percentage of hours in which mean direction is from four cardinal directions.
The climate is tropical, specifically a tropical wet and dry climate with hot summers and moderate winters. The moderate temperature reaches $47 \mathrm{C}$ and minimum temperature is $19 \mathrm{C}$. While the average humidity is at $78 \%$, it receives rainfall from both south-west monsoon (June-September) and north-east monsoon (October-December).[17]

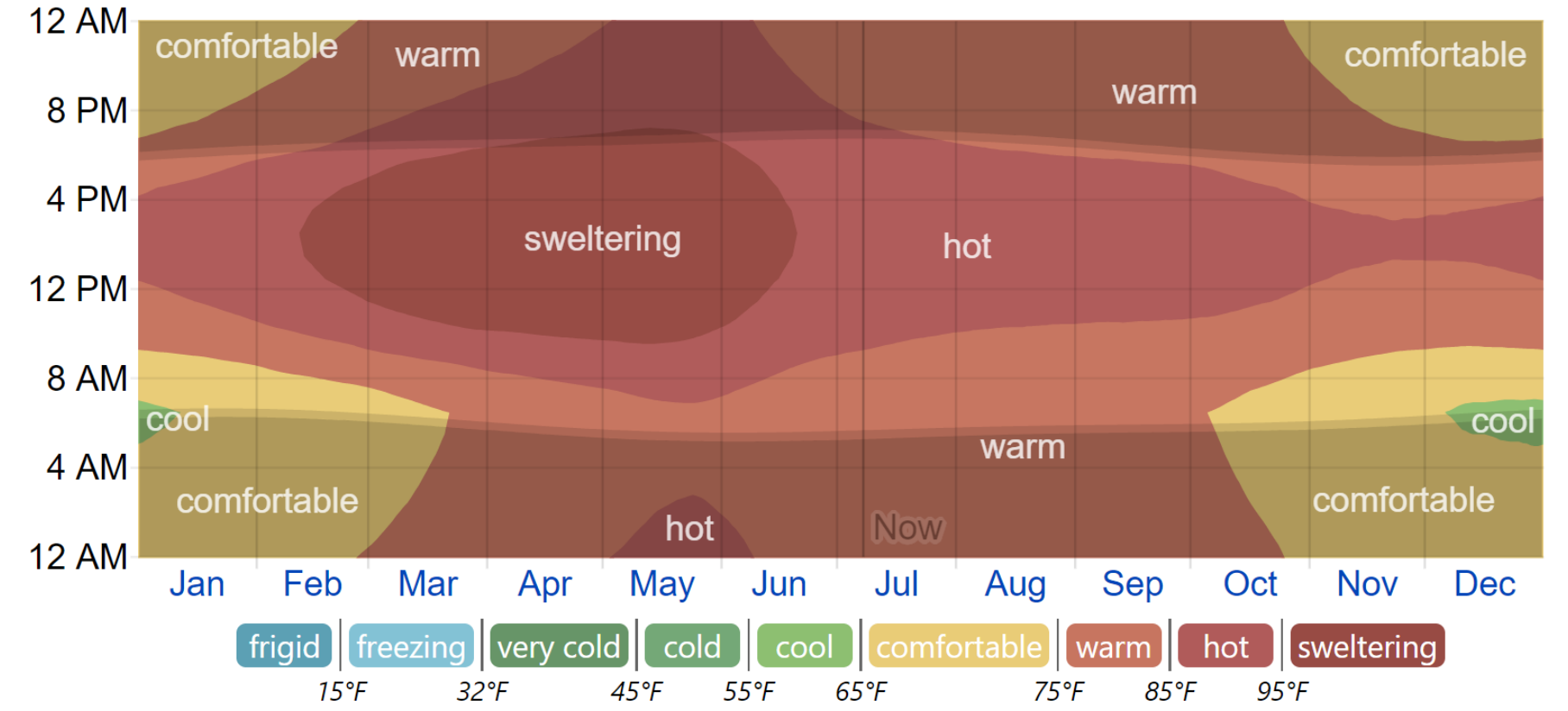

49

The average hourly temperature, color coded into bands. The shaded overlays indicate night and civil twilight. 


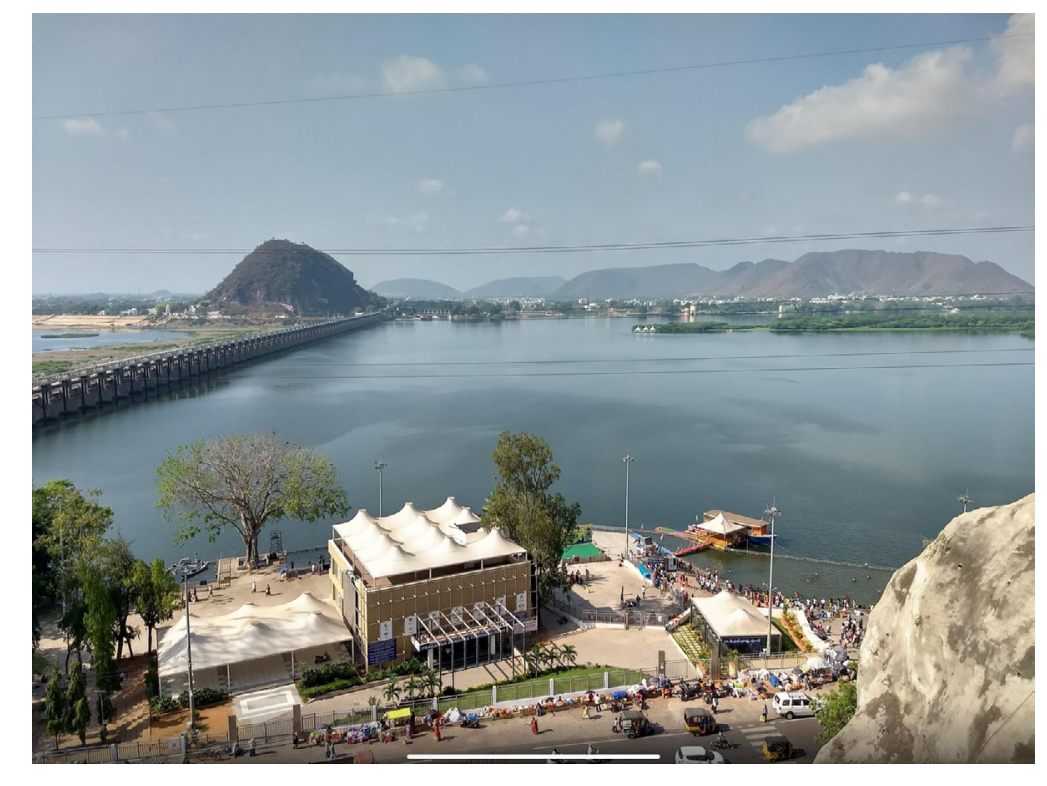

50

View from Durga temple.

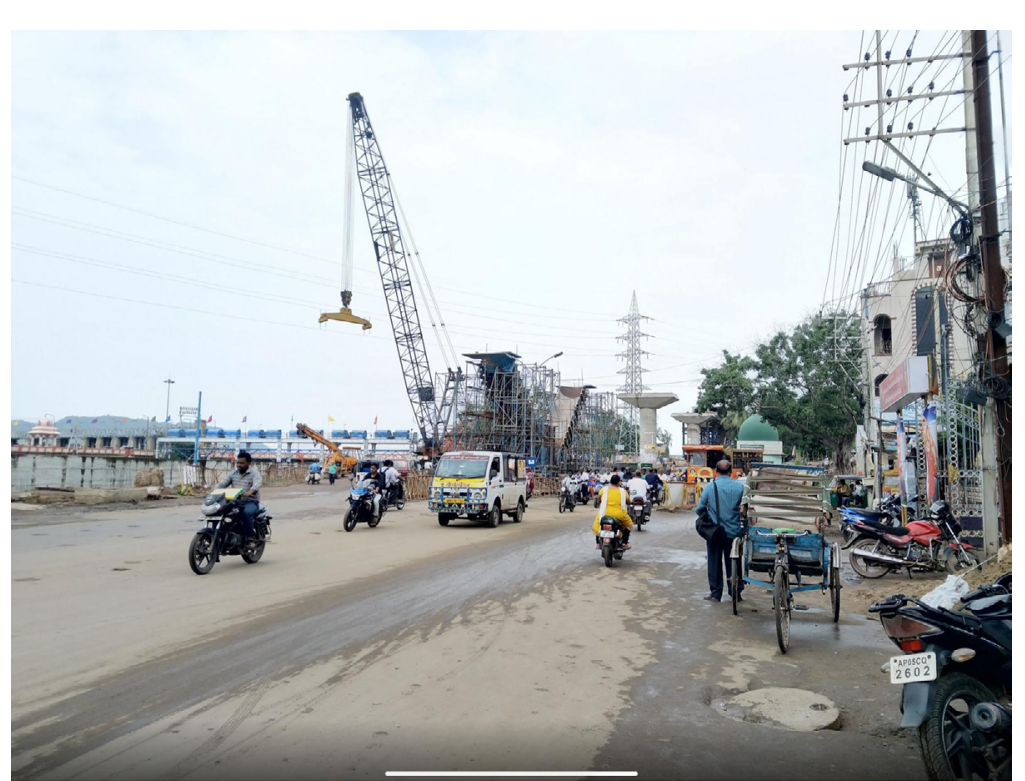

The city has a spiritual reverberation as it recognizes many religious structures of all faiths with the same sincerity. However, the main temple of the city is the Durga temple residing on the Indrakeeladri hill, presiding over the city. Also, at the foot of the hill is a mosque which is a sign of communal harmony. The streets that direct a devotee towards the temple is the same road the connects the mosque They are adaptable to handle huge crowds and support another event with different requirements on another day. Various businesses in the city can be seen in the form of street vendors, who play an important role in and around the temple premises.

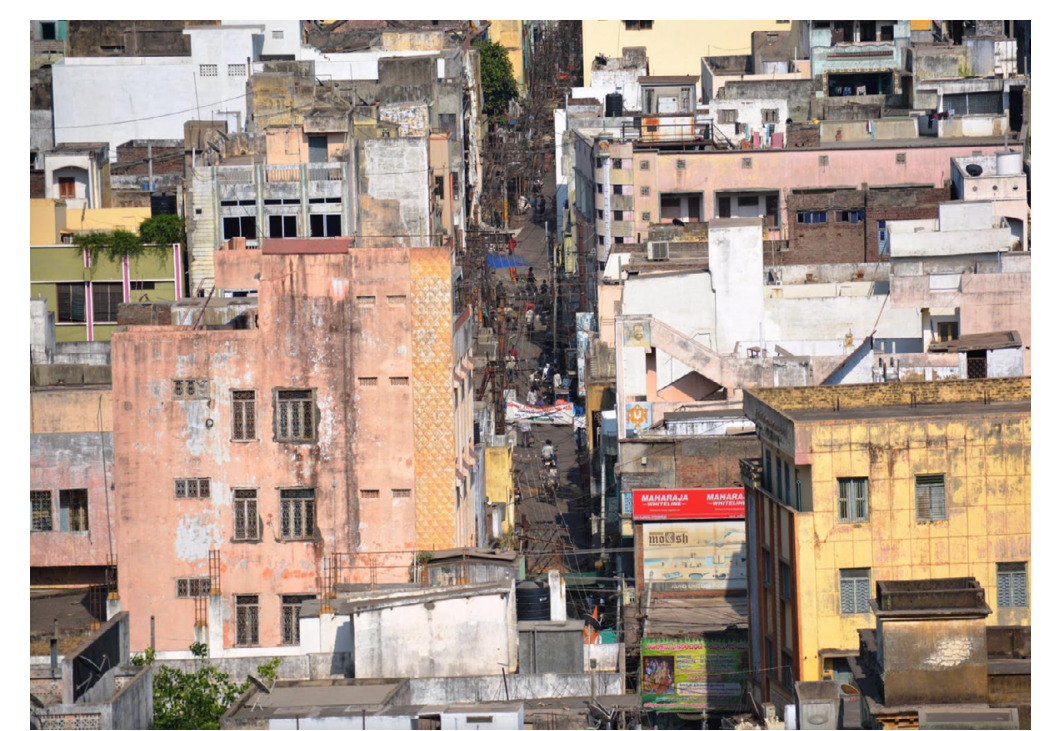




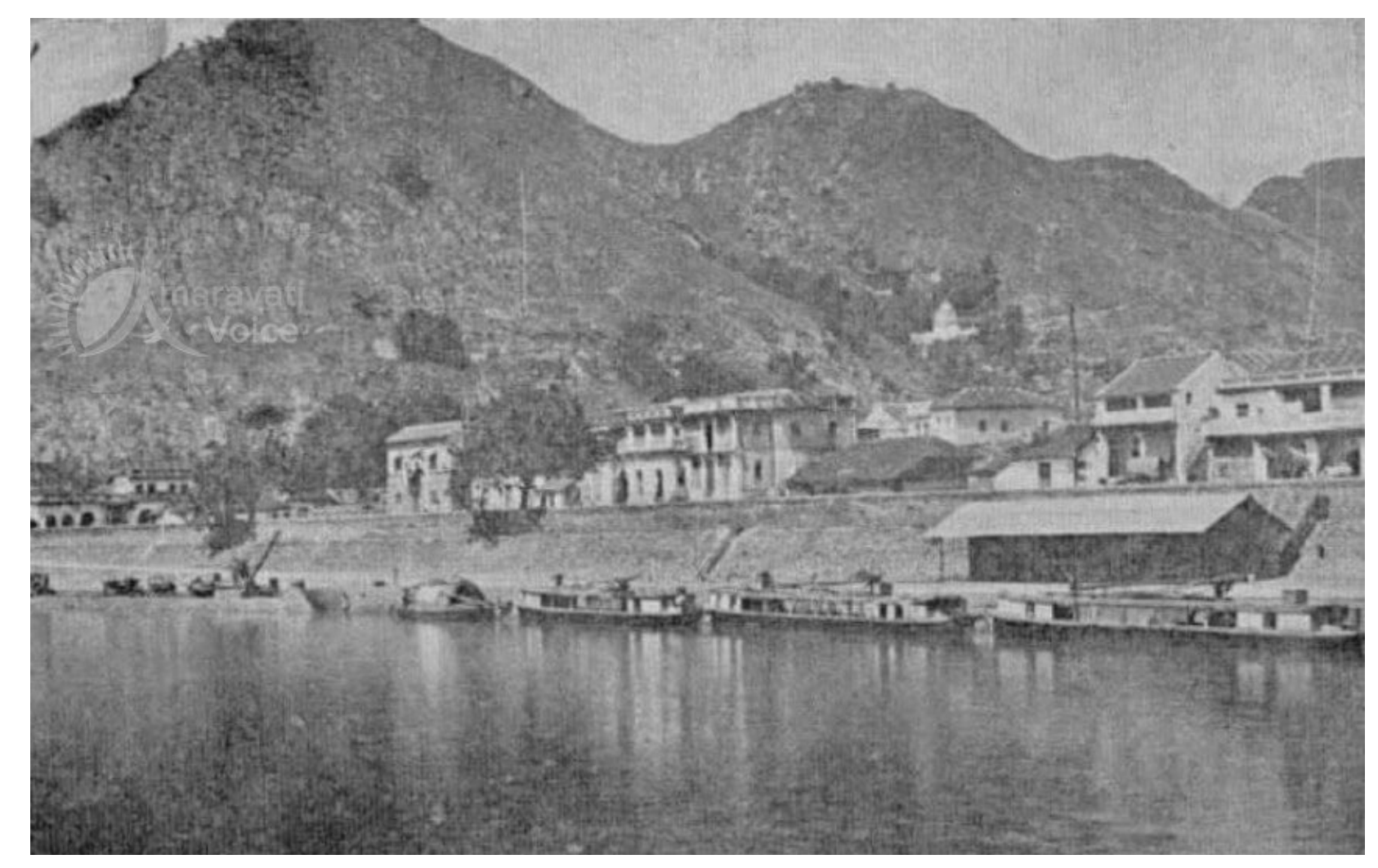

Ghats and Durga temple in the background, 1900's

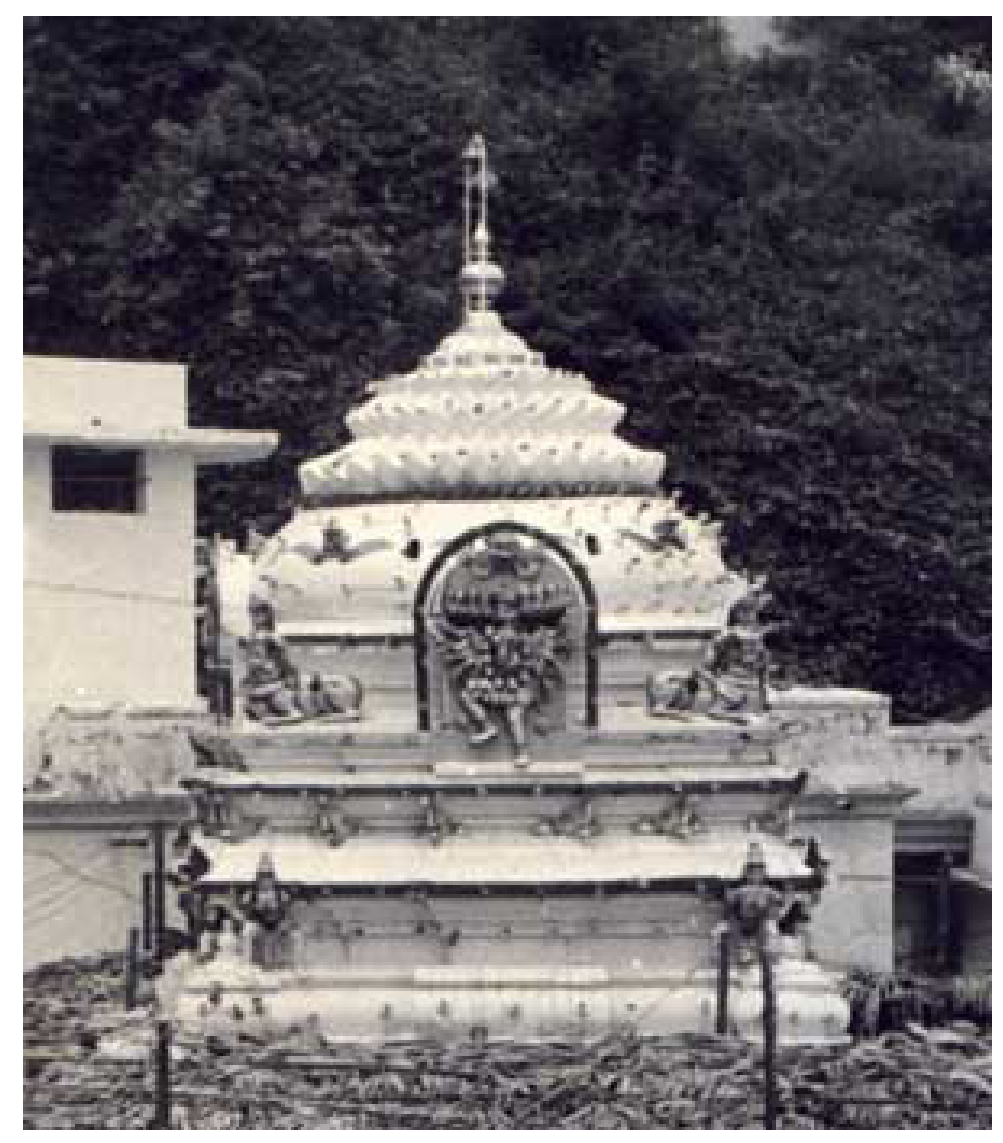

54 Durga temple gopuram. 1900's.

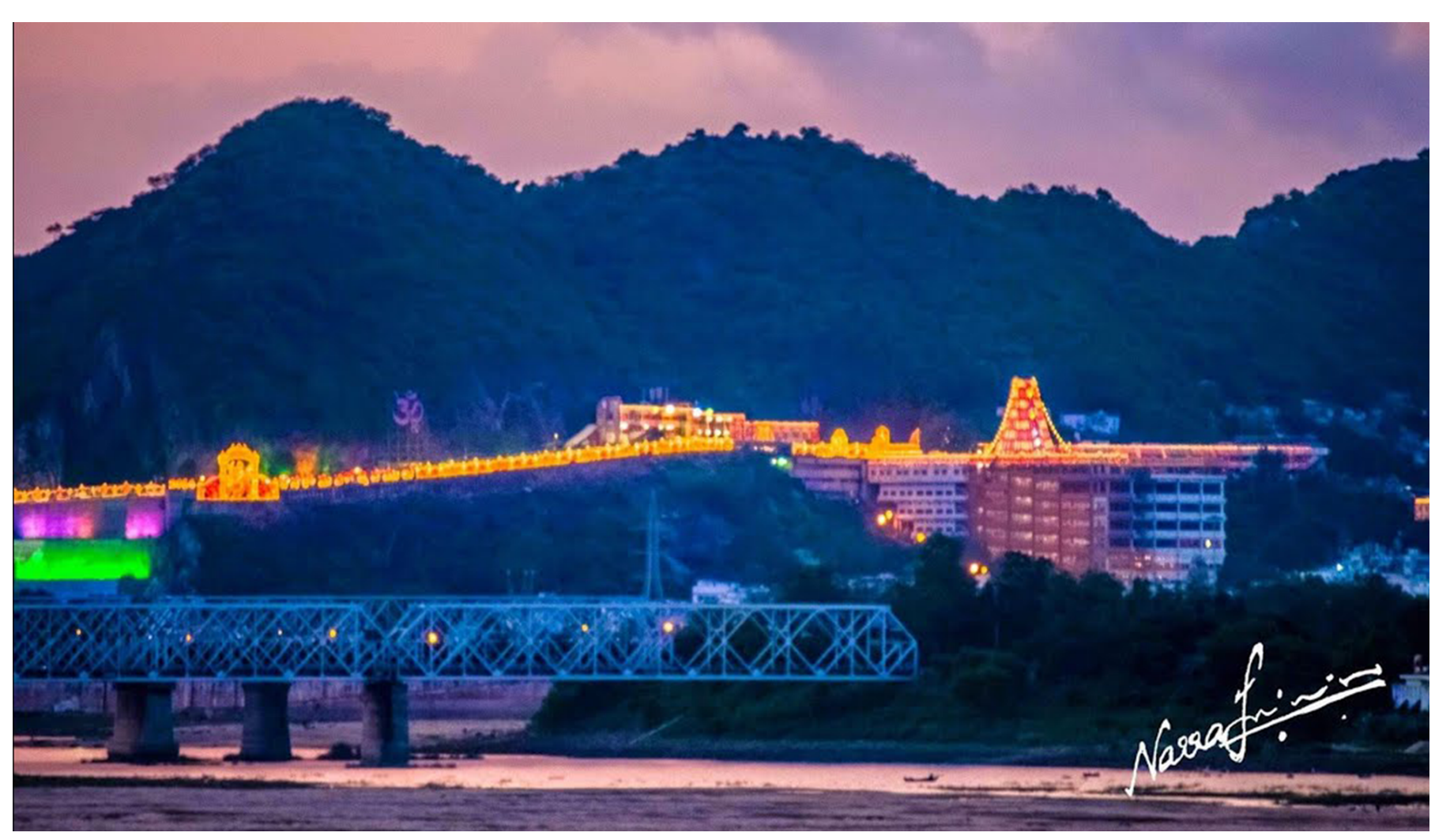

55 Ghats and Durga temple. 2016. 


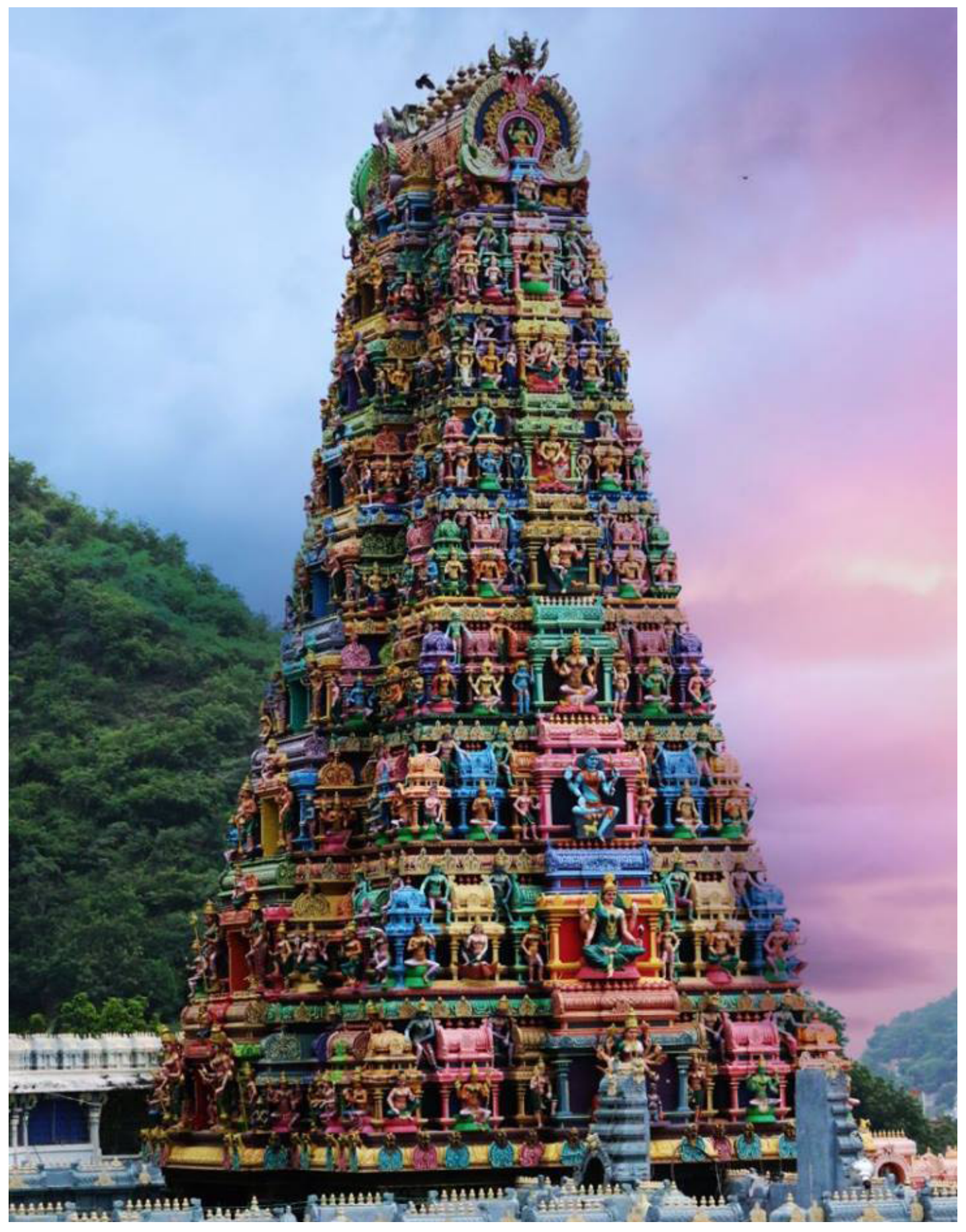
arrogance, selfishness, greed, jealousy, desire to harm others etc.) and Her sitting on it reminds us to control these qualities, so that we are not controlled by them.

Durga has been a warrior goddess, and she is believed to be created with the collective energy of all gods. Born fully grown and beautiful, Durga presents a fierce menacing form to her enemies. She is usually shown riding a lion and with 8 or 10 arms, each holding the special weapon of one of the gods, who presented them to her for her battle against the demon. 9 avatars of the goddess depicts a certain point in Her life.

Also, Durga goddess is a part of a major sect in Hindui religion called Shaktism, where the metaphysical reality is considered metaphorically a woman and Shakti is regarded as the supreme godhead. One of the iconographies associated with this goddess is the Sri Yantra or Sri Chakra, often seen as a two-dimensional diagram or a three dimensional pyramid form. [18] 


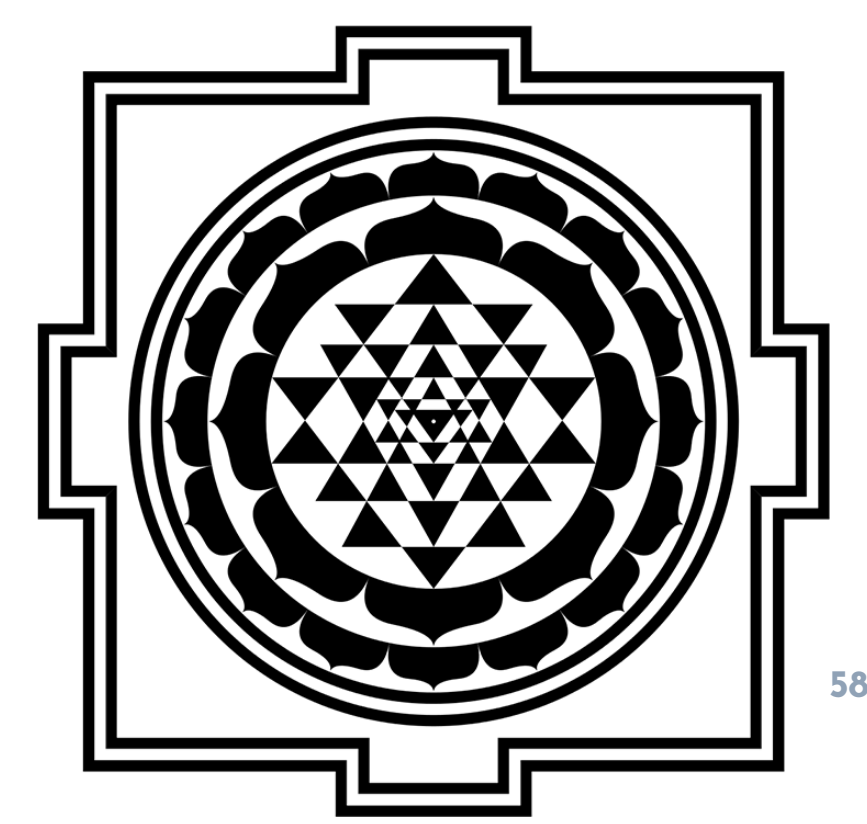

Sri Yantra, Vaastu shastra iconography
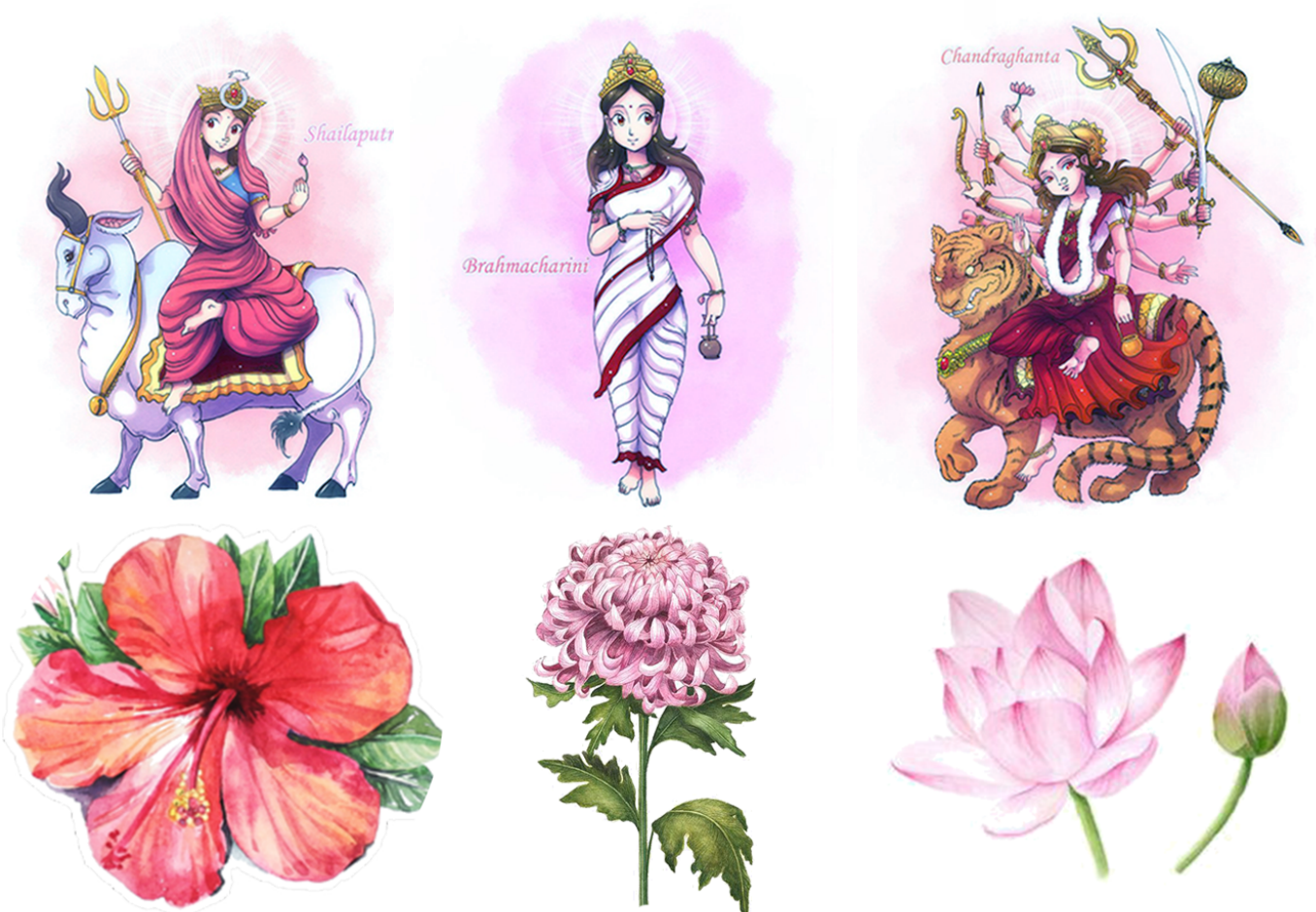

Vaastu is a traditional Indian system of architecture originating in India. Texts from the Indian subcontinent describe principles of design, layout, measurements, ground preparation, space arrangement, and spatial geometry. The designs aim to integrate architecture with nature, the relative functions of various parts of the structure, and ancient beliefs utilising geometric patterns (yantra), symmetry, and directional alignments. [8]

Vaastu is a vast subject which has many subfields. For the ease of understanding, and continuity of the design concept, the iconography shown on the left is considered. It is designed according to geometry and science. Also, believed to represent the cosmic universe.
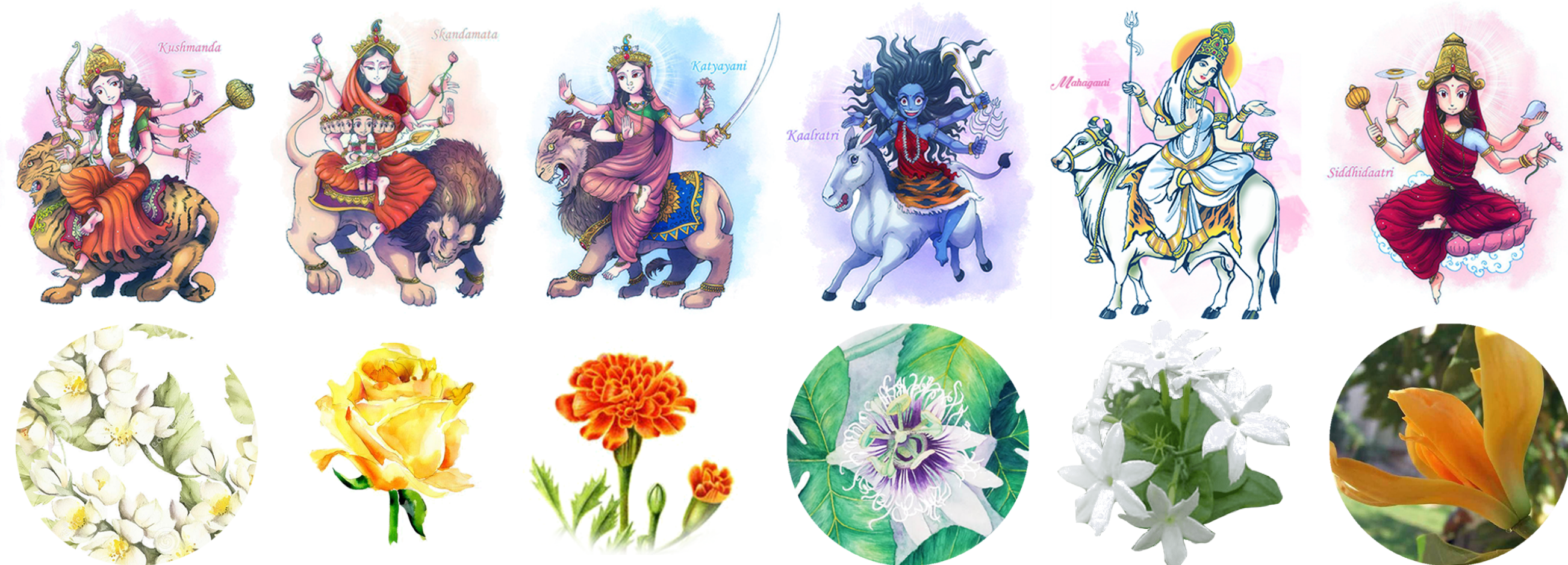


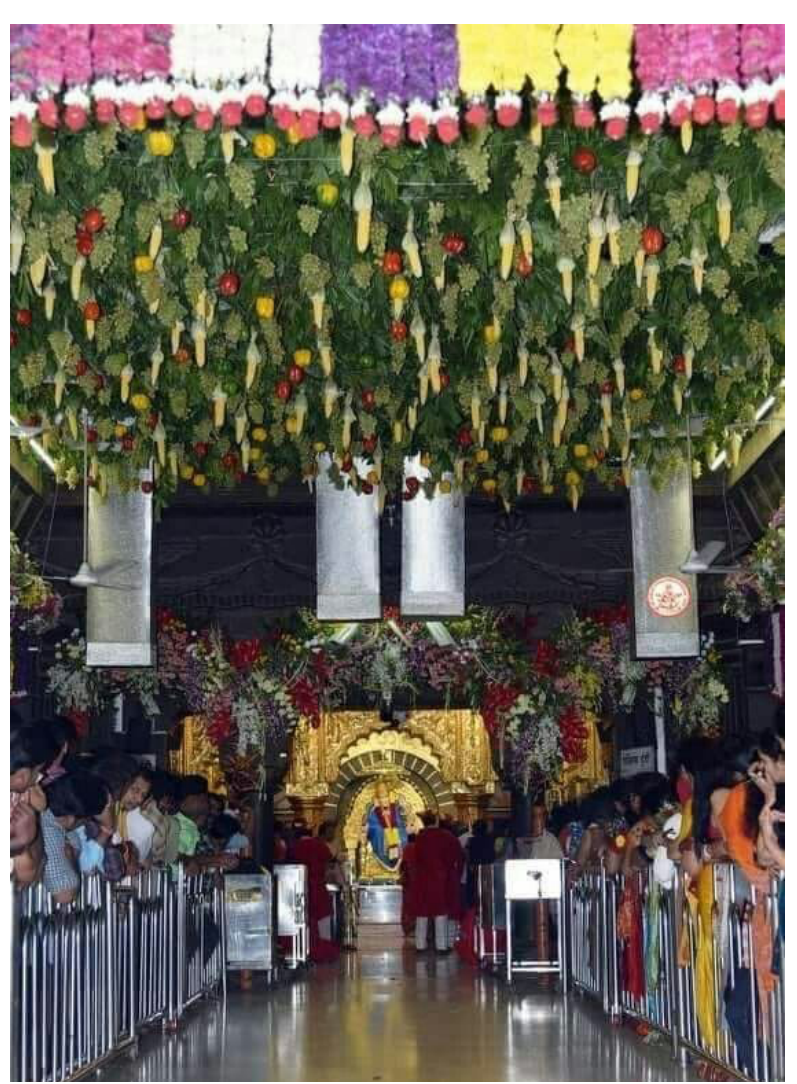

60 festivals

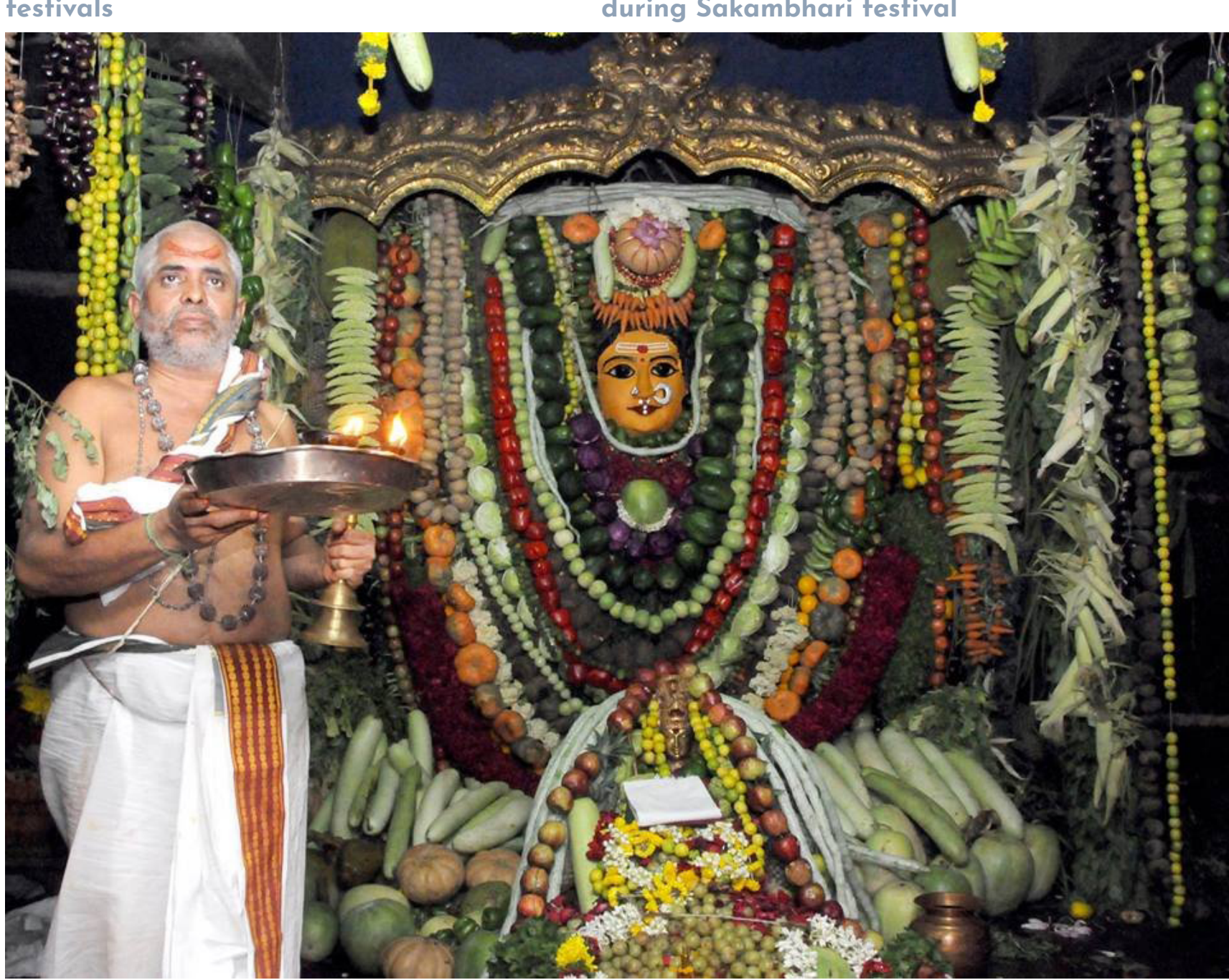

Durga devi decorated with vegetables and fruits for Sakambhari festival.

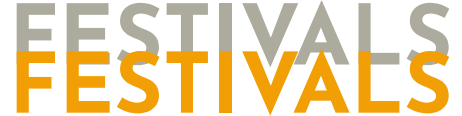

Sakambhari festival

Goddess Sakambhari festival is celebrated in Ashadha month(Hindu Lunar (alendar) annually, during a three-day-long festival, goddess Kanaka Durga assumes the form of 'Sakambhari' where prayers are offered to the Goddess to bless all vegetables, agriculture, and food so that they are plentiful and capable of nourishing the multitude.

\section{Teppotsavam event}

Marking the end of a 10-day Dasara festival period, the goddess is paraded in a boat decorated with flowers, which is designed in the shape of a swan. Crowds gather together to witness the end of the festival and bid a goodbye to the god and goddess and pray in order to bless them until the next year. The beauty in this event and the history surrounded by it is explained in the form of a sound and light show that performs all through the day. Generally, all events on a normal day would commence before the sunrise and end just after sunset. However, during teppotsavam, festivities continue along after dusk, illuminating with lights that adorn the city life. [18] 


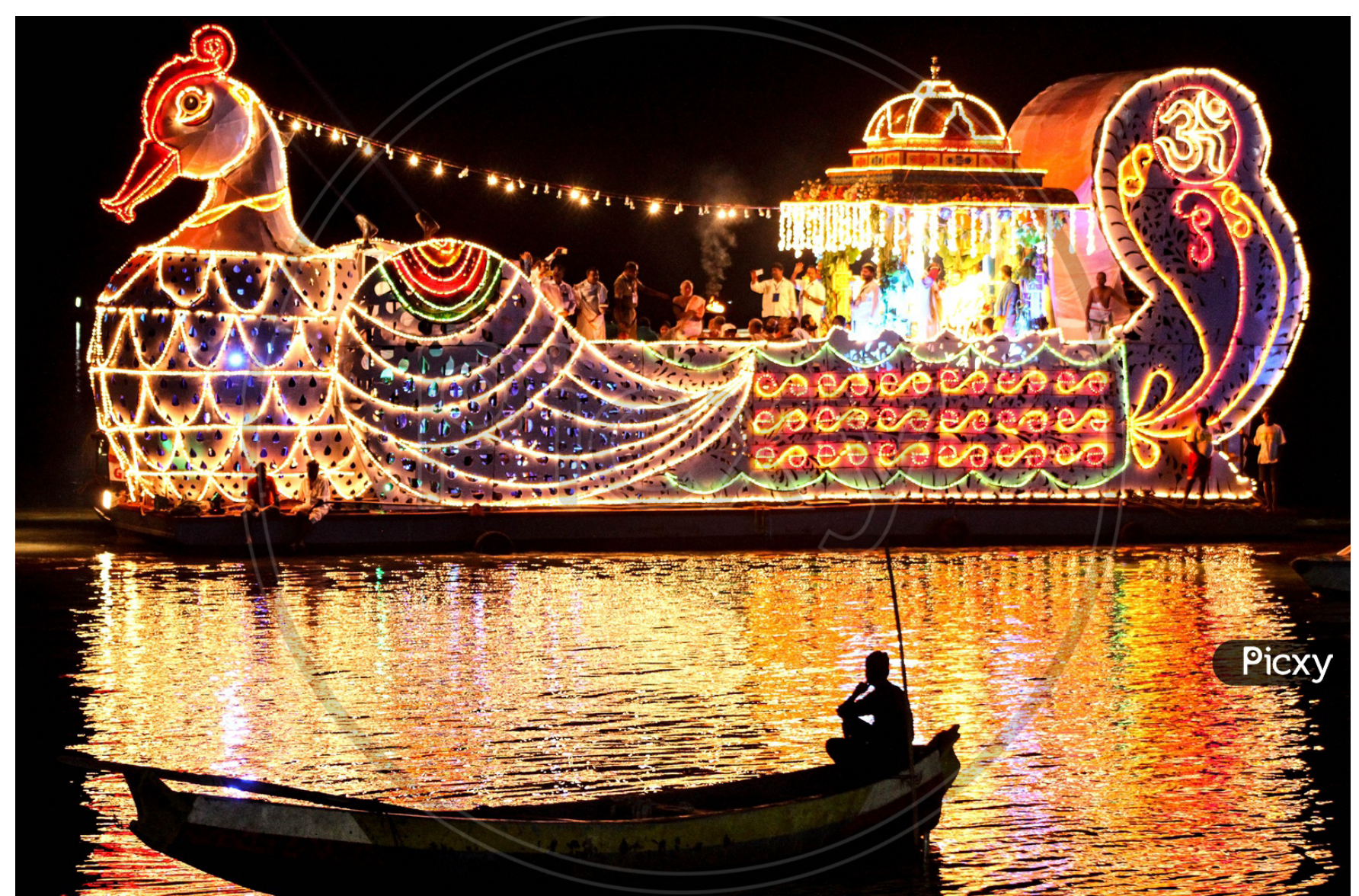

Boat decorated in the shape of swan, for the parade marking the end of Dasara festival.

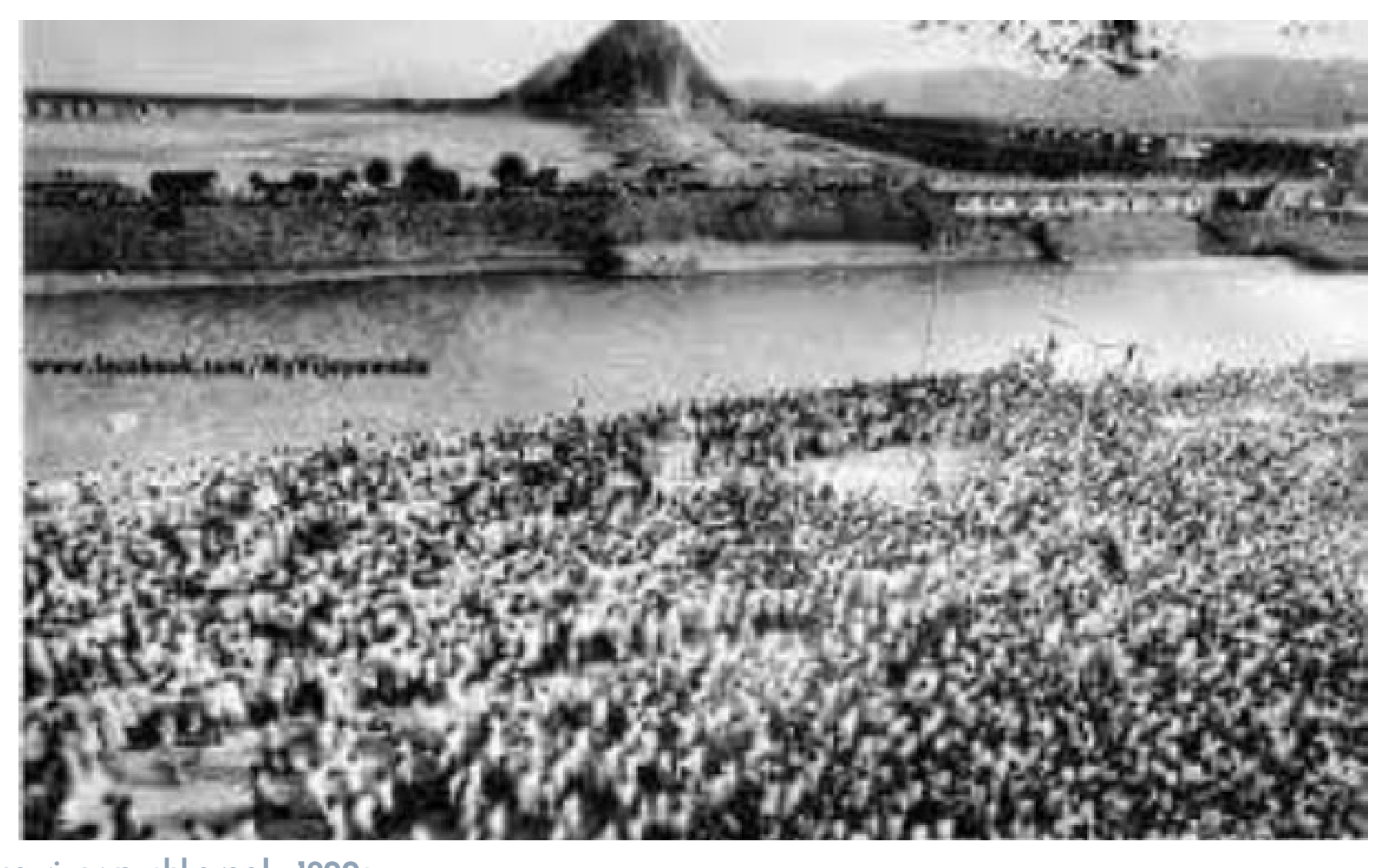

Krishna Pushkaraalu

Krishna Pushkaraalu is a festival of River Krishna which normally occurs once in every 12 years and is celebrated with much glory. The Pushkaram is observed for a period of 12 days from the time of entry of Jupiter into Virgo (Kanya rasi). It is celebrated at shrines along the banks of 12 major sacred rivers in India, in the form of ancestor worship, spiritual discourses, devotional music and cultural programmes. The celebration happens annually, once in 12 years along each river. Each river is associated with a zodiac sign, and the river for each year's festival is based on which sign Jupiter is in at the time. A dip in the sacred river is believed to erase all sins. The first twelve days are known as Adi Pushkaram, and the last twelve days are called Anthya Pushkaram. It is believed that during the above period of twenty-four days, "Pushkar", imbued with the power to make any river holy. 


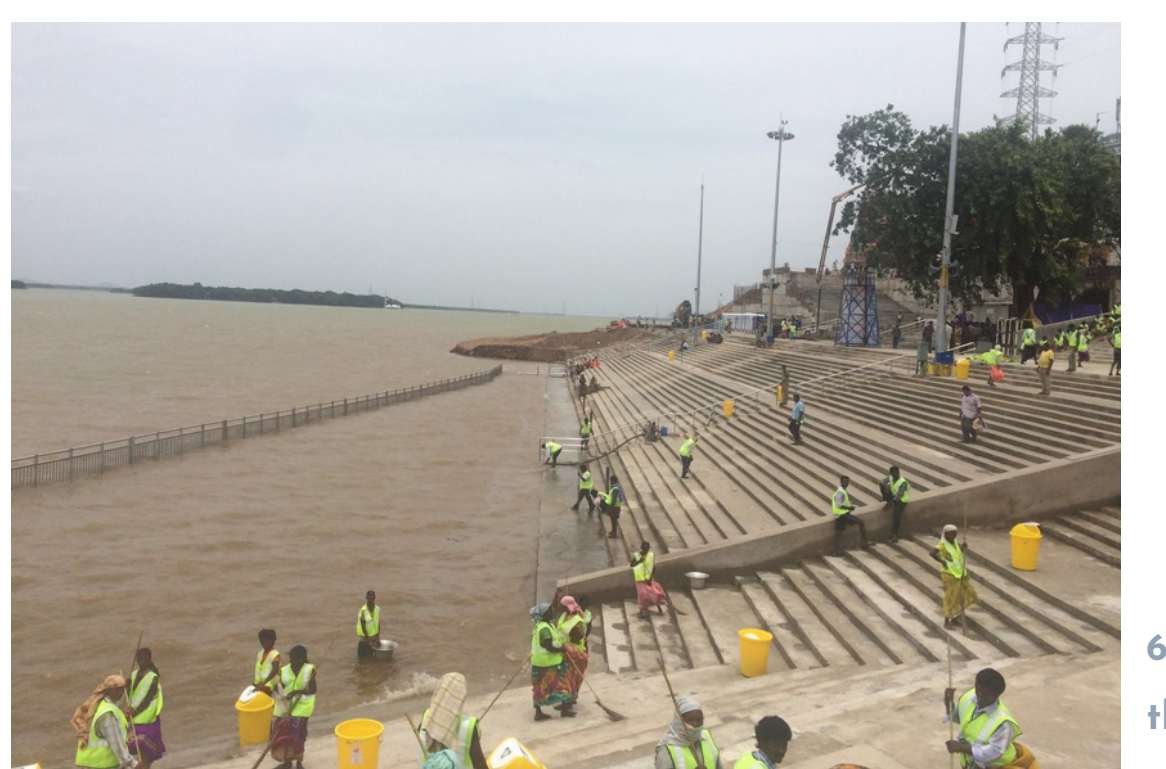

Cleaning of the ghat prior to the event by sanitation workers.

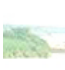
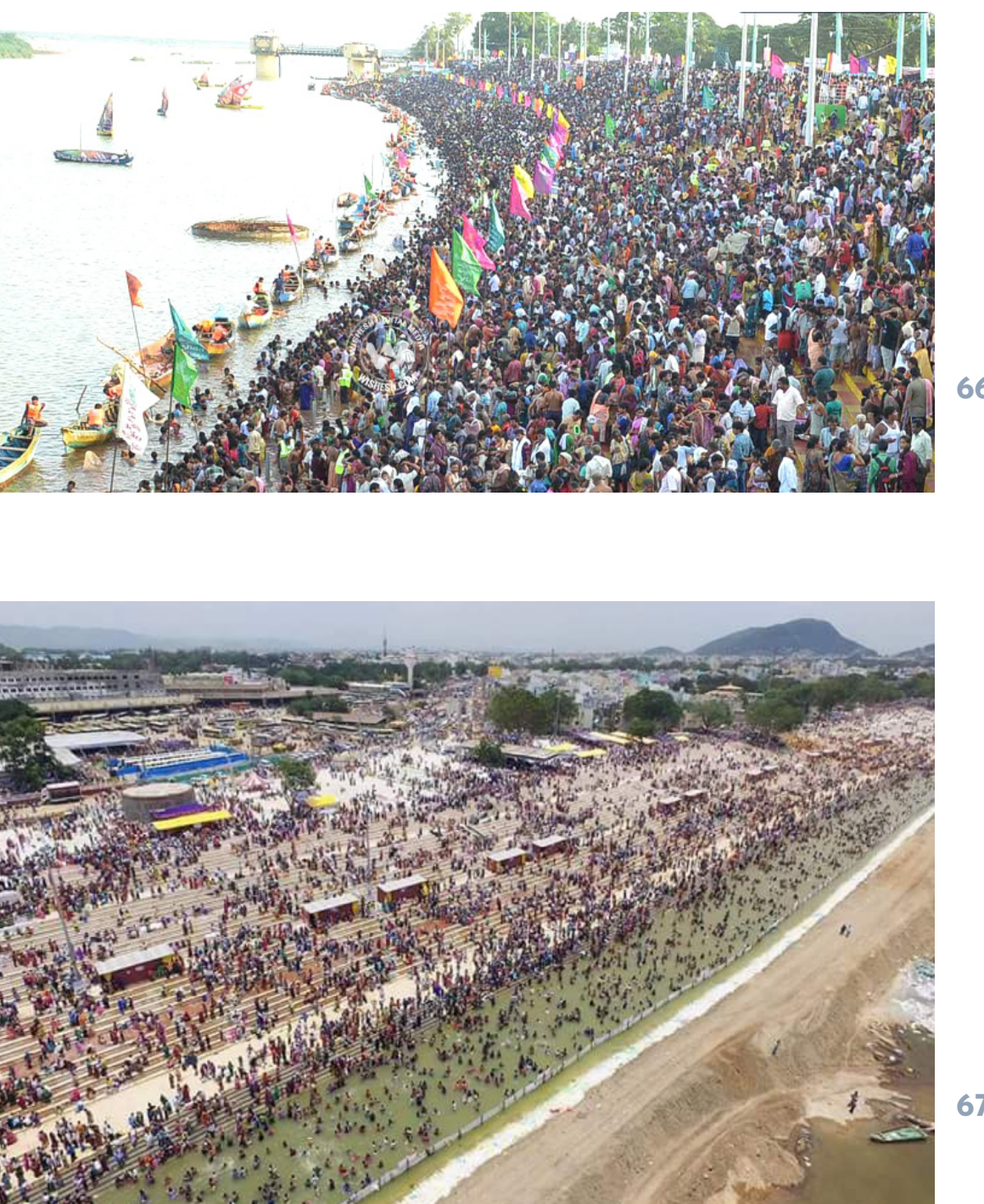

Krishna Pushkaraalu 2015

66 - Krishna Pushkaraalu 2015.

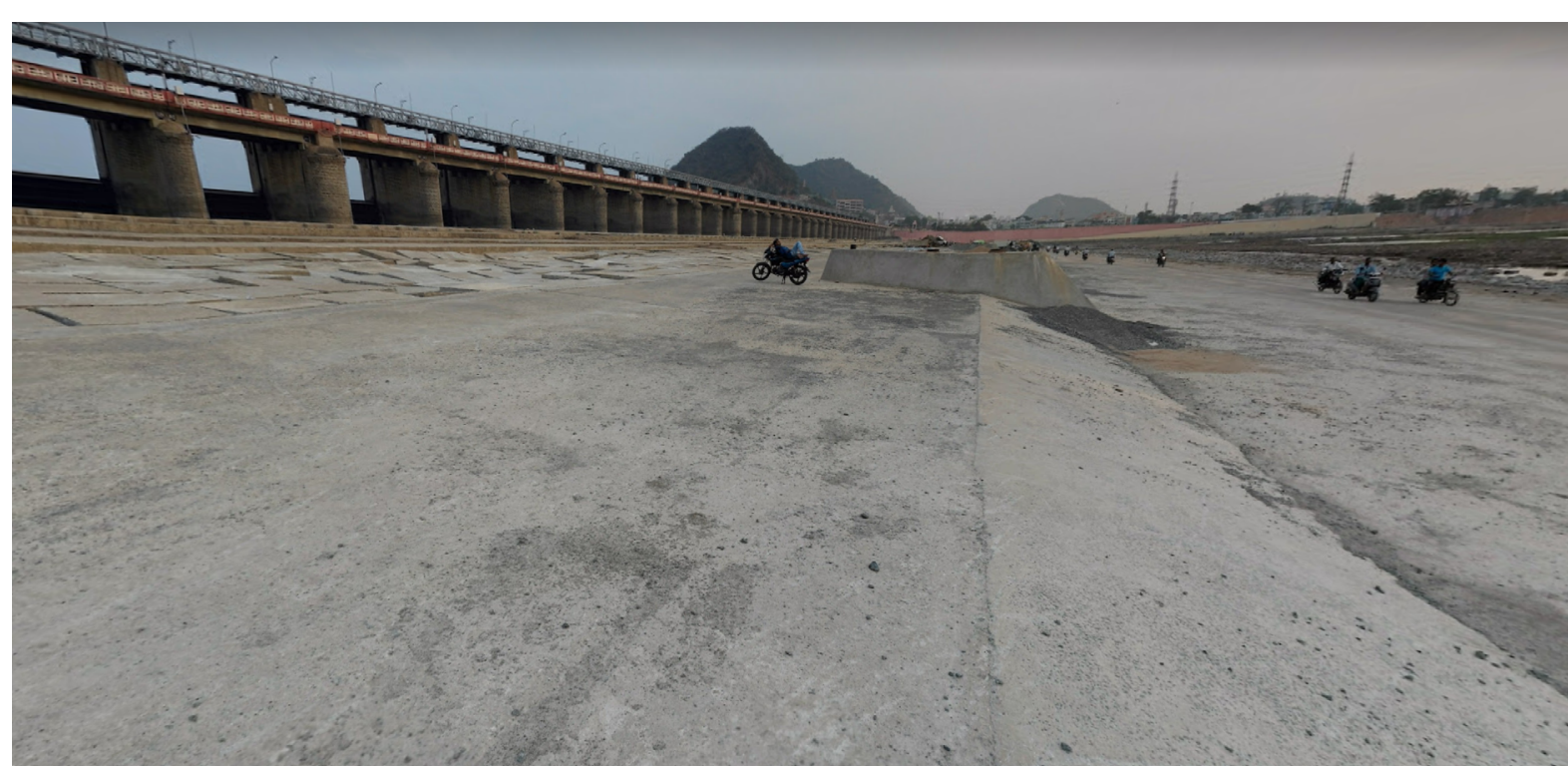

Prakasam Barrage, when dam gates are closed is used as an official passage across the river.

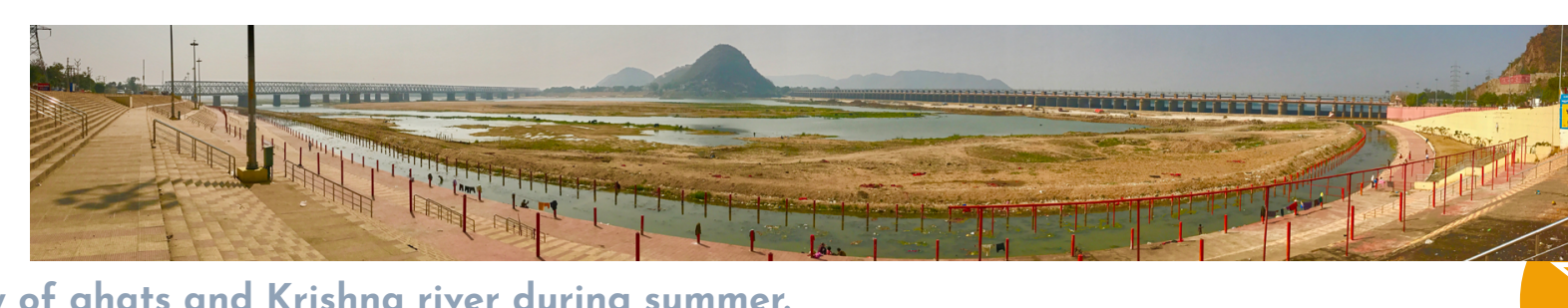

Ghat, a term used in the Indian subcontinent, depending on the context could either refer to a range of stepped-hill such as Eastern Ghats and Western Ghats; or the series of steps leading down to a body of water or wharf, such bathing or cremation place along the banks of a river or pond. 


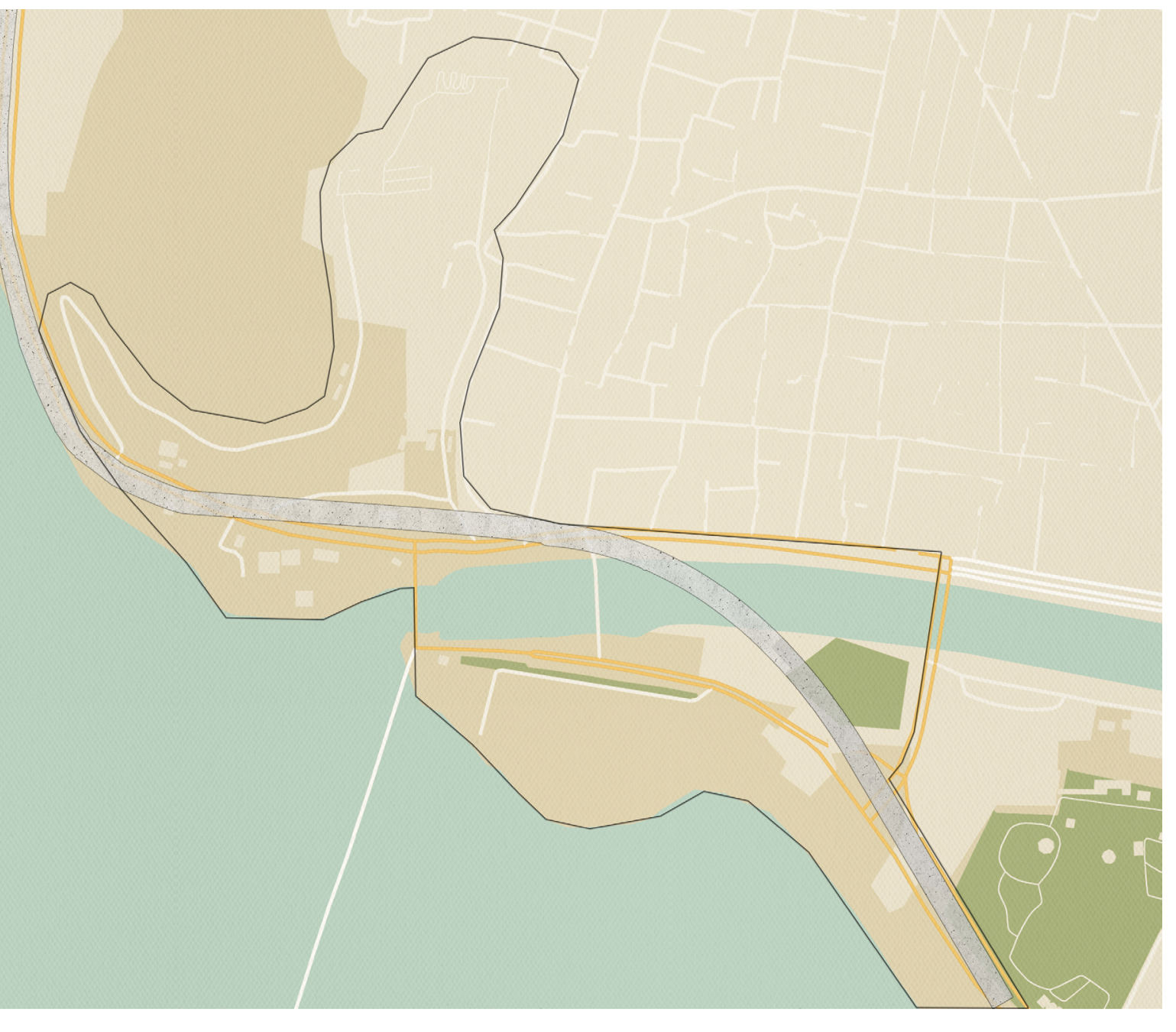

Site Boundary

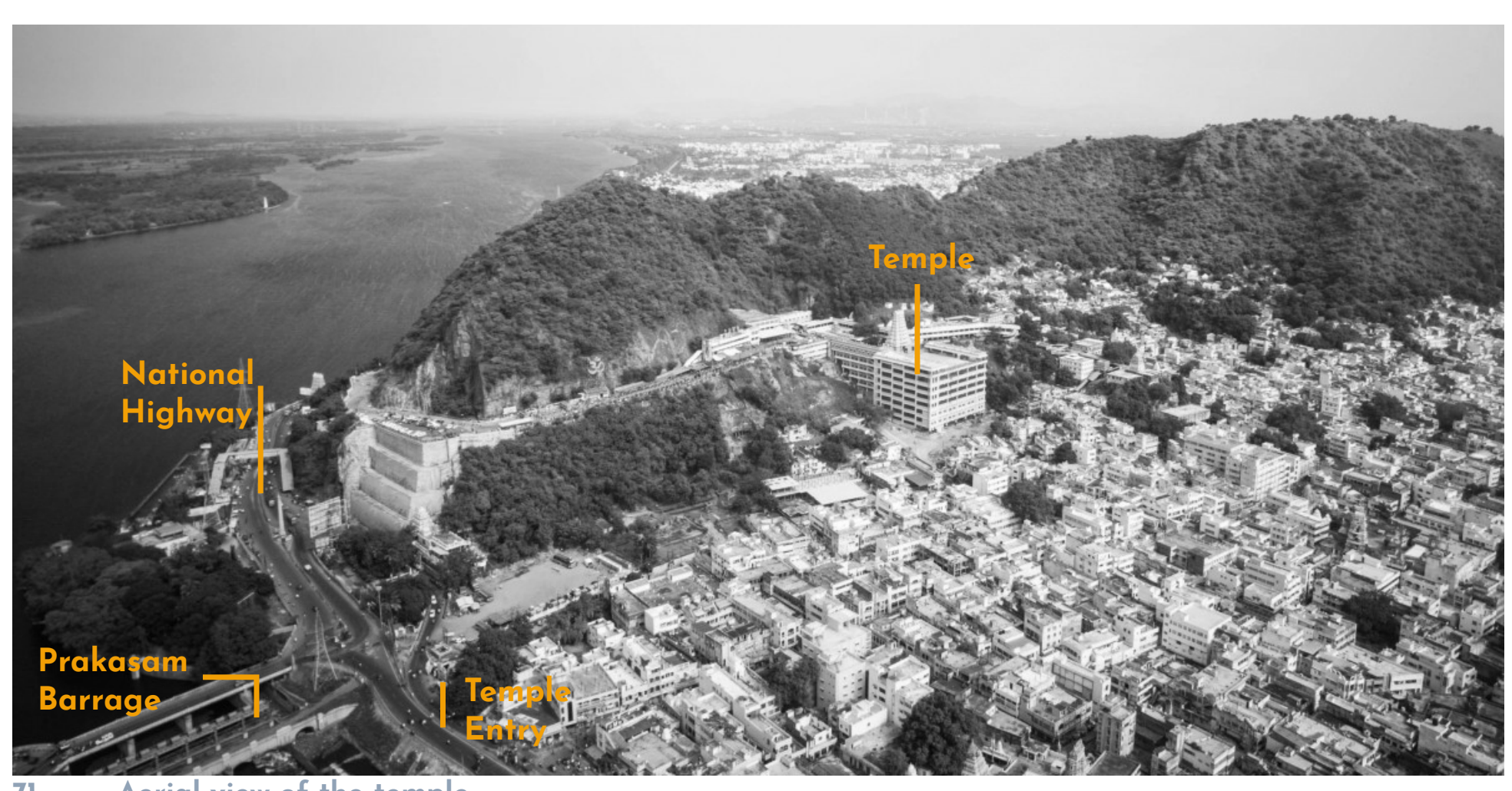

Durga temple is one of the famous landmarks in the state that holds a spiritual significance for Hindus. Also, 'Prakasam Barrage', the bridge/dam that connects the city to the other side of the river, is an iconic structure that helps in irrigating over 1 million acres of land and has an emotional connect to many. The site selected branches out from the convergence of a national highway and the bridge, connecting the temple atop the 'Indrakeeladri' hill. 

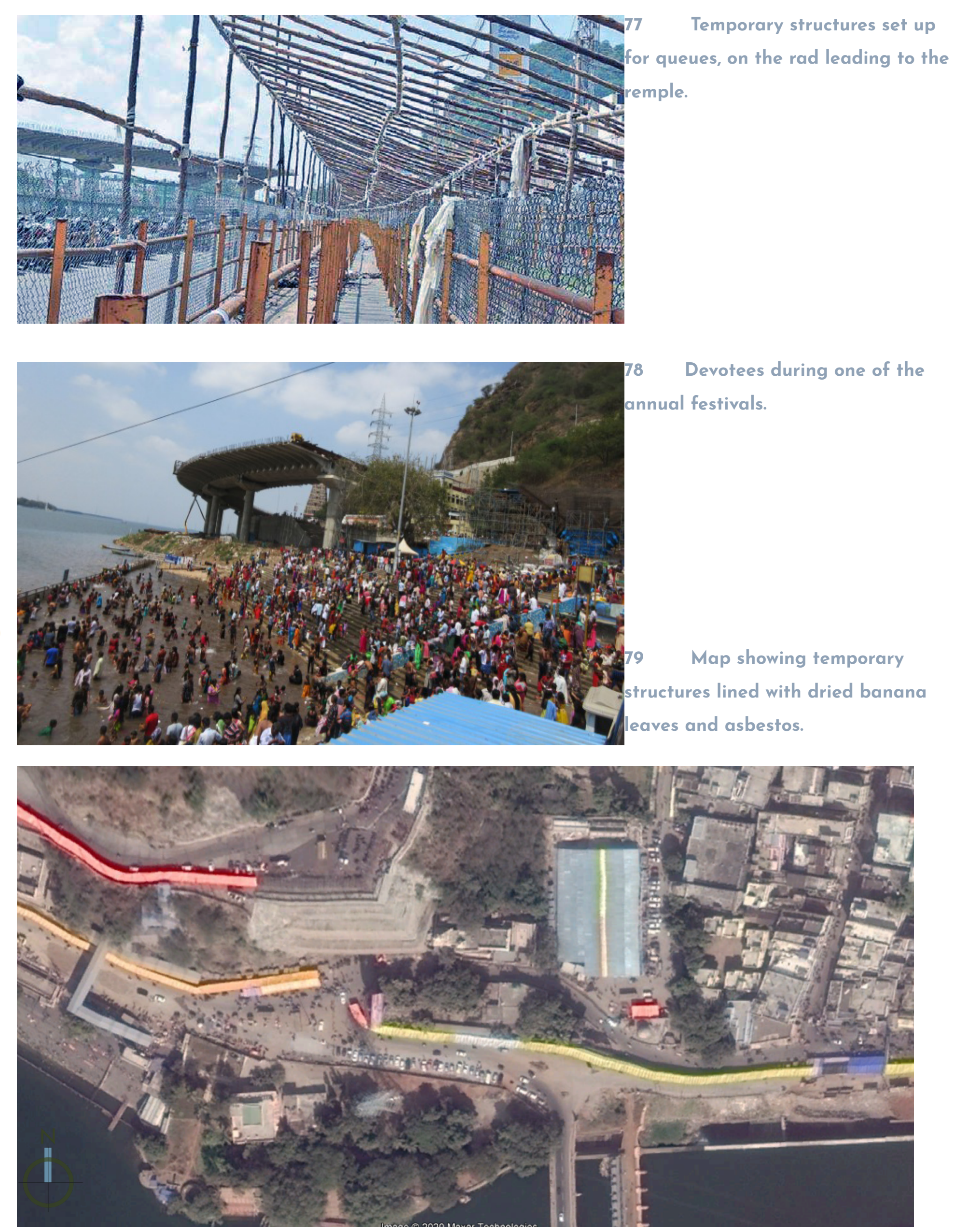

Problems identified

- Corridor connecting the ghat to the temple is irregular and overlapped usage as parking spot.

- Congestion due to traffic and pilgrims using the same road. (National Highway adjacent to the site).

- Pressure on the bank of the river from heavy flow of water during monsoon and pilgrims visiting for holy events.

- Parking, ticket counters and other essential uses have undefined areas.

\section{Probable solutions}

- Corridor connecting ghats to the temple with defined boundaries for activities.

- Providing a permanent parking, ticket issuing and other required administrational space.

- Dedicated space for devotees offering prayers at ghats.

- Green space for leisure activities of devotees.

- Design that allows devotees to have a safe and secure visit from the ghats to temple. 


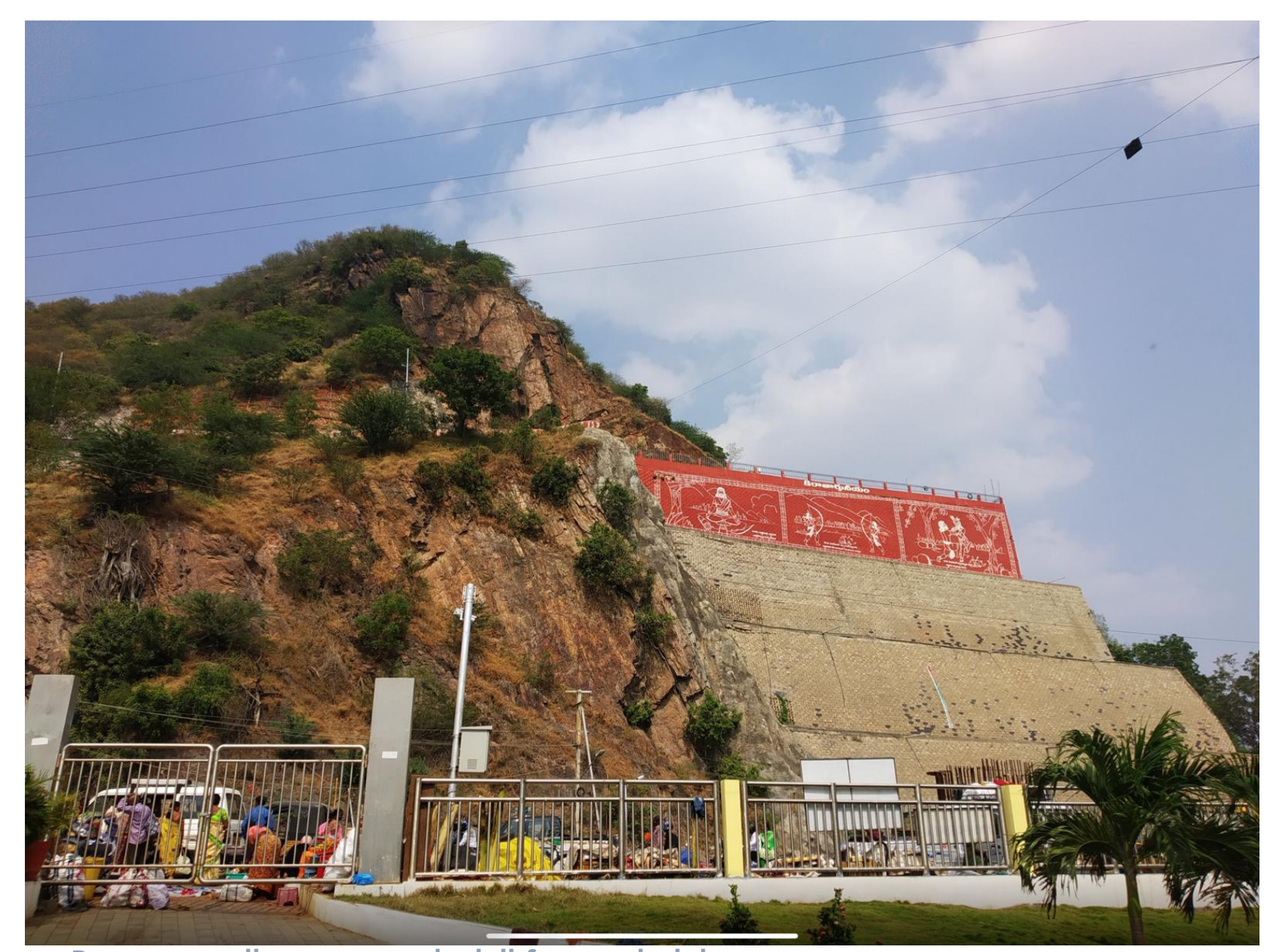

80

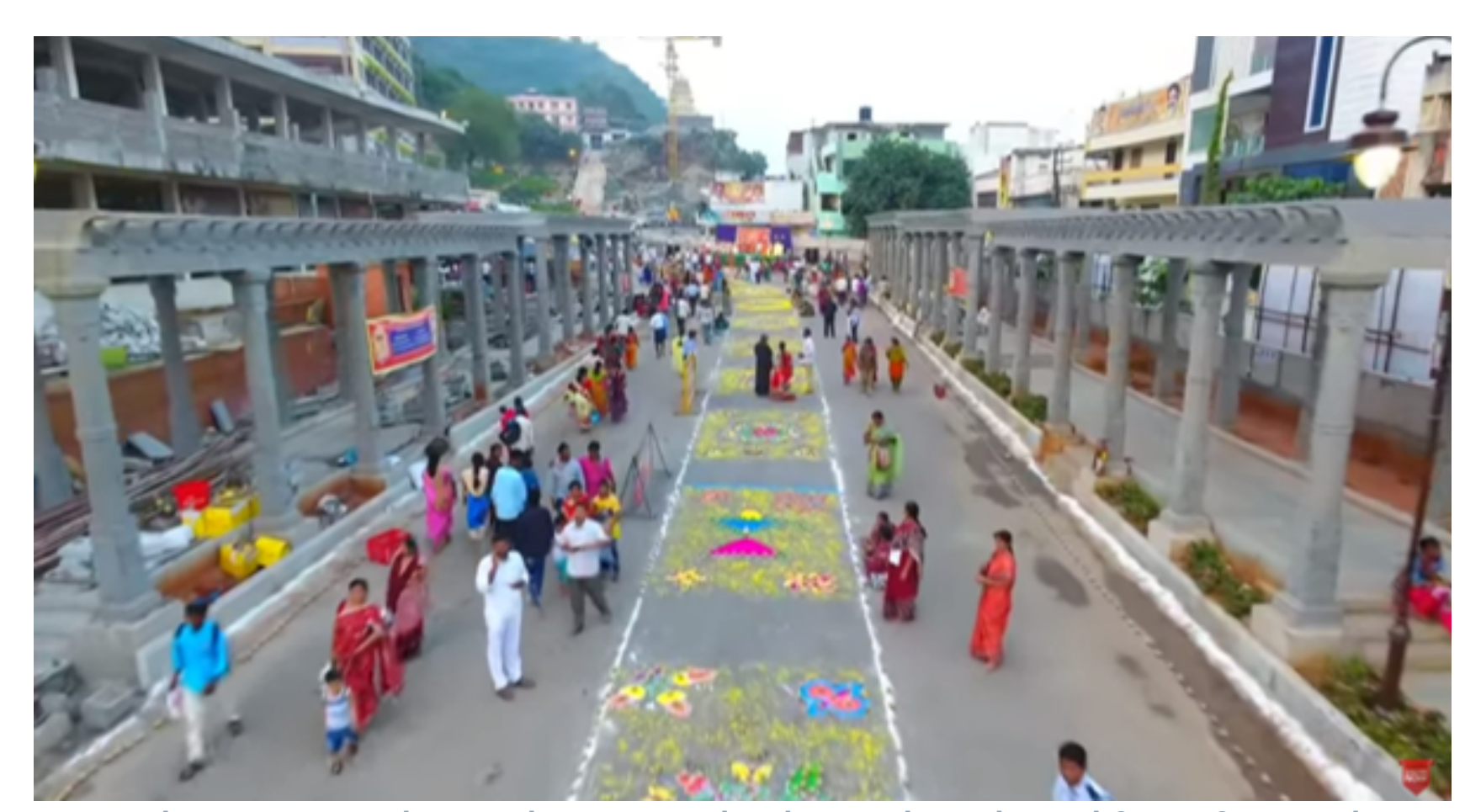

81

from rice flour and artificial colors powder.
STRENGTHS

1. Connectivity

2. Preferred Public Place for gatherings.

3. With proper design techniques, there can be a growth in economy. (religious tourism).

4. Scenic views of the river and bridge.

\section{WEAKNESS}

1. Height limit for buildings around temple at $12 \mathrm{~m}$.

2. Traffic

3. Unavailability of new space for parking.

4. Residential Neighborhood

\section{OPPORTUNITIES}

1. Design of new park.

2. Canal front development.

3. Riverfront development

4. Develop into center for religious tourism.

\section{THREATS}

1. Flash Floods

2. Rock slide on the Hill.

3. Traffic.

4. Stampede during festivals.

5. Speed of the river during monsoon. 


\section{---- Devotees \\ ---- Street Vendors \\ ---- Inter-city buses \\ ---- Tourists}

---- Office route

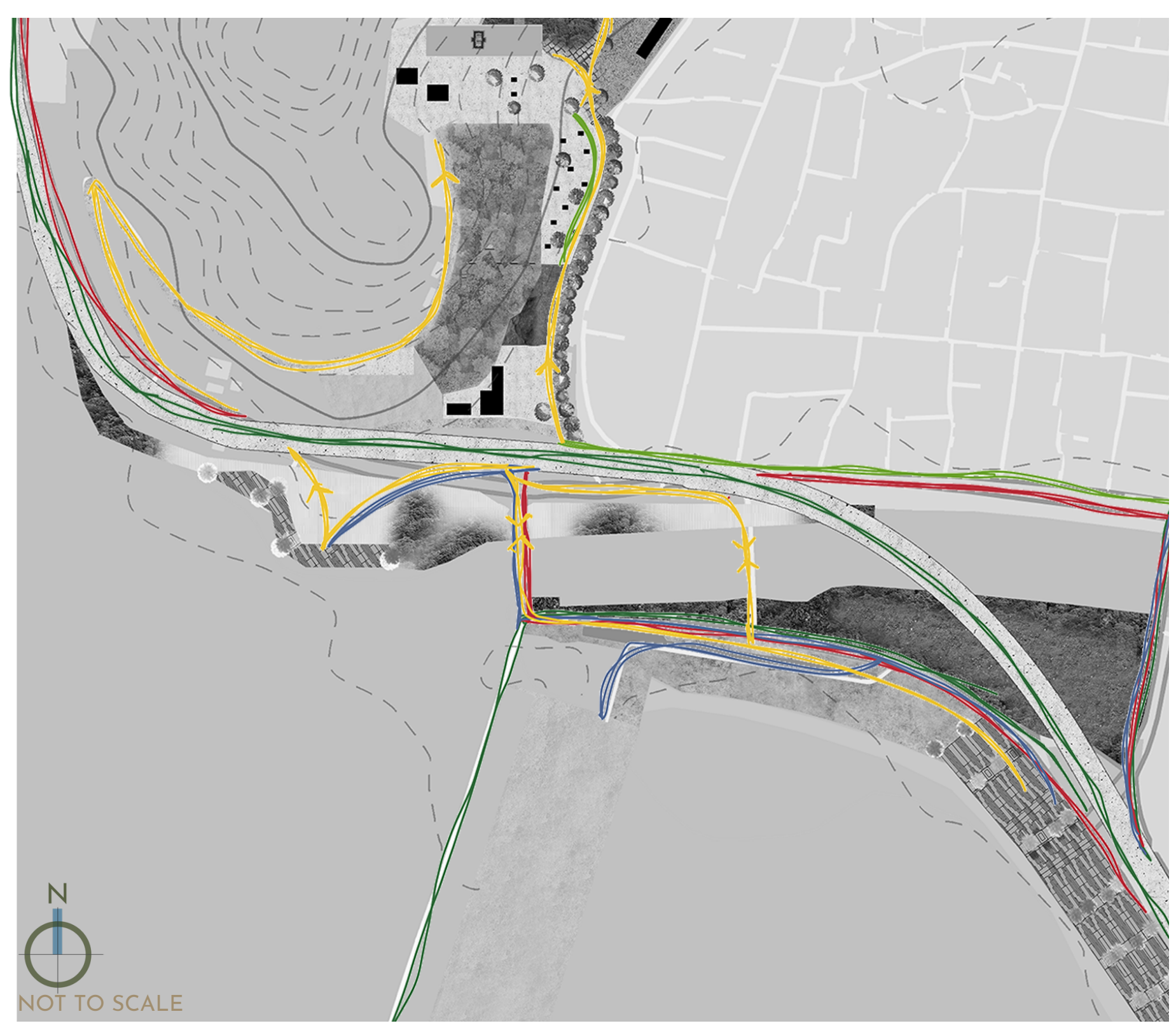

Typical path a devotee takes to reach the temple. 1. A holy dip in the river.

2. street vendors on the way to the temple.

3. Entering into the temple complex.

Devotee route

83

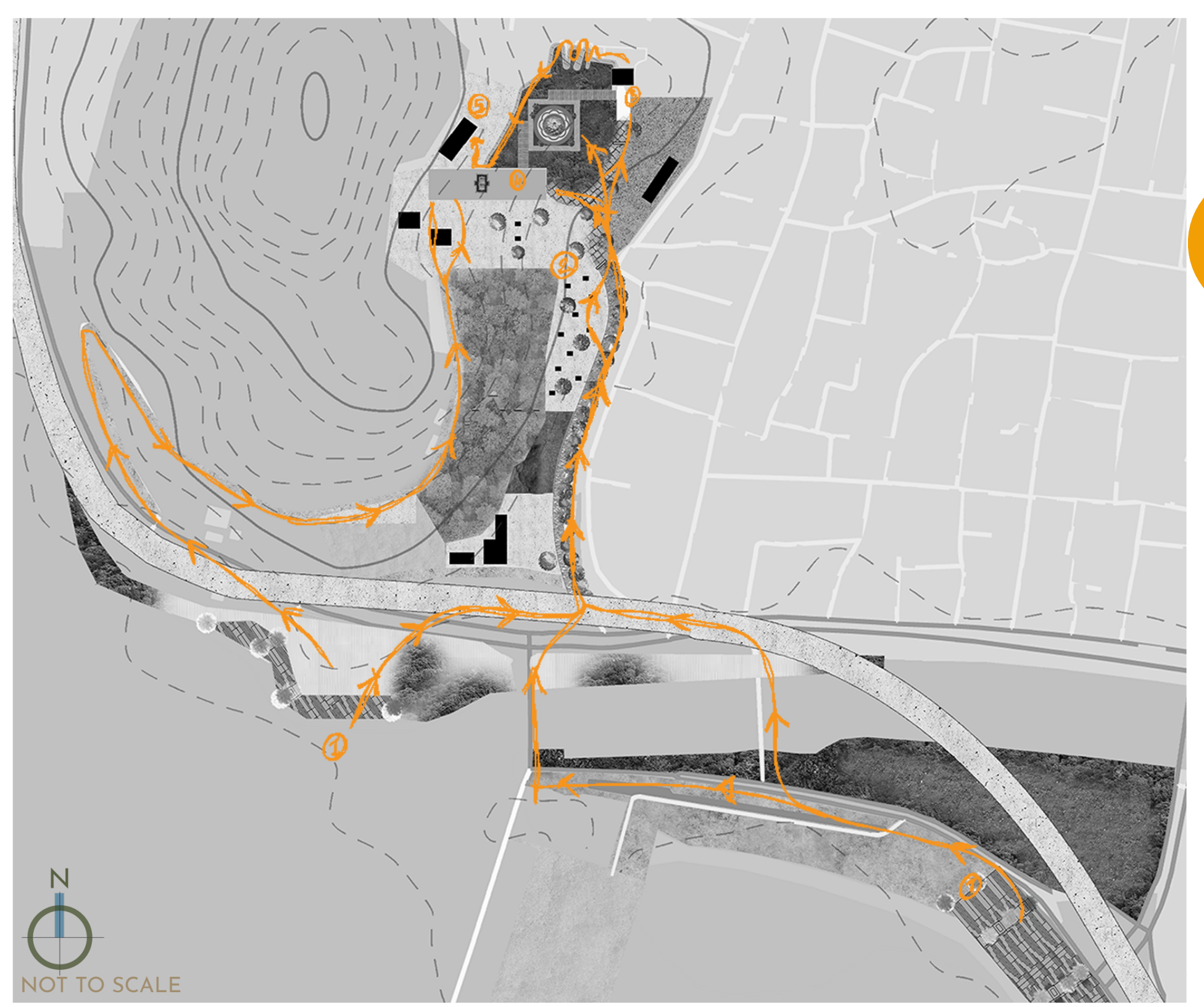




\section{ÁCF|V|TY MAPP|NGE}

Concept sketches and ideas during intital stage of design development

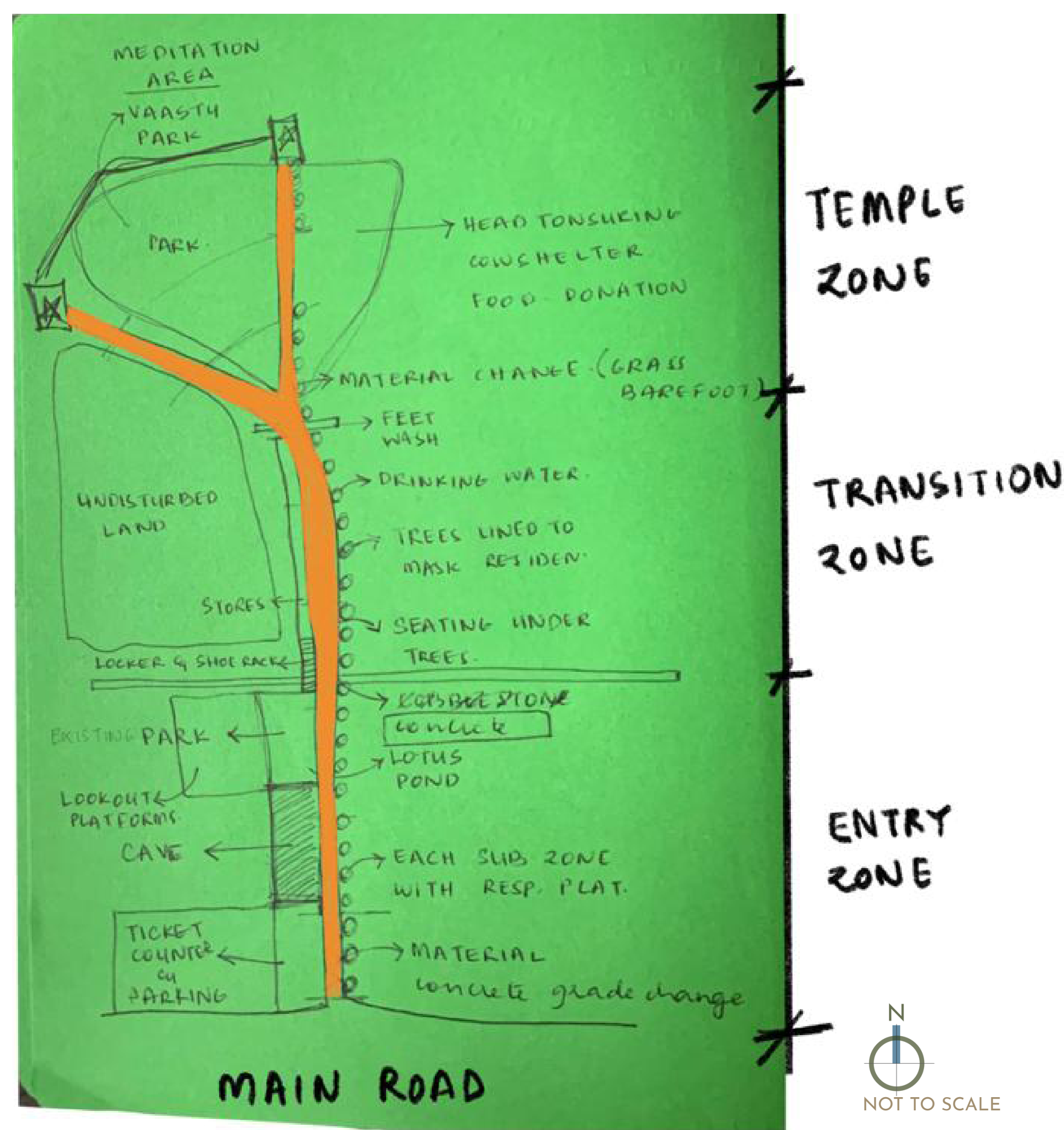

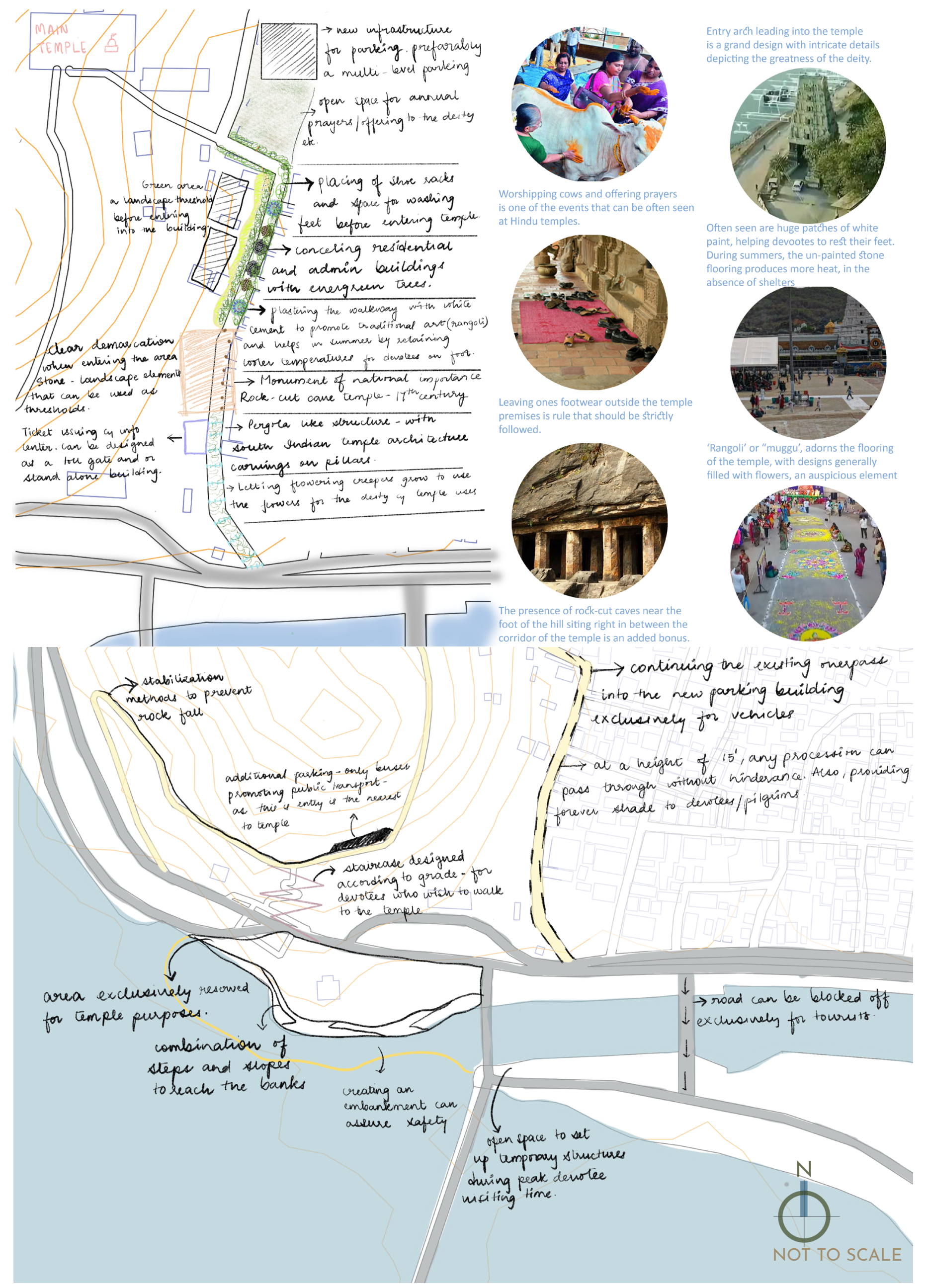



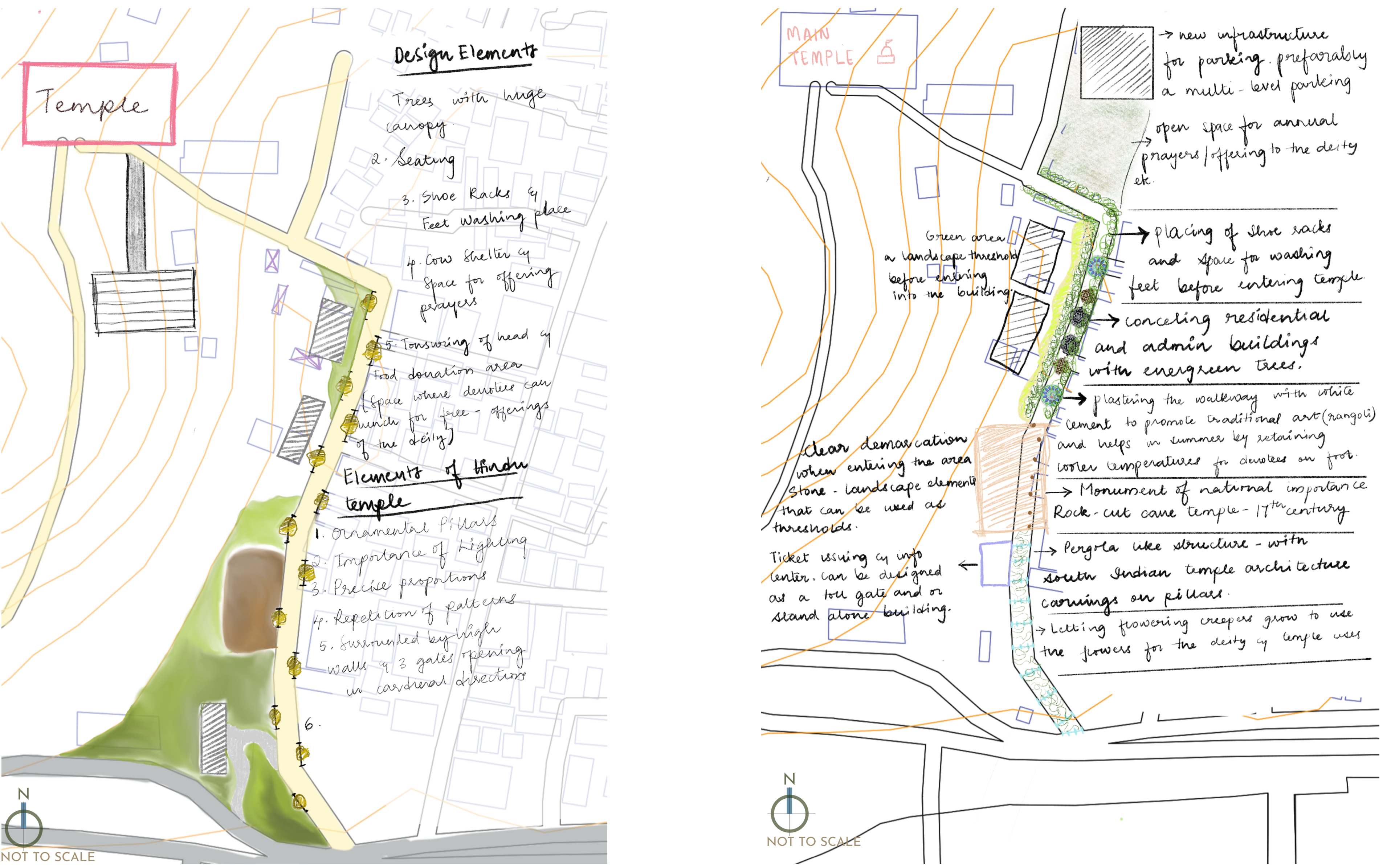

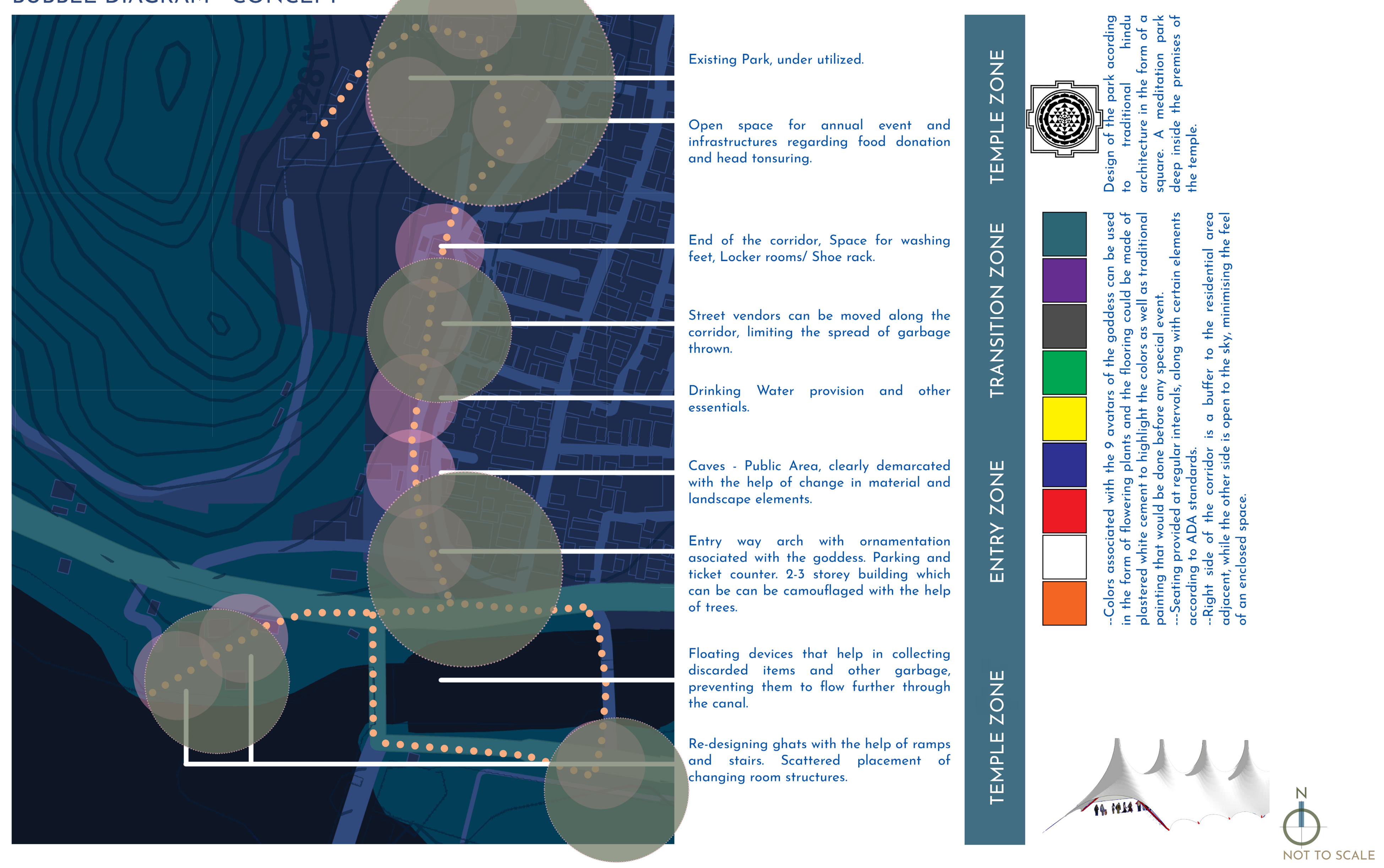


\section{叫罾界}

4

5

$\infty$

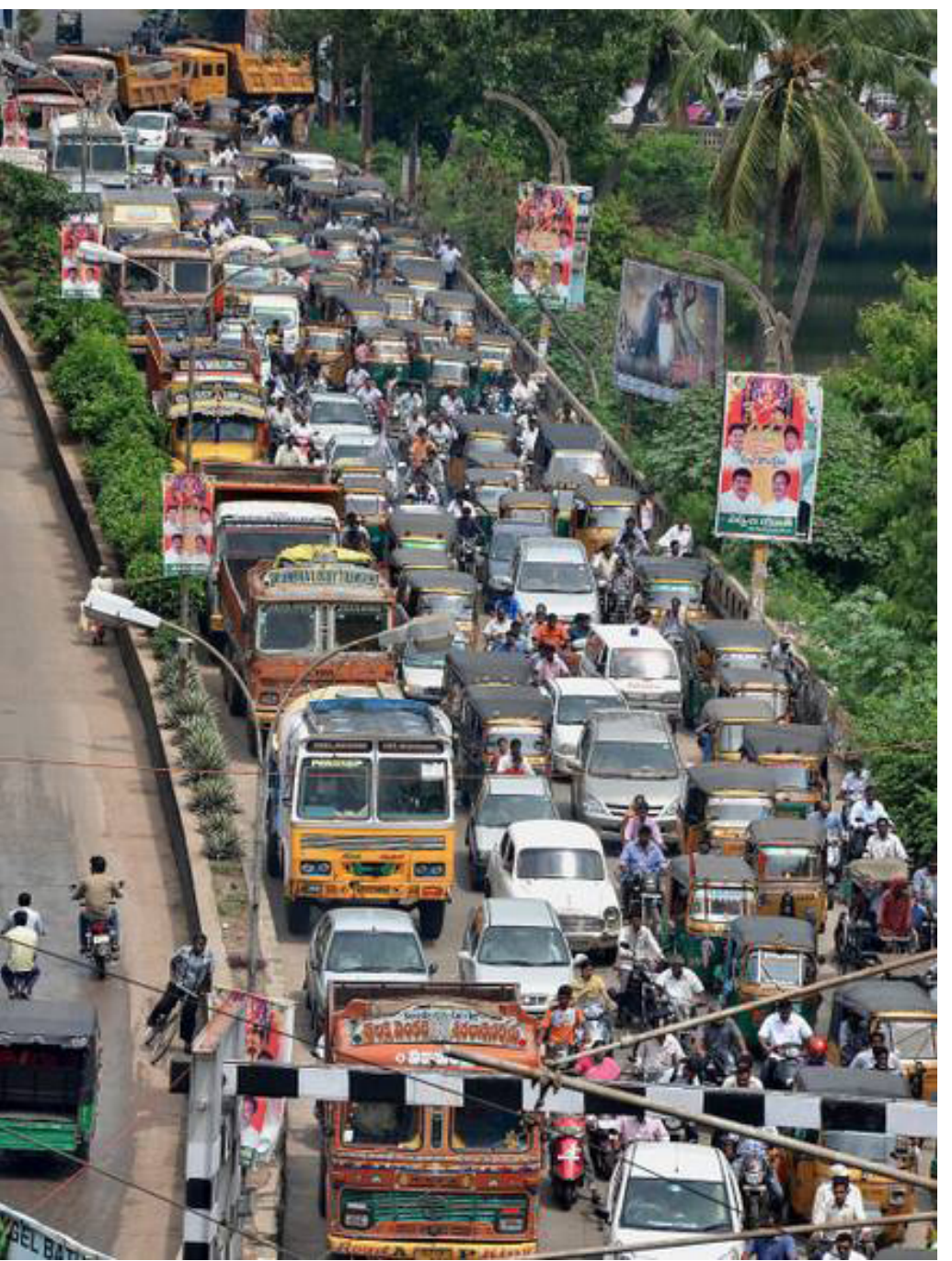

As an individual who grew up learning about the temple and visiting it frequently while maintaining a sacred relation with the nature is something that comes instinctively to me. And while moving away to another country might put a break on my rituals, it goes without saying that it has always been on my mind to improve the conditions in my homeland. With recent changes in the environment both political and nature, I wanted to create a proposal that would look into the problems in detail pertaining to the river and its ecology. But, the presence of temple was an important detail that cannot be overlooked, so, the design of the corridor connecting the ghats to the temple which are overlapped by urban area and the canal became the center of the study.

ÂIM

In response to the lack of basic amenities and disregard of local characteristics, this design is proposed in hopes of getting to educate people about the significance of protecting riverbanks and making it a safe space for multipurpose functions offering prayers and also a public space for casual hangout.

This design thesis is focused on creating a corridor, that blends the urban context, often overlapping into the religious spaces. 

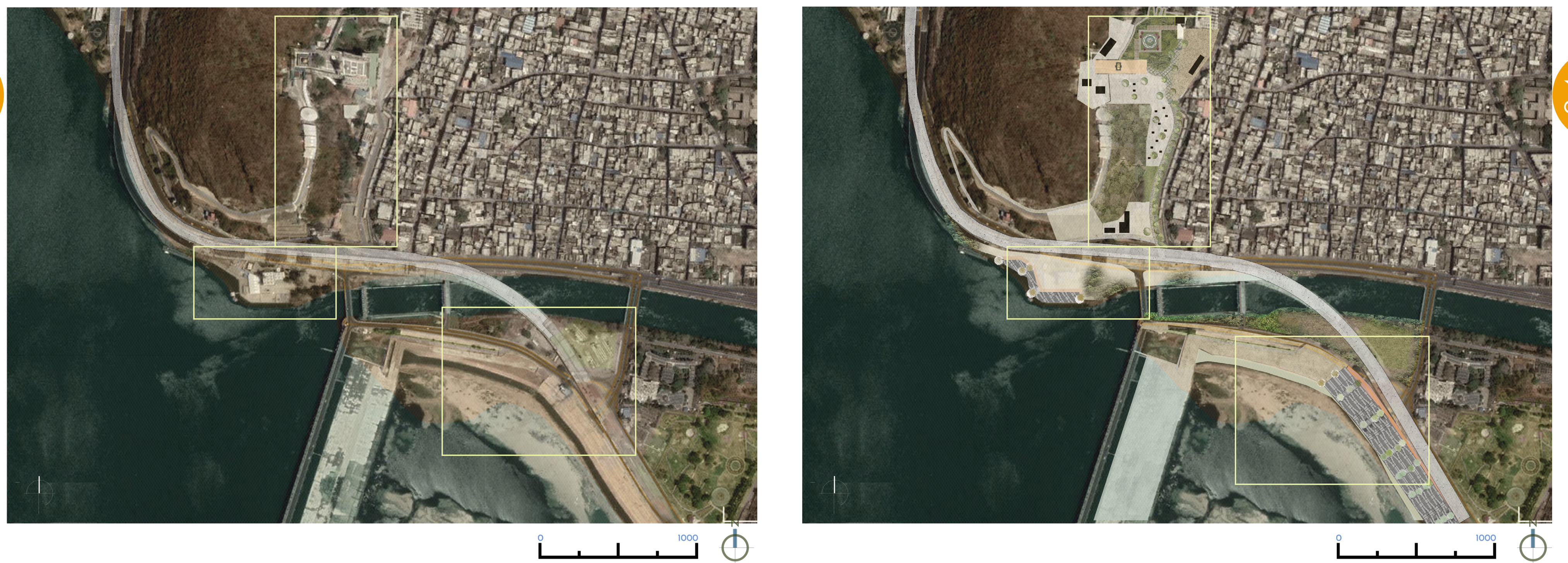


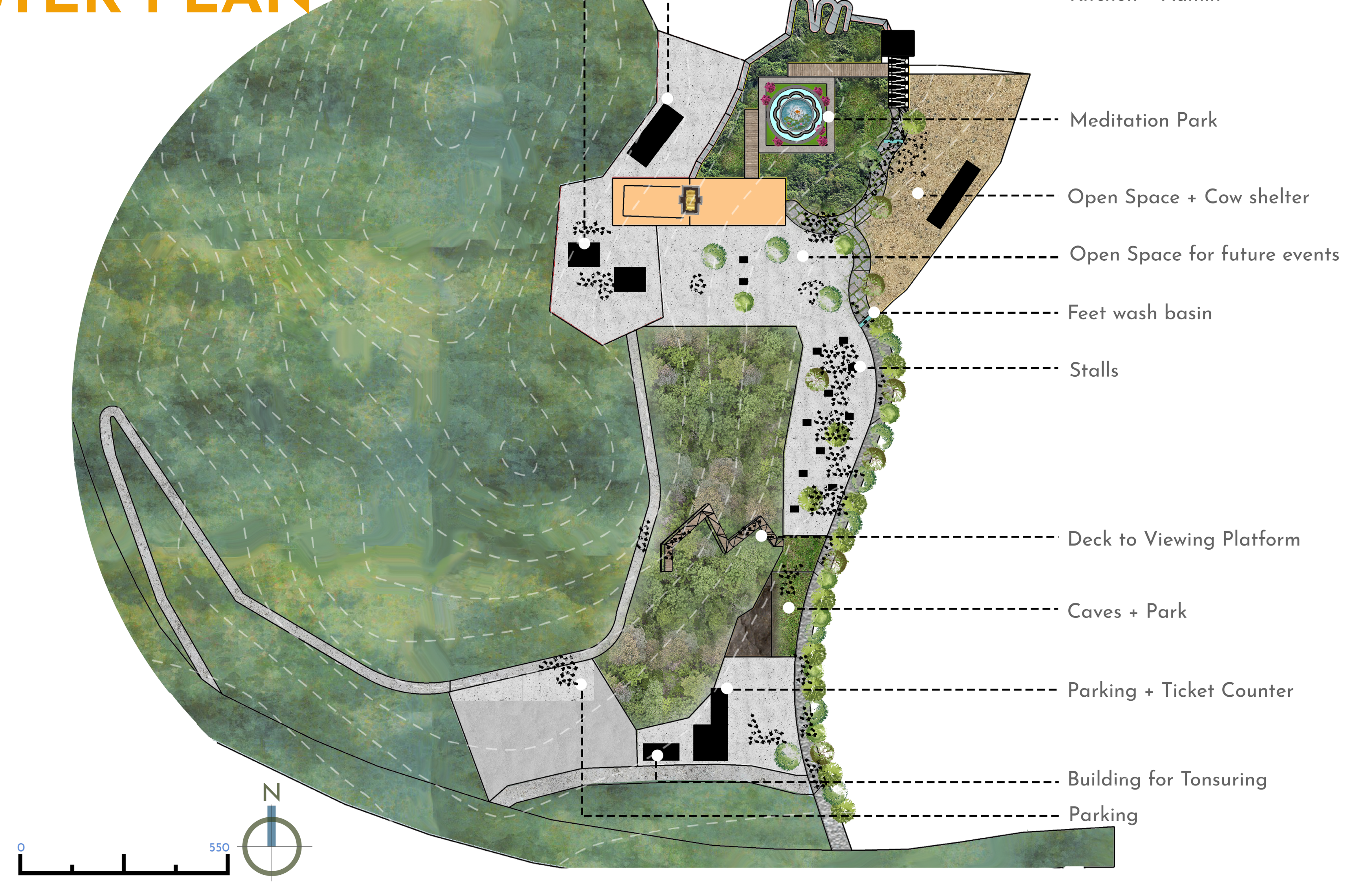




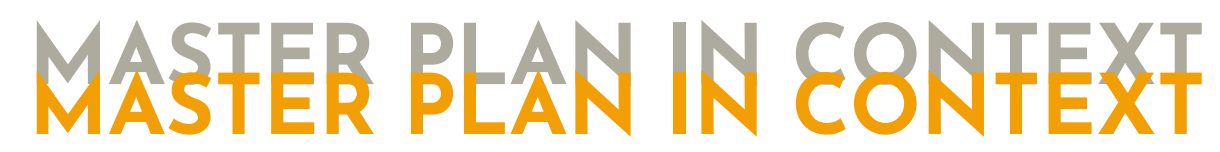

Map showing design proposal in context with river and huge gatherings of devotees during Pushkaraalu. Also, can be seen are boats equipped with safety gear and life guards in case of an emergency.

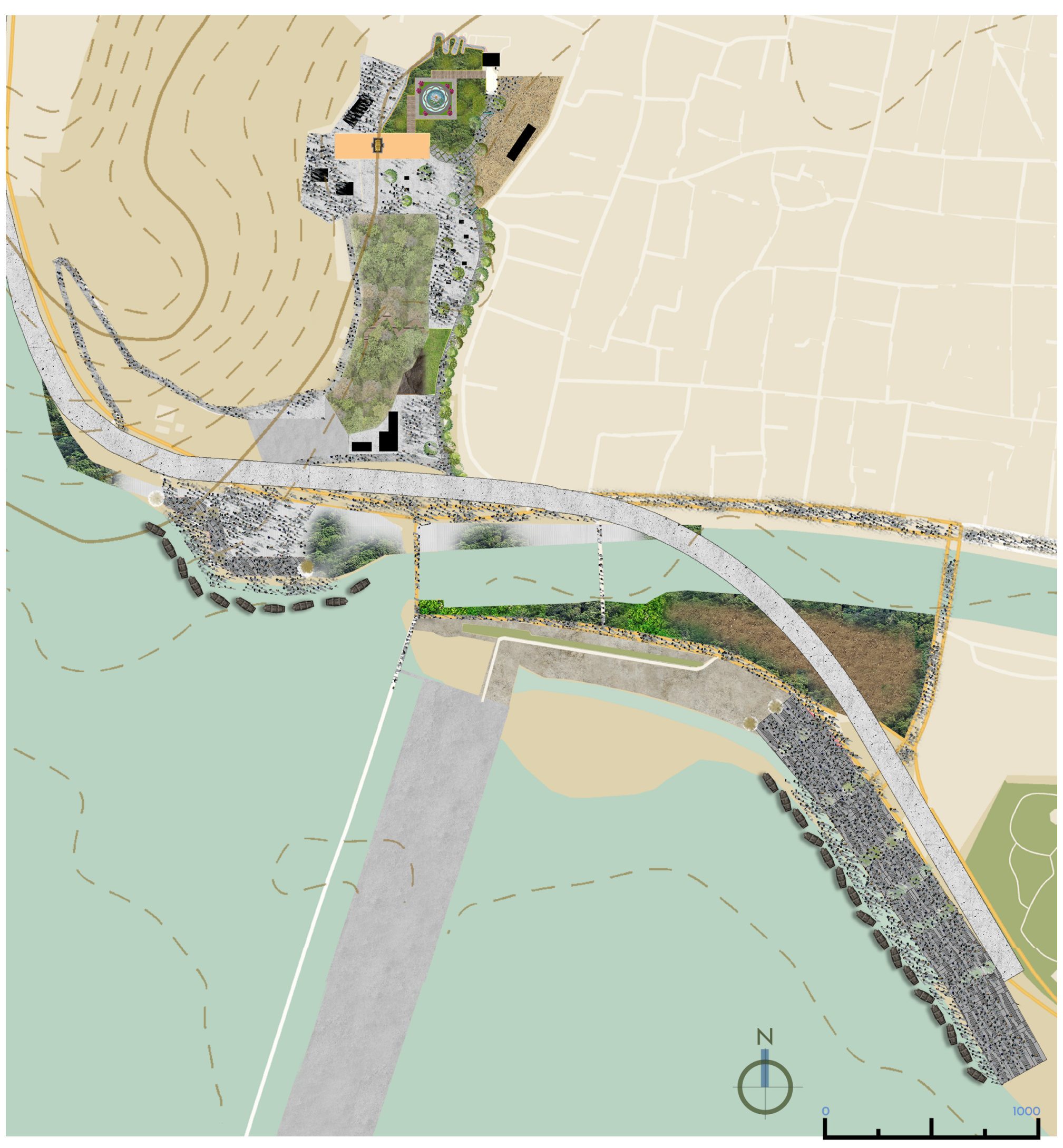

Map showing design proposal in context with river and small gatherings of people during annual events and festivals.

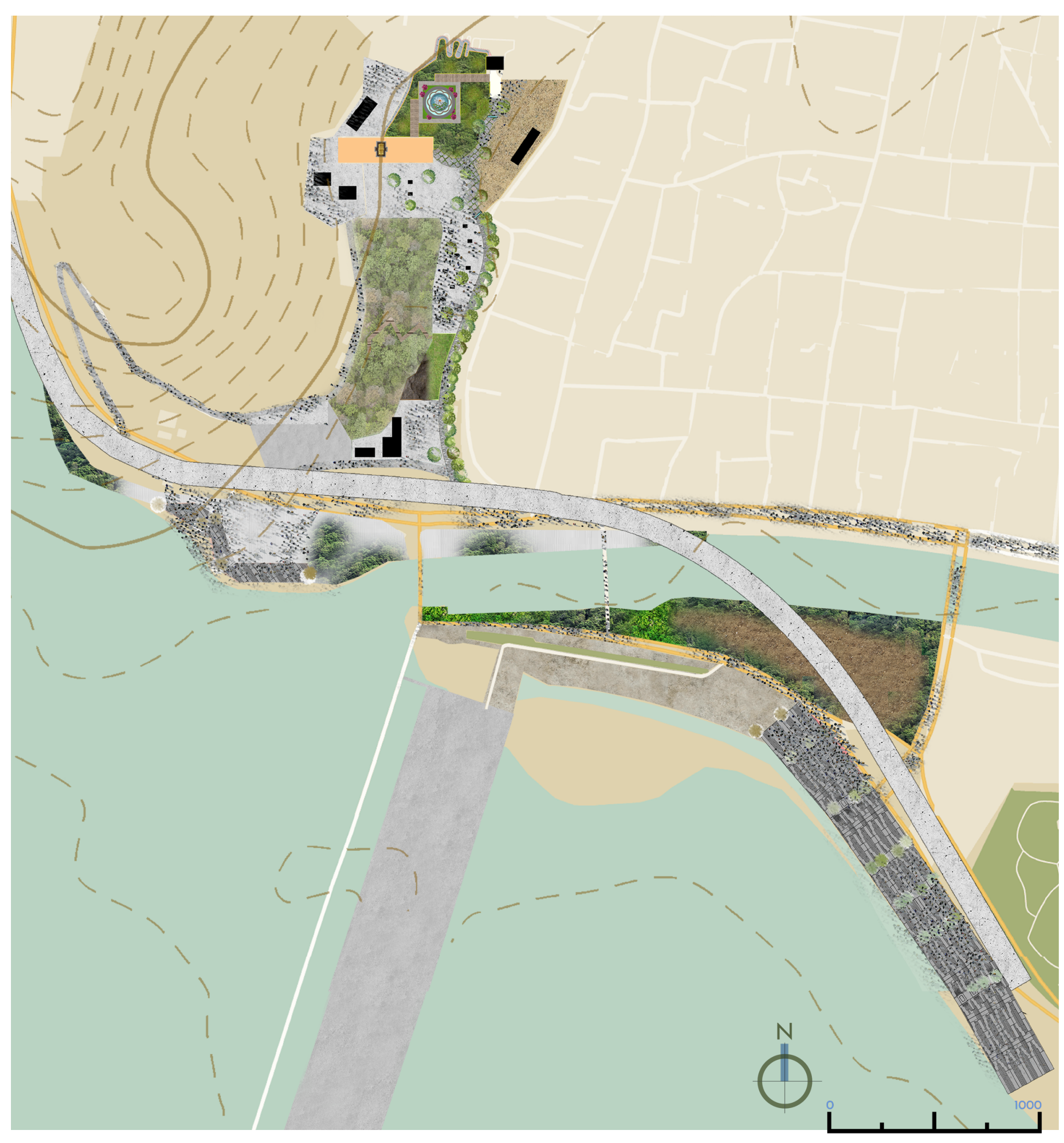




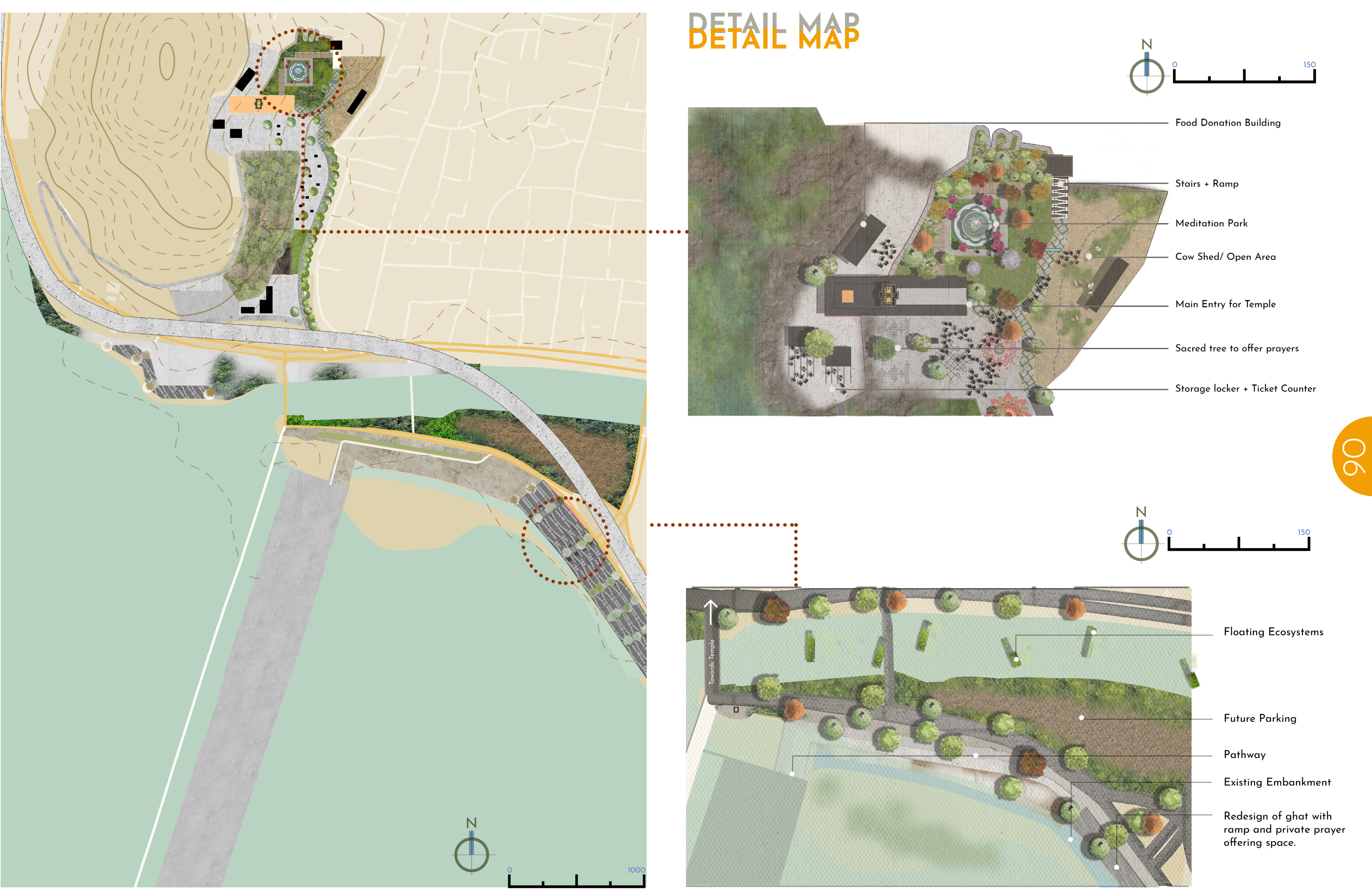




\section{PERSPECTIVES \\ PERSPECTIVES}

This perspective shows the caves and the wooden walkway to the lookout point. Although this part of the corridor, that connects the temple to the ghats, is closed during festivals that witnesses huge gatherings, it is still one of must visit locations in the city, often recommened for tourists.

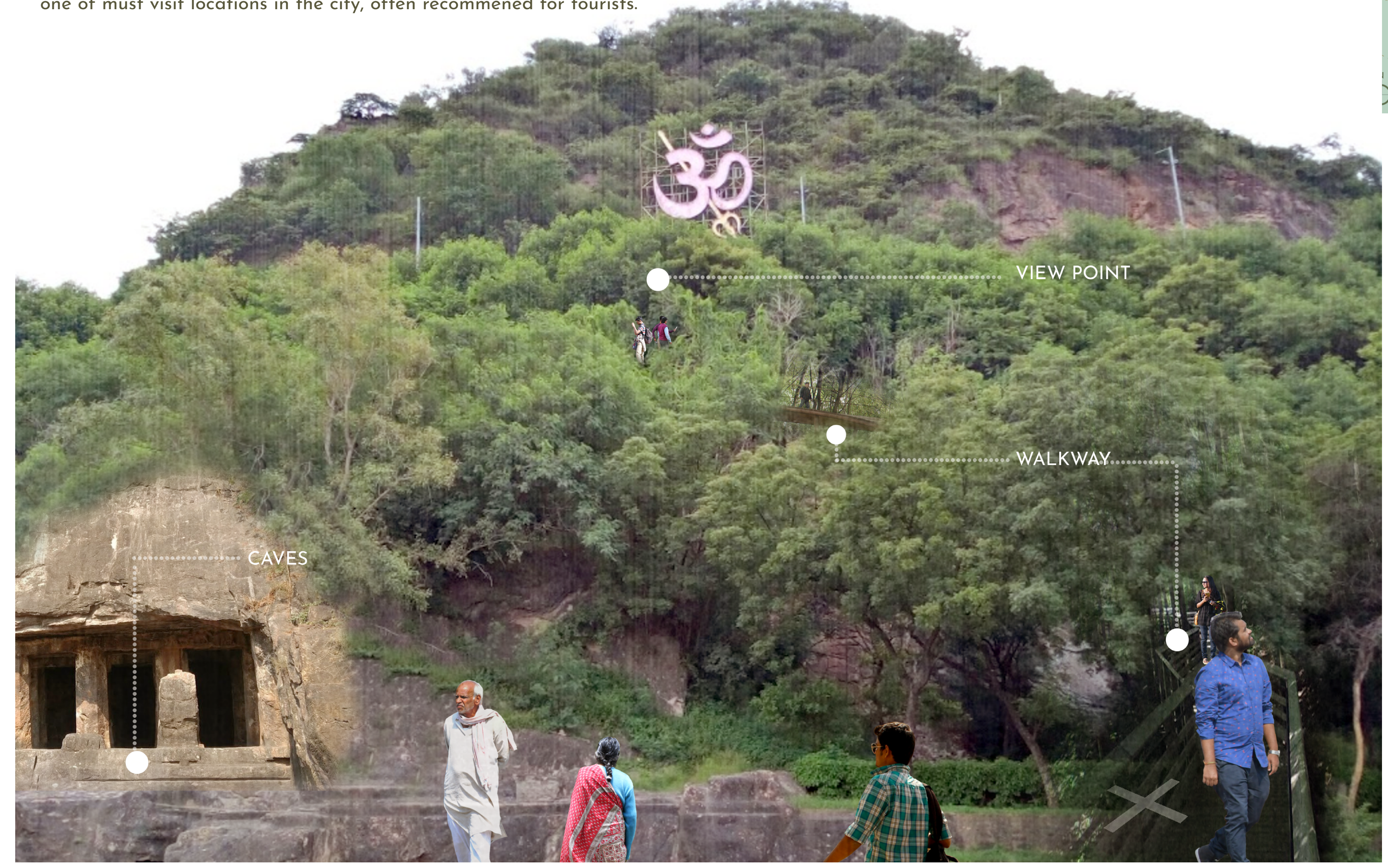


This perspective shows the ghats during one of the annual events, where various activities liike meditating, display of cultural music, social gathring etc, along with mundane tasks like sitting and enjoying the view or photographing the life of the city, takes place.
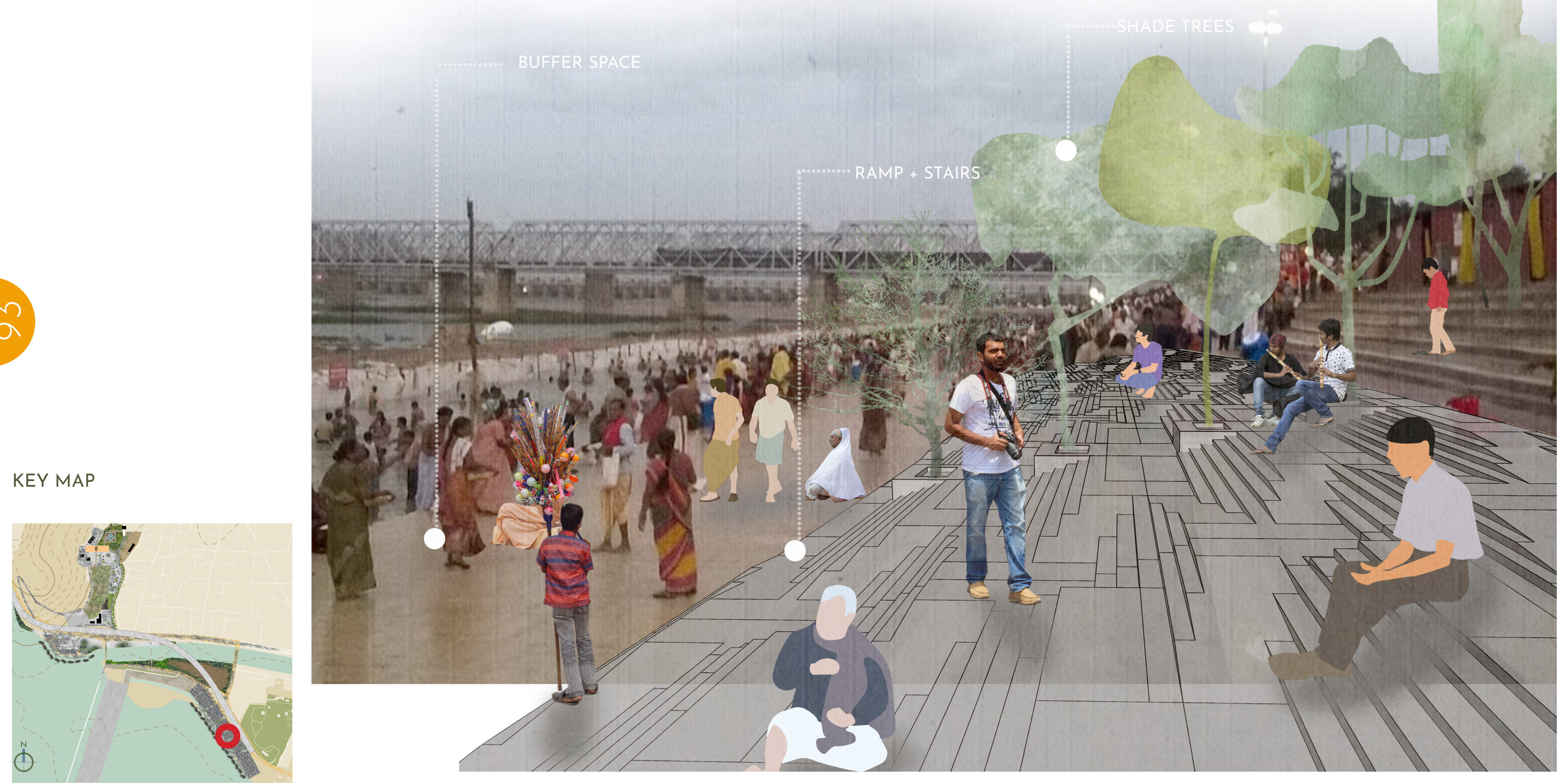
This perspective shows the meditation park with a lotus pond and other native plants and trees, which provide with fruits and flowers which are then used as an offering to the Goddess. Tucked into the corner of the temple and supported by the hill in the background, various pockets are created with the trees where one can meditate in silence, even with huge crowd gatherings.
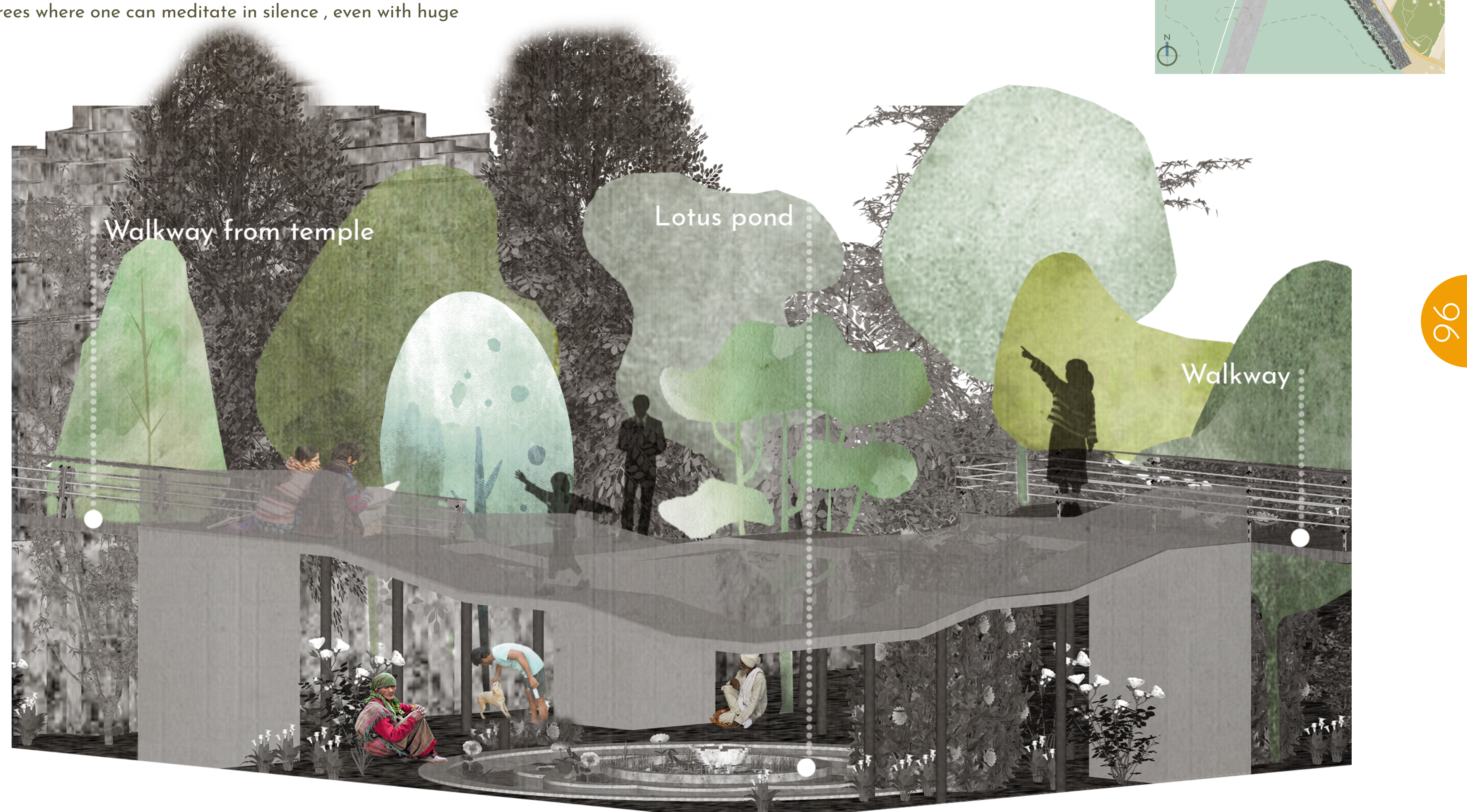


\section{乌EE干|8N AA}

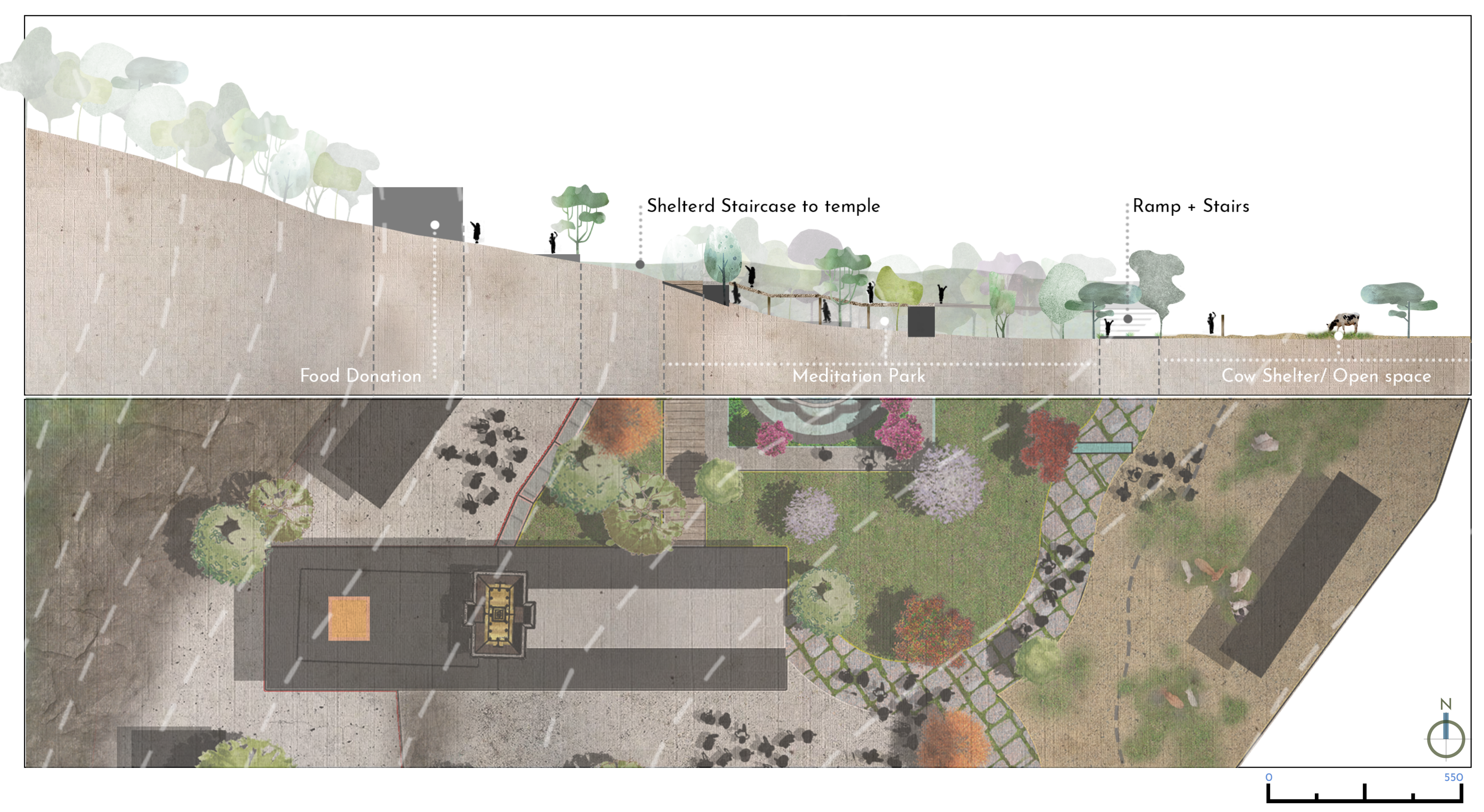




\section{SEEEF|8N 䠉'}
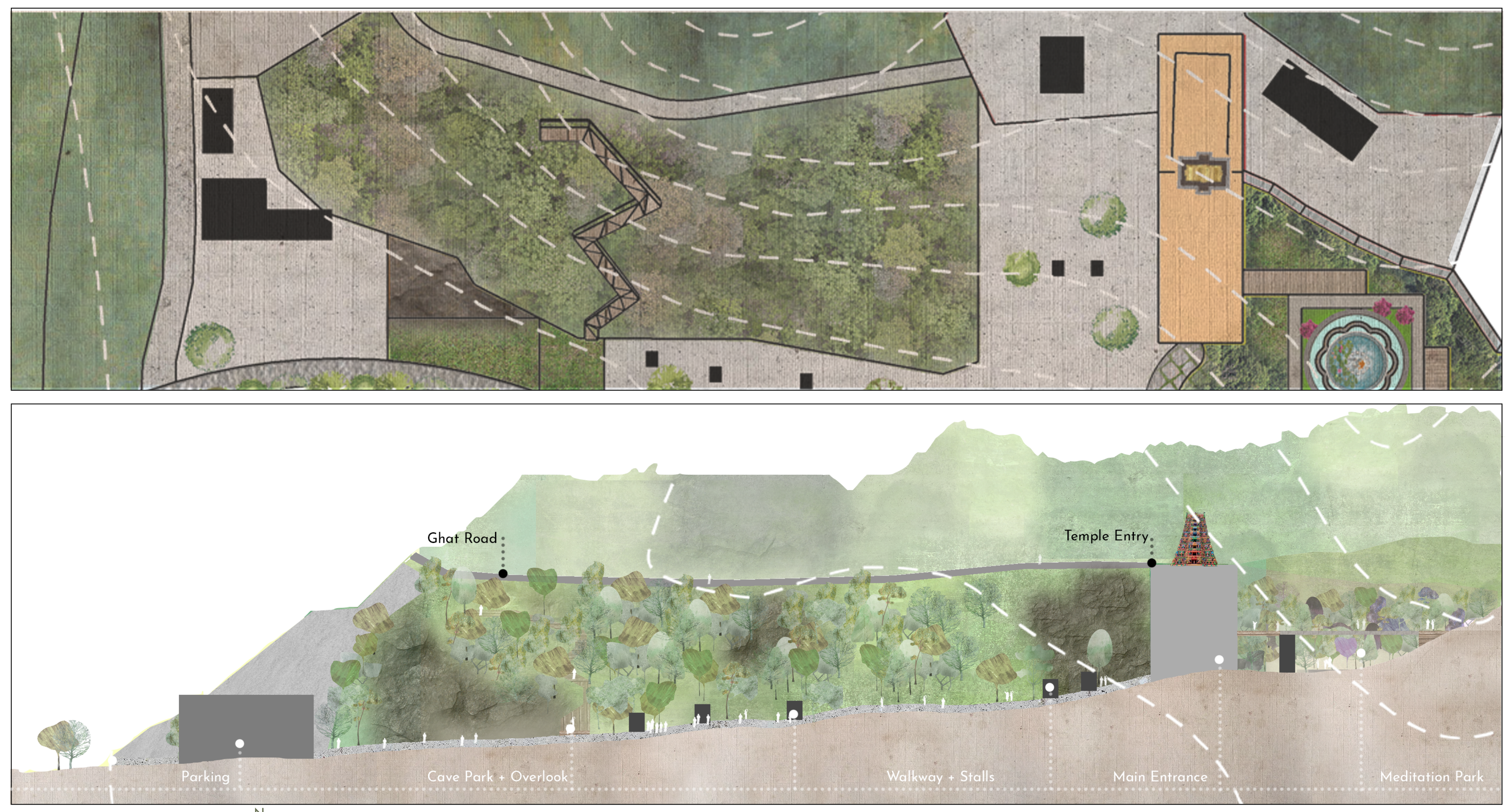

$\stackrel{0}{1}+\mathbf{L}^{5}$ 


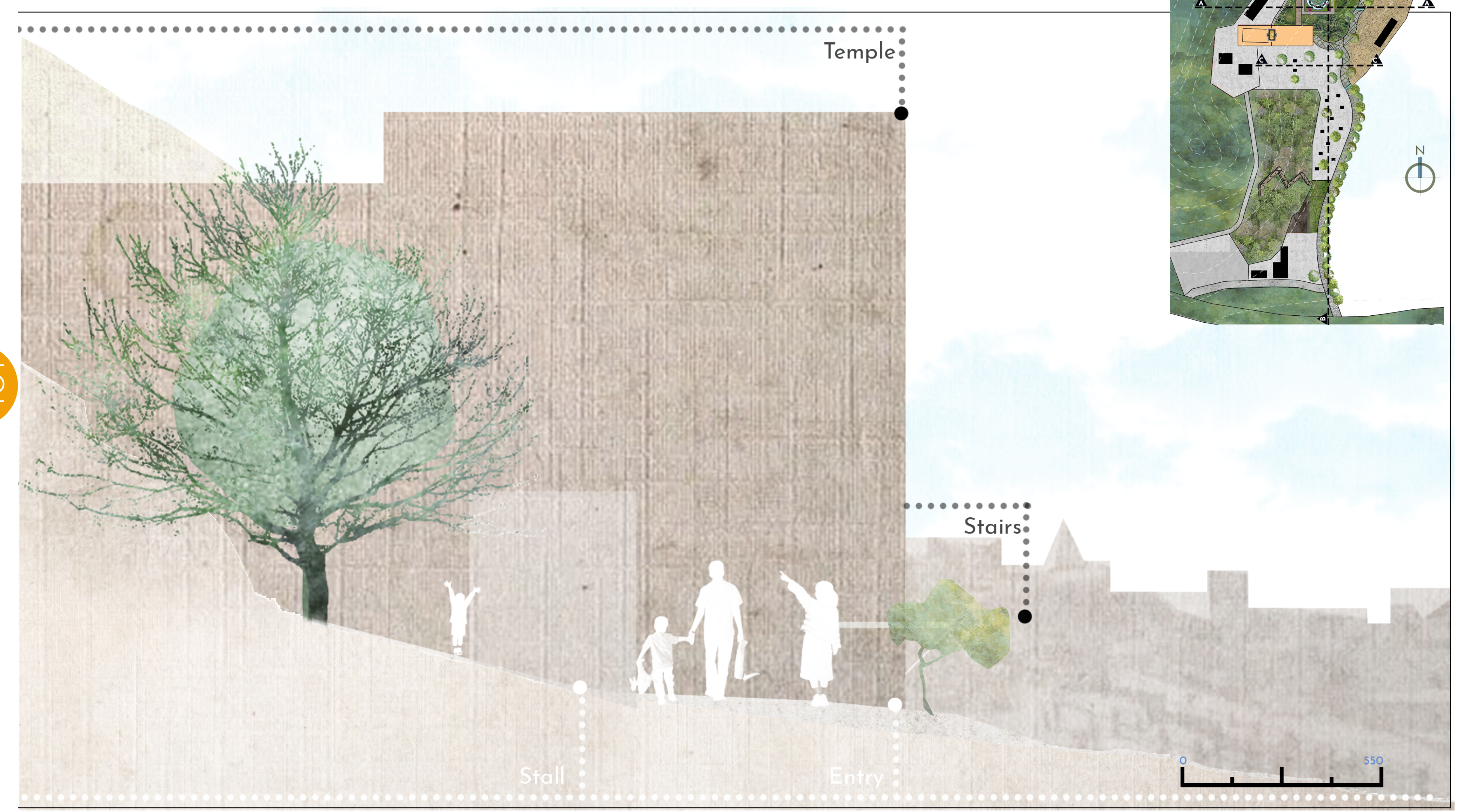



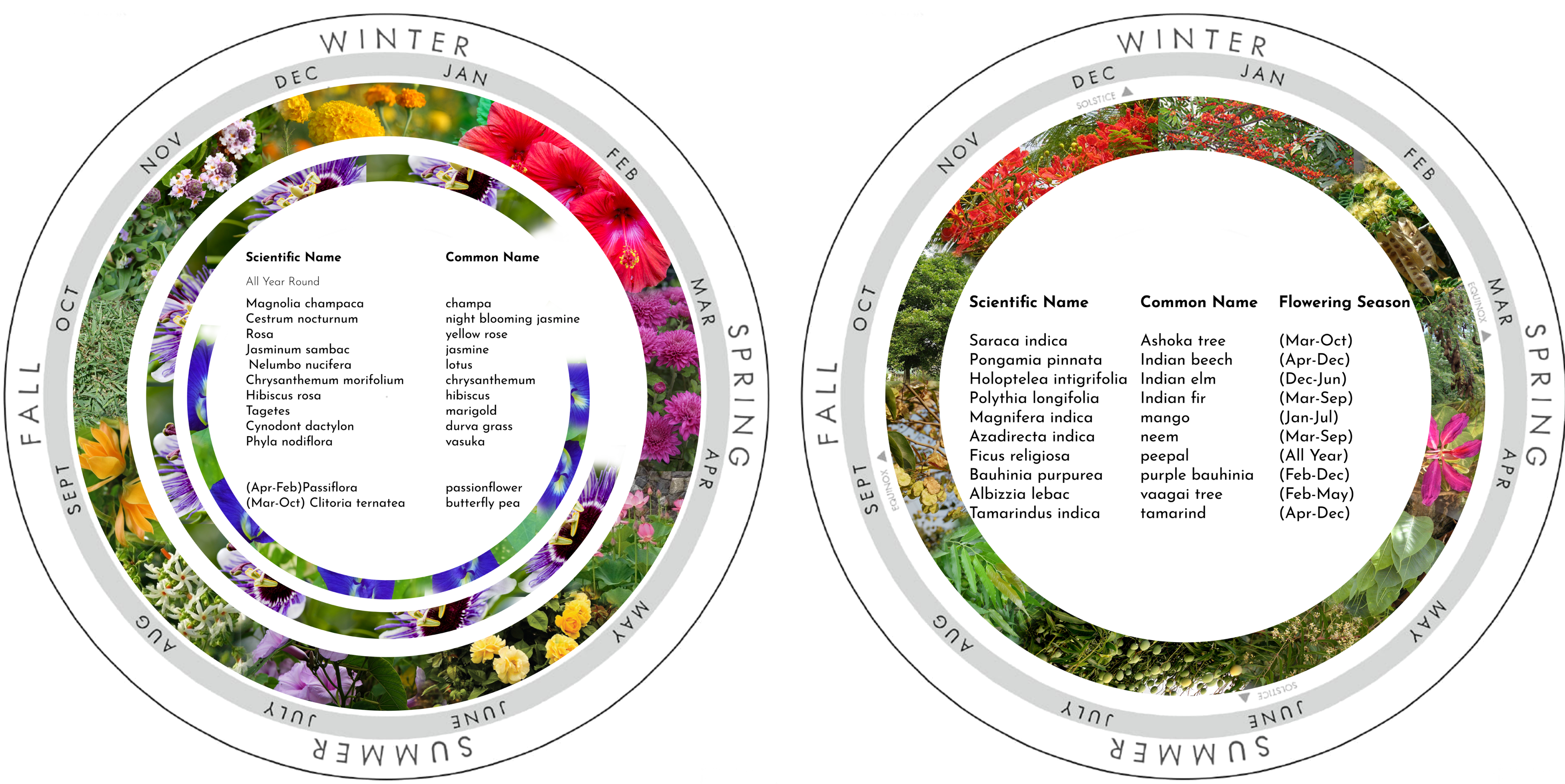


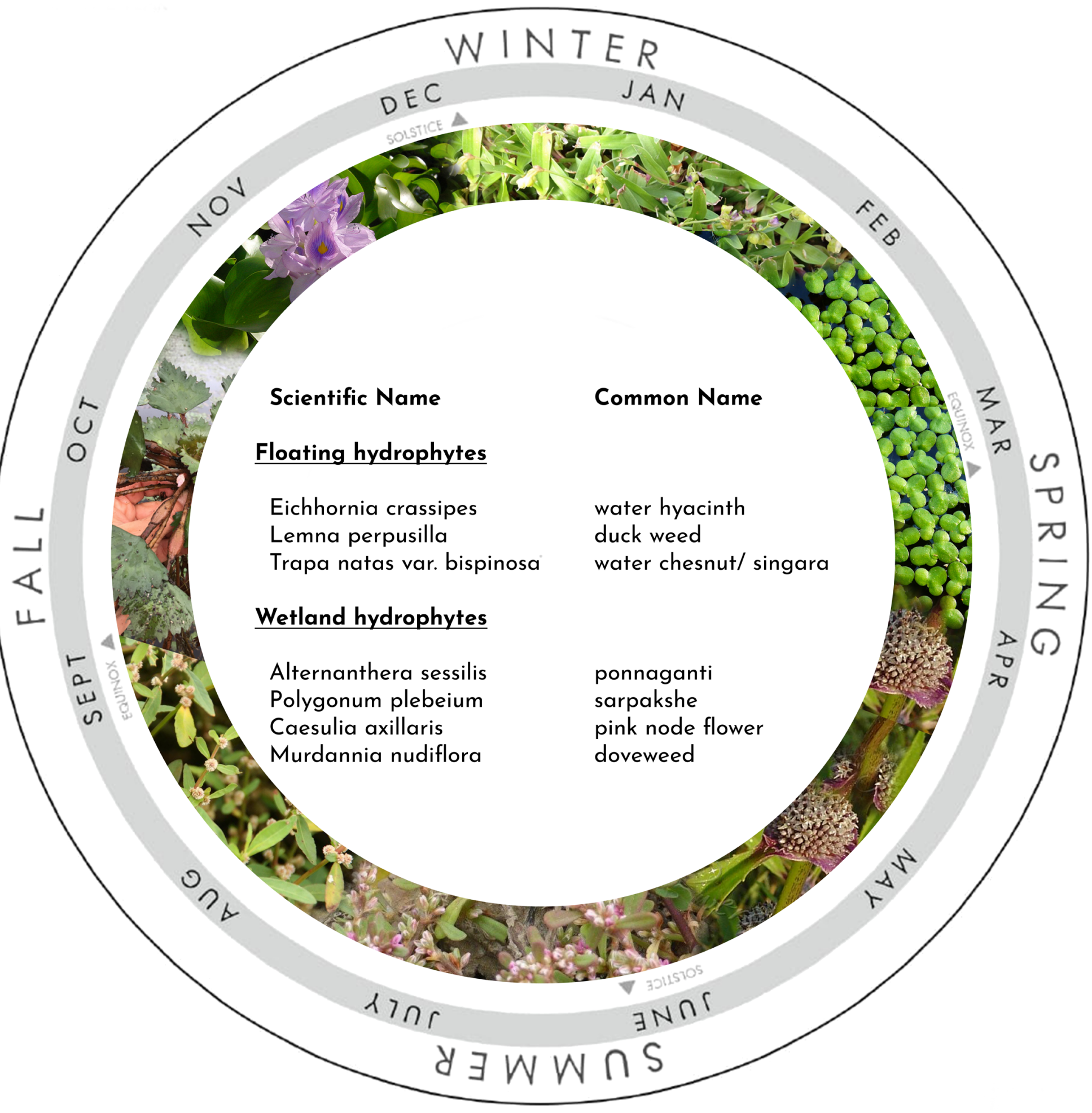

A varied selection of plants, trees and aquatic vegetation, native to the area have been selected. Also, the trees are commonly planted as avenue trees in India along with having various medcinal benefits. For example, Azodirecta Indica also known as neem, is known for its versatile nature in curing various diseases, although planted as avenue tree. Most of the selection is evergreen, which is considered a symbol of eternity, immortality and fertility. Worshipping of trees is a common sight in Hindu culture and one of the trees that receive this treatment is Ficus religiosa or commonly called as peepal, considered as the tree form of 3 main gods, namely Brahma, Vishnu and Shiva. A red cloth or thread is tied around the tree, rituals and prayers are offered and cutting down a peepal tree is considered inauspicios. [19] [20] [22]

For a corridor of length $1100 \mathrm{ft}$, and an approximate area of $3.5 \mathrm{acres}$, calculated using Google Earth $\odot$, the number of trees and plants that should be planted are 3500. [A] 


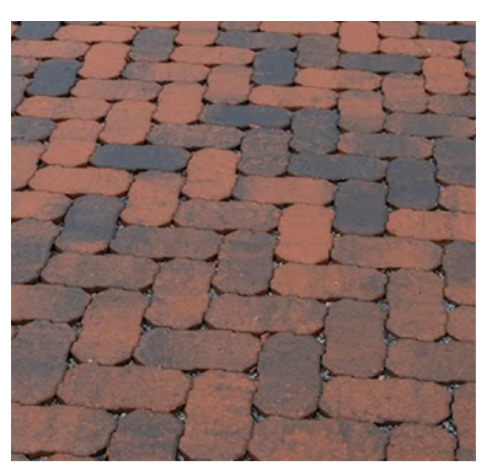

Permeable tiles for Parking

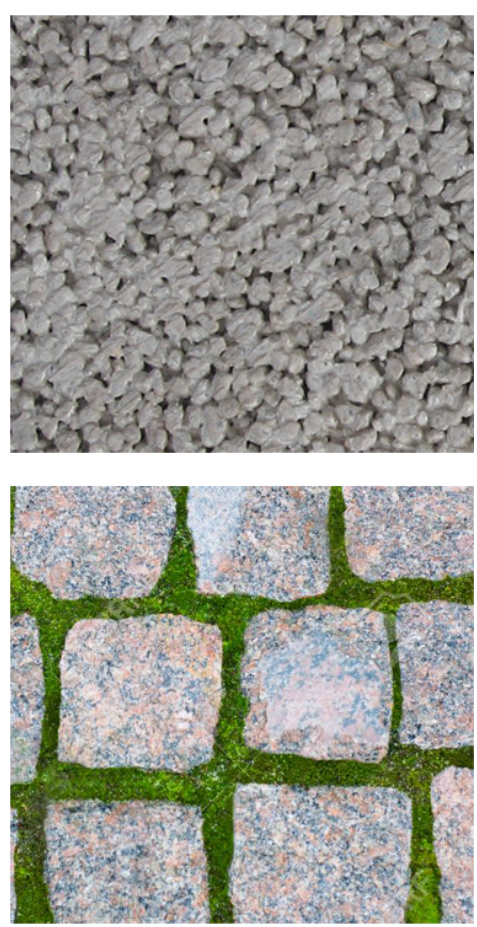

Permeable concrete for walkway, for visibility of rangol illustrations

Grass Pavers at the temple entrance, to dry off feet after washing
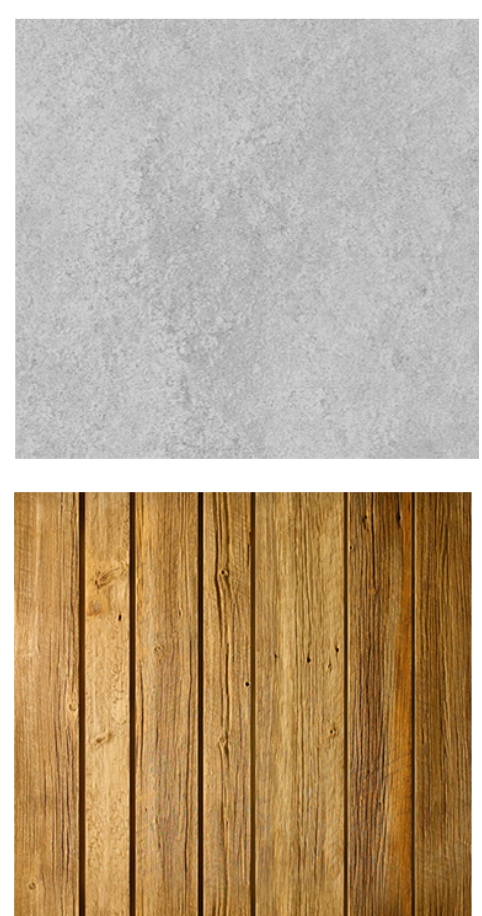

Stone used for meditation park walkway for a difference in texture

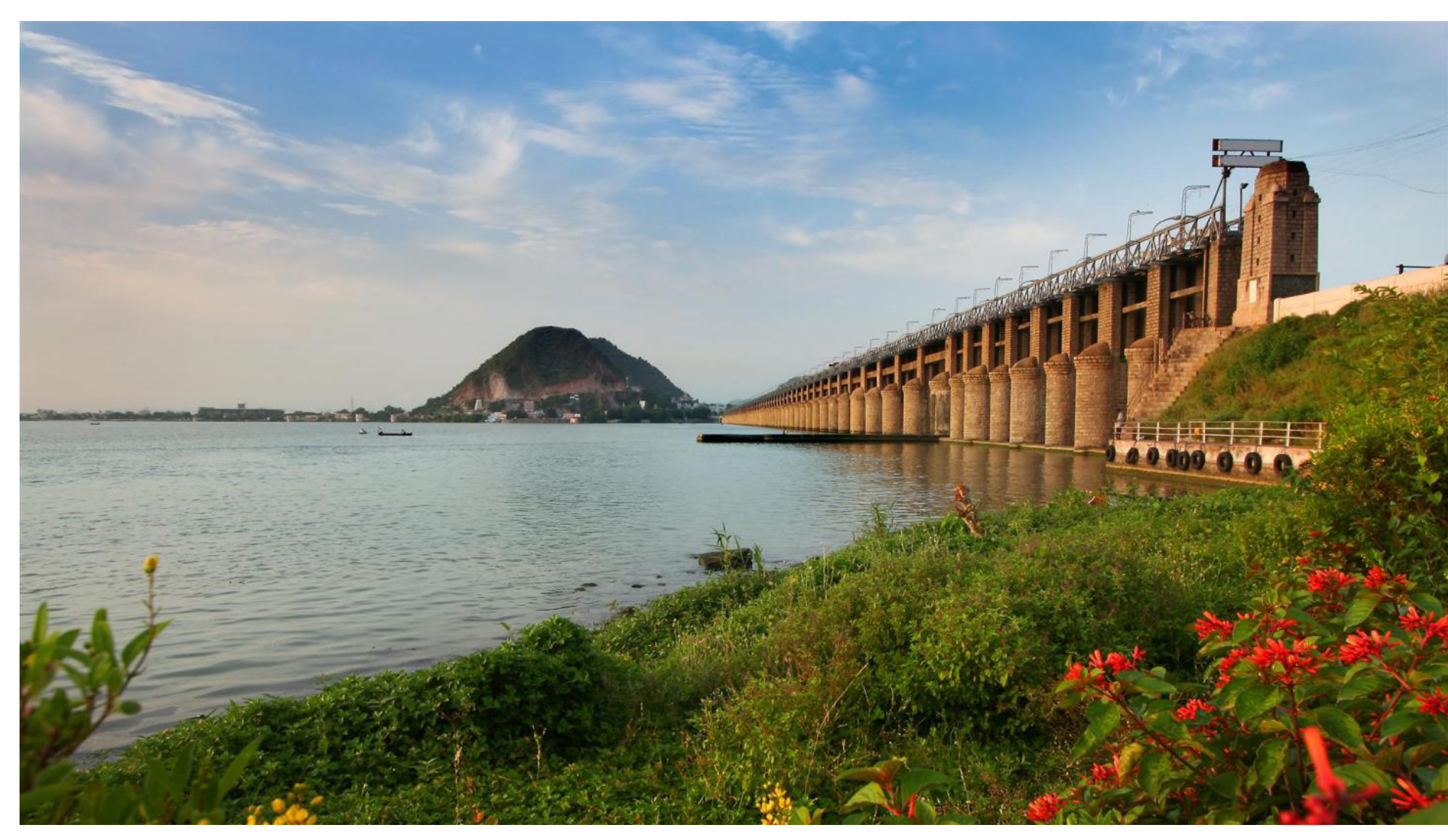

55 


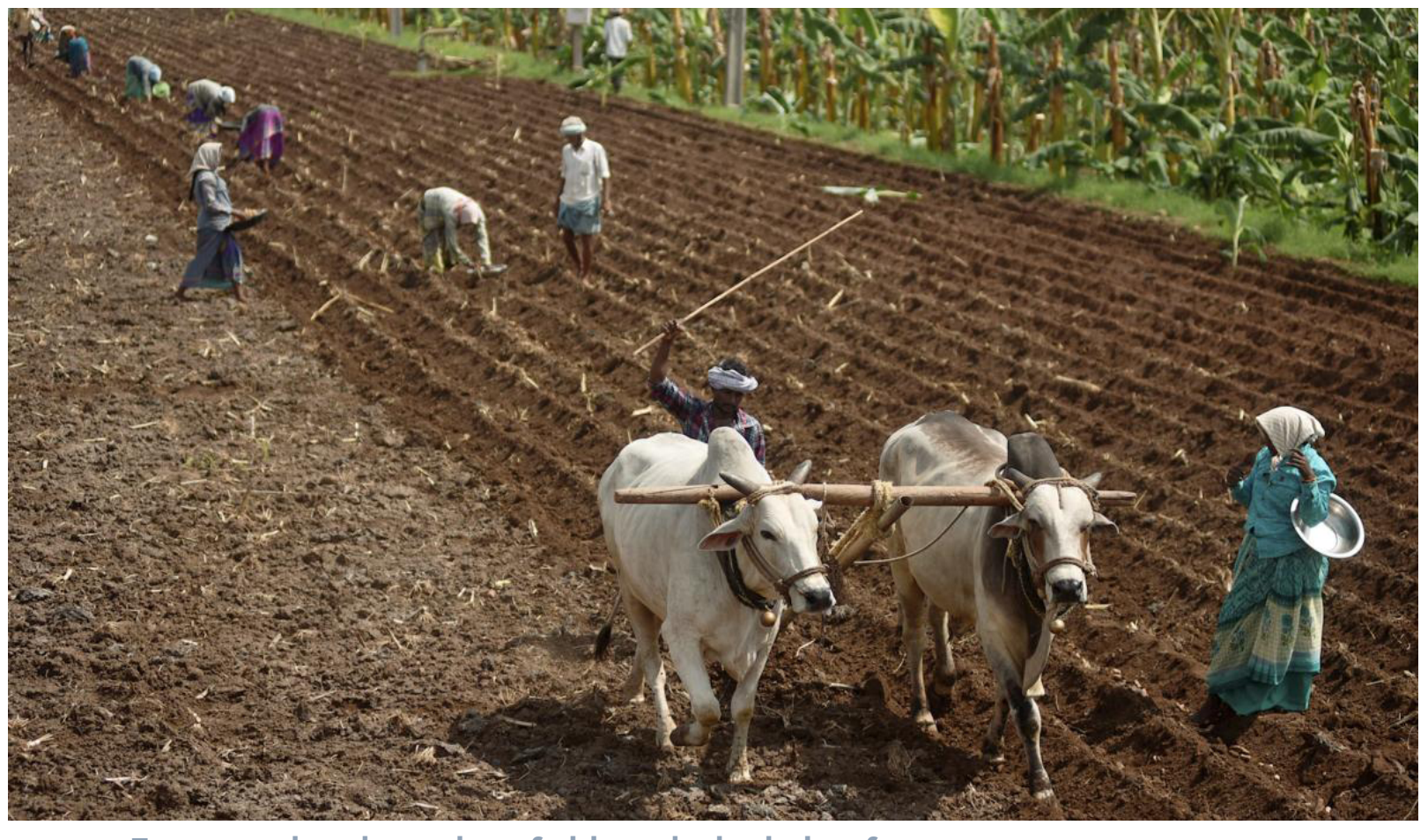

88

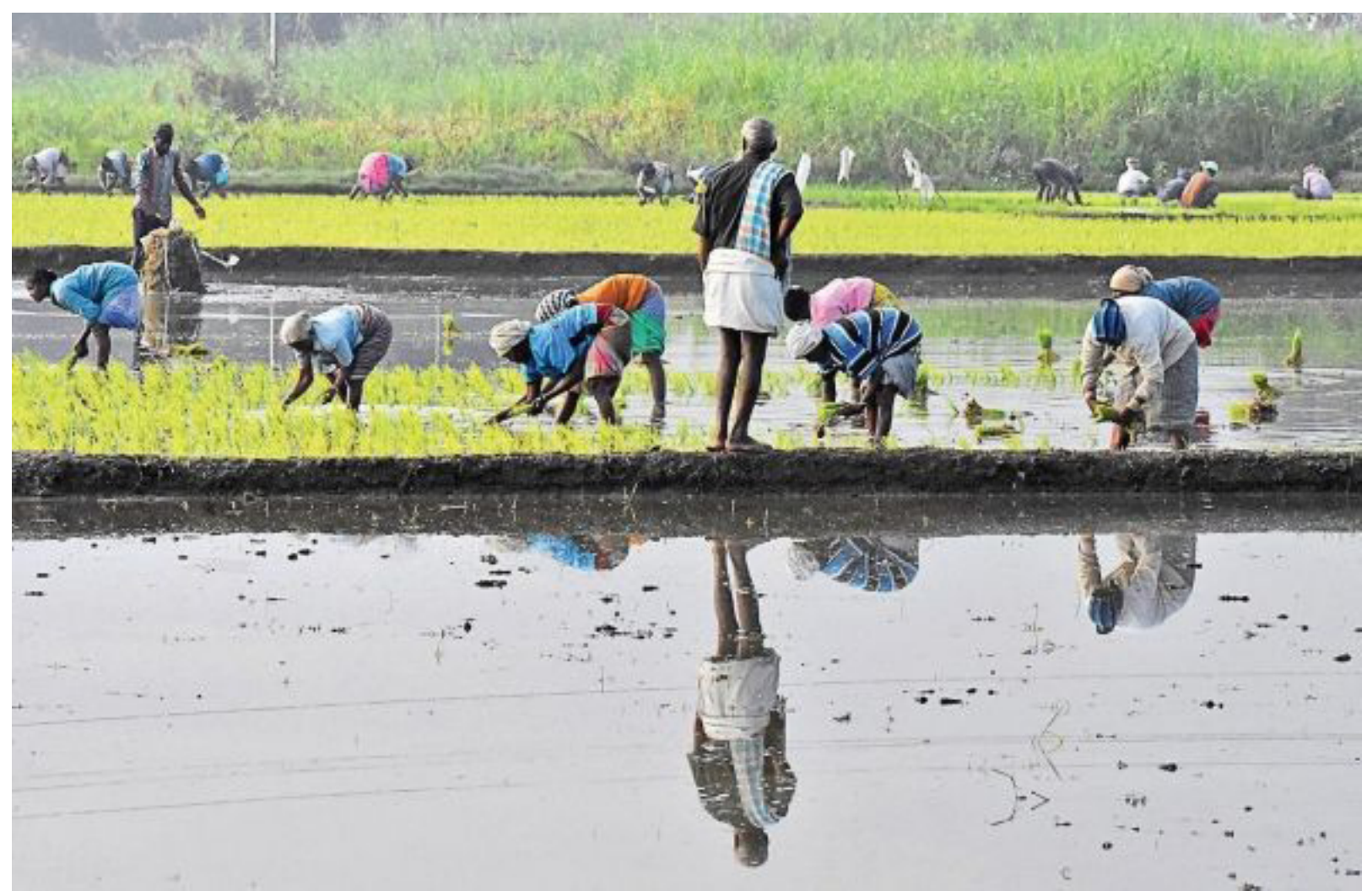

89 Farmers working on their fields in Vijayawada, India.
Agriculture is the most important sector of Indian Economy, accounting to $18 \%$ of the country's GDP. Rainfall and irrigation techniques assist the farmers to produce timely crops. Some of the irrigation techniques include a network of major and minor canals from the rivers. And these canals provide vast resources of water to agricultural lands and for drinking purposes. In Andhra Pradesh, a southern state in India, $63 \%$ of agricultural lands are cultivated by irrigation canals (I. e.) 2.7 million hectares.

The city of Vijayawada is surrounded by the river Krishna on the south, Budameru rivulet on the north. Also, three canals originate from the river Krishna that run through the city for irrigation, helping the rich and fertile agricultural lands. Taking into advantage the natural slope of the city (i.e.) West to East, the canals are designed to support farmers without additional equipment that would need electricity to pump the machines, further putting a burden on farmers in increased bills. The north and north-western parts of the city are covered by a low range of hills, while the central, south-western and north-western parts are covered in fertile agricultural lands. 
The agricultural crop year in India is from July-June. The cropping season is classified into two main season Kharif (July- October) during southwest monsoon and Rabi (October-March) during Winter. There is also a brief period between March - July called the Zaid season.

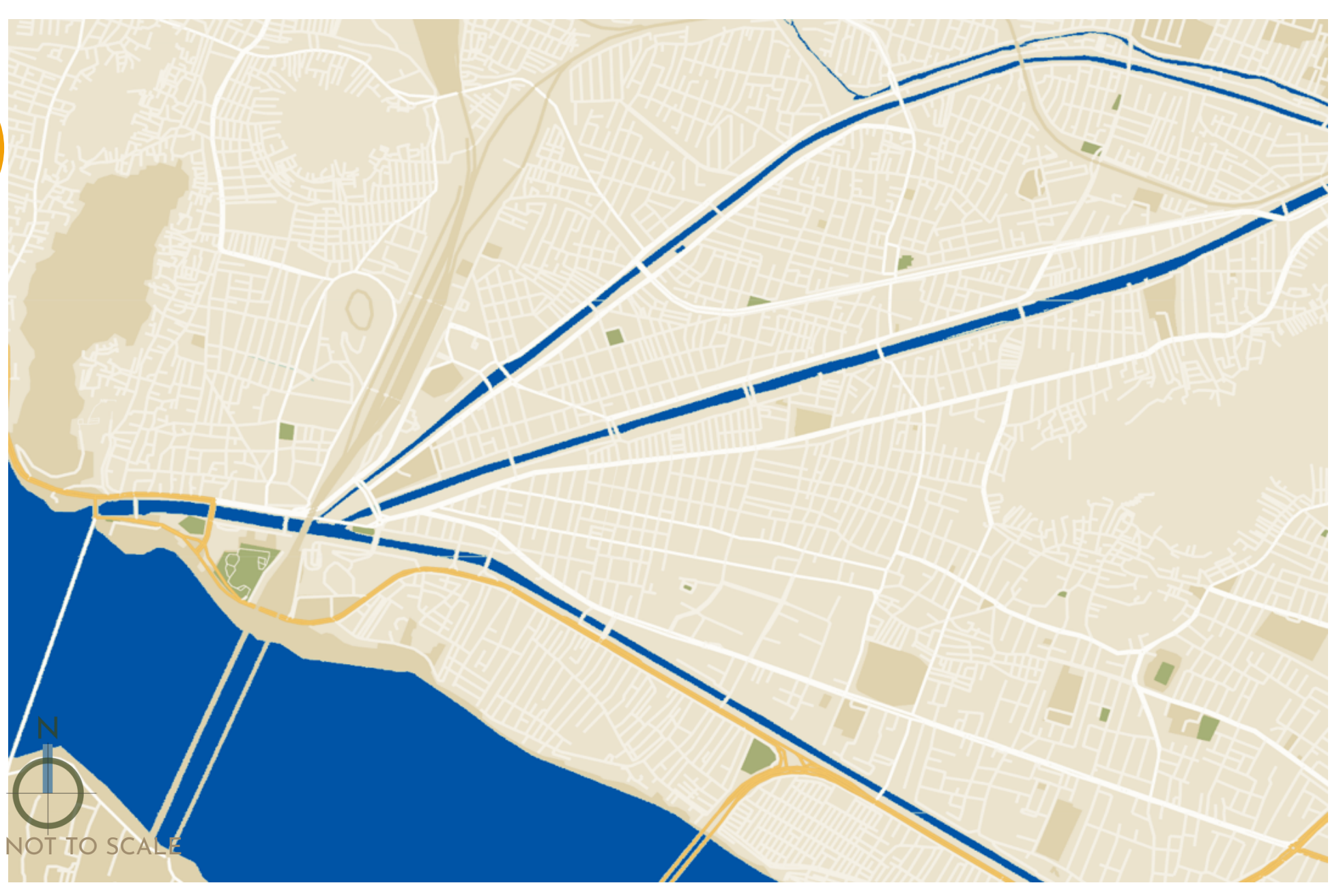

\begin{tabular}{|l|l|l|}
\hline KHARIF SEASON & RABI SEASON & ZAID SEASON \\
\hline $\begin{array}{l}\text { Black gram/ Urad Lentil } \\
\text { Chickpea } \\
\text { Green gram } \\
\text { Horse gram }\end{array}$ & $\begin{array}{l}\text { Black gram/ Urad Lentil } \\
\text { Chickpea } \\
\text { Green gram }\end{array}$ & \\
$\begin{array}{l}\text { Maize } \\
\text { Peas }\end{array}$ & Green gram \\
$\begin{array}{l}\text { Pulses } \\
\text { Red gram/ Arhar } \\
\text { Rice/ Paddy }\end{array}$ & \\
Sugarcane & $\begin{array}{l}\text { Red gram/ Arhar } \\
\text { Rice/ Paddy \& Wheat }\end{array}$ & \\
\hline
\end{tabular}



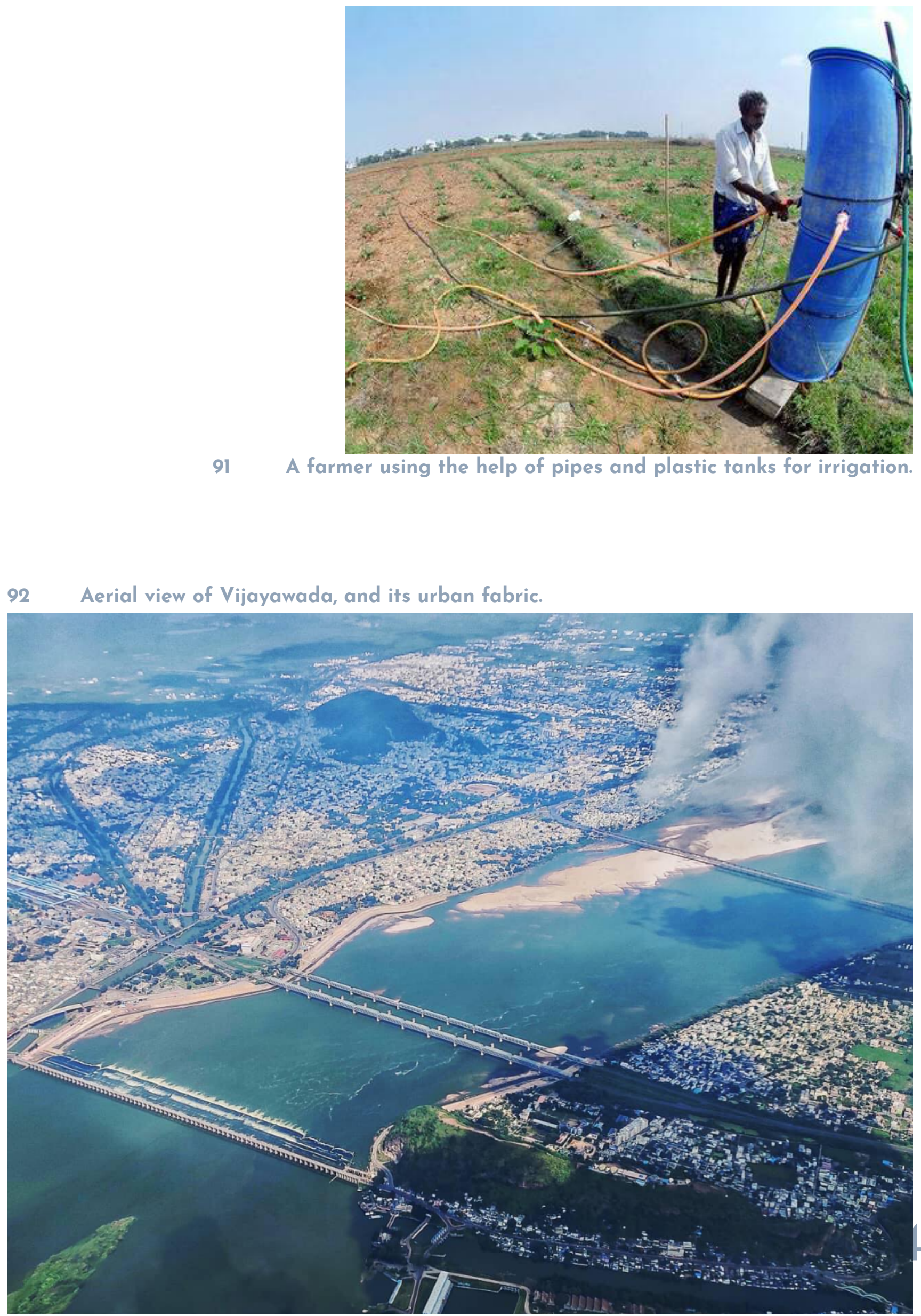

Eluru, Bandar and Ryves are the three canals, that originate from the northern side of the Prakasam Barrage reservoir. They were designed and constructed in 1855 for irrigation and navigation purposes measuring more than $32 \mathrm{~km}$ in length. The city started its growth along the banks of the river in 1855 and slowly spread to developing around the canals in 1905 with an increase of 60 sq.km in100 years. With the help of urbanization, these canals have been neglected and residential garbage is being accumulated which eventually led for the canal to stagnate with little to no flow. This situation has only worsened when the municipal authorities decided to let stormwater drains flow into these canals.

Additionally, Eichhornia or water Hyacinth, an alien weed, has infested the waters of the canal. It was the major contributor to the ecological loss to farmers and fishermen while the government has said it was a financial burden to eradicate such weeds, since its appearance the previous year. Further tests conducted on a sample of the canals' water concluded the presence of various physicochemical parameters exceeding the limits according to $\mathrm{WHO}$ and concentrations of toxic metals are found in slight excess at some locations. [23] 


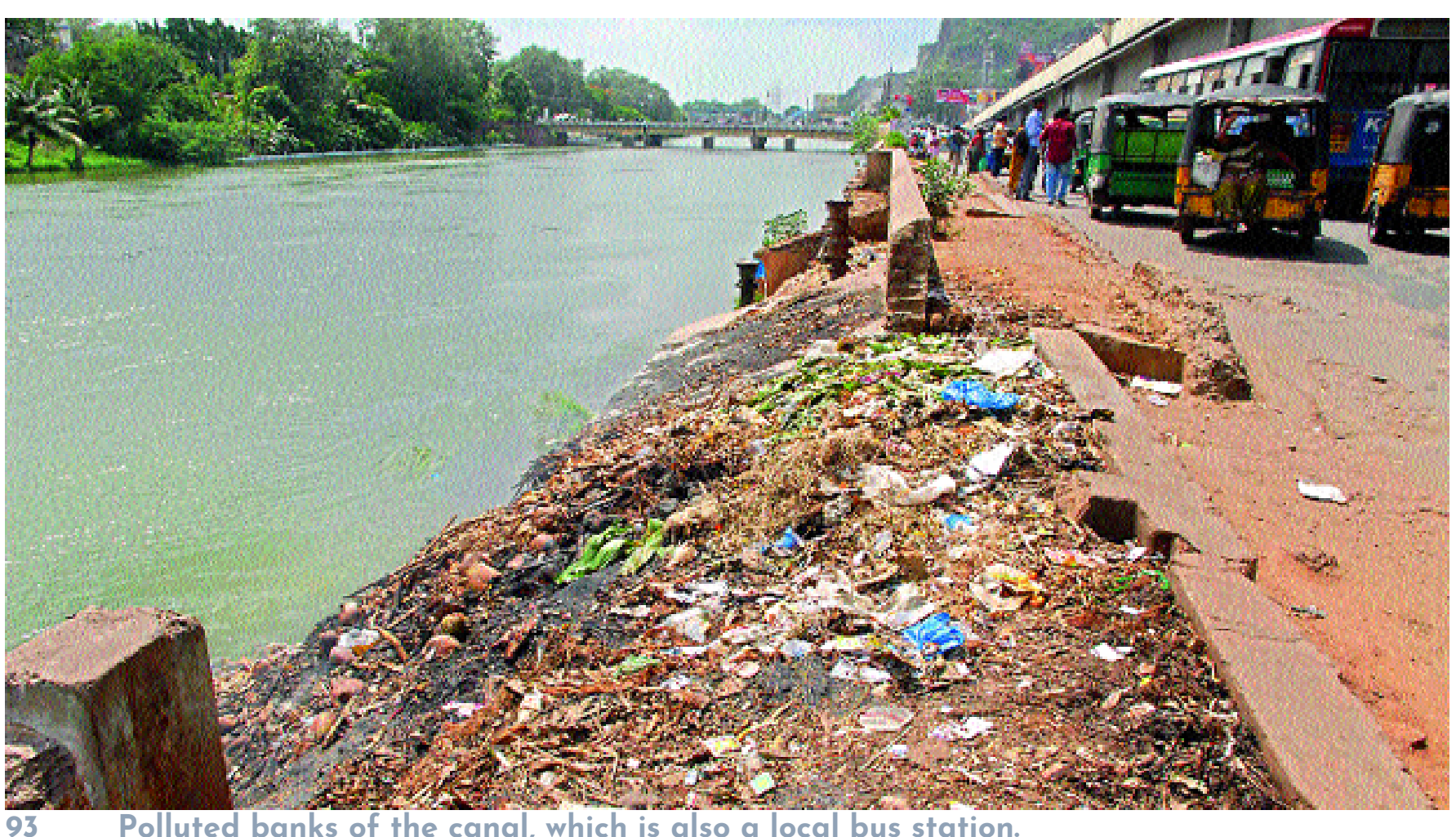

Polluted banks of the canal, which is also a local bus station.

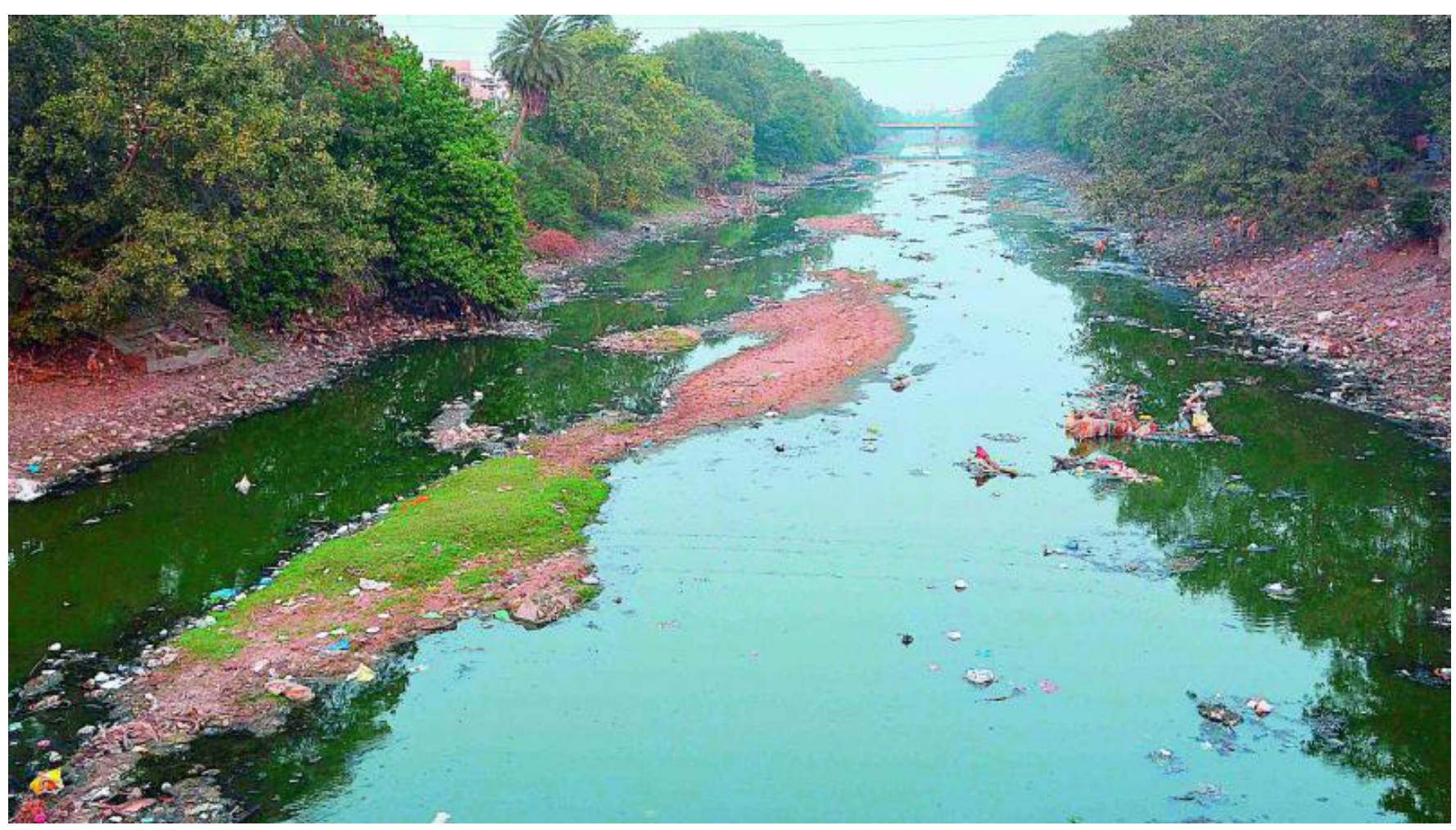

94. Polluted canal with garbage and other sewage material that are diverted to canals, proving the absence of propoer sewage system in the city.
In 2019, local government officials decided to take up a mission to clean these canals for beautification and irrigation among other reasons. The proposal was to develop green belts on both sides of the canal and install iron fences at a reasonable height to prevent further dumping of garbage and other plastic waste. A public notice asking residents to volunteer was circulated and CCTV cameras were installed at major intersections of roads and canals, these being the latest developments. Although parts of the canal were cleaned and pockets of greenery were placed on either side of the canal, the situation started to deteriorate quickly. Necessary precautions to prevent soil erosion were lacking and it further polluted the canal water. According to Invasive Species Compendium, Eichhornia is the most troublesome aquatic plant, as it affects fishing, water transport and biodiversity of the region. Despite the eradication efforts taken by the officials, it is said to be impossible to eradicate, and often only an integrated management strategy, inclusive of biological control can provide a long-term solution to this pest. [23] 


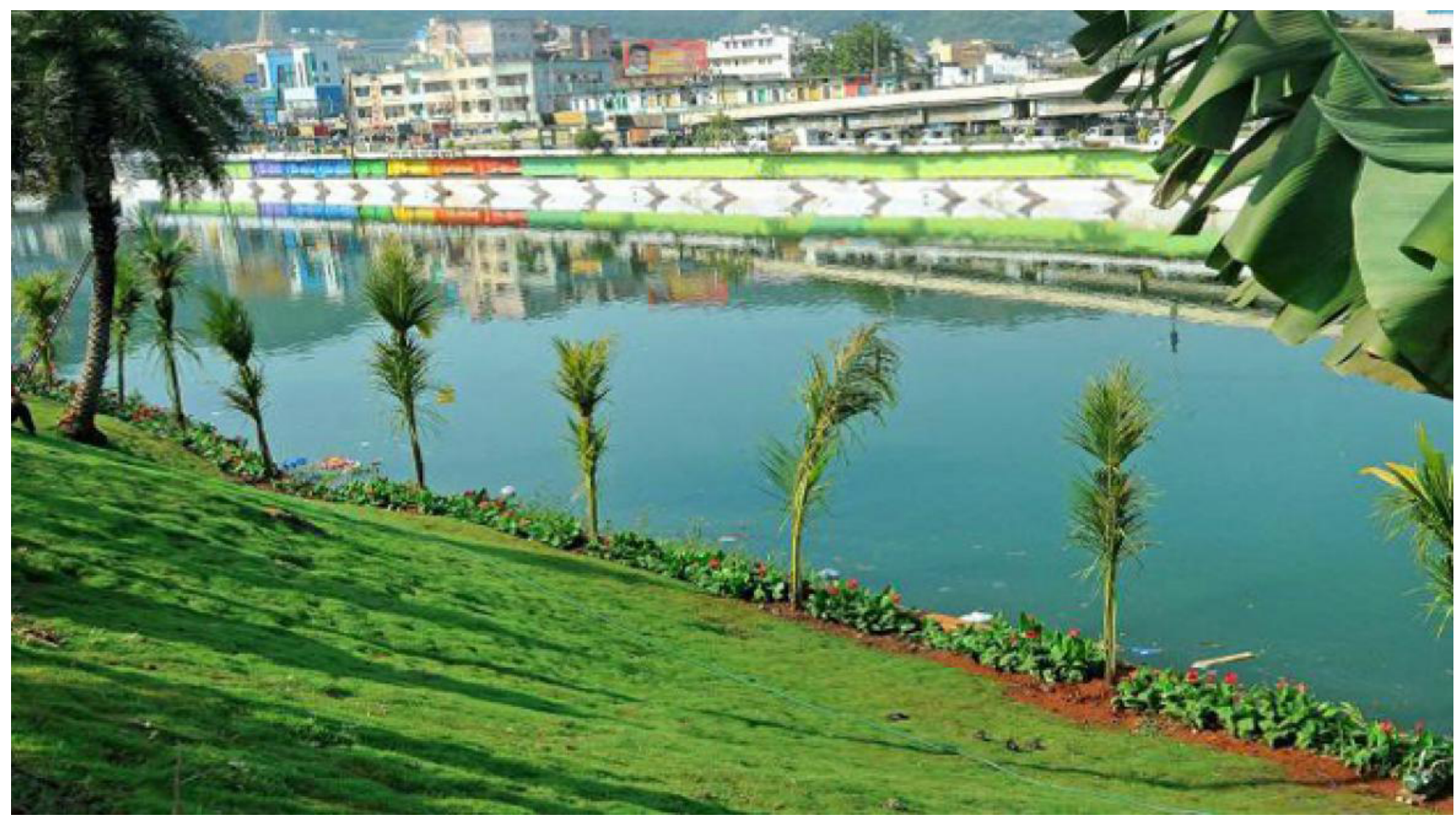

95 A portion of one of the canal banks that was developed during a municipal check, but soon after started collecting garbage as seen on the lower bank of the canal.

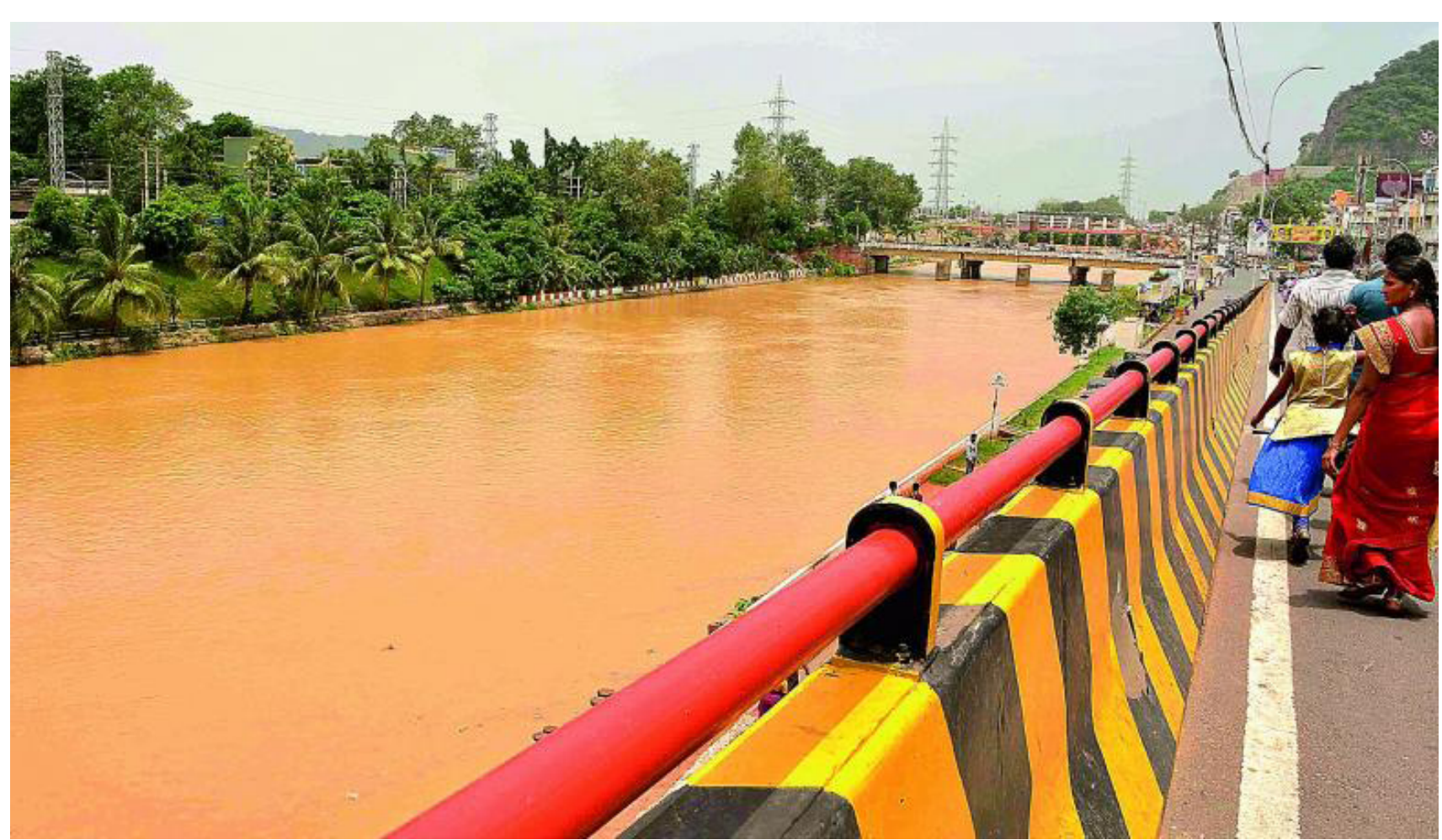

96 Canal flow of water during monsoon, the existing garbage and other unwanted material washed further down the canal due to heavy inflow.
Design proposal for ecological restoration of the canals.

Stage 1: Clearing of pollution and preventive measures

Stage 2: Eradicating invasive plant species and preventive measures

Stage 3: Floating Ecosystem

Stage 4: Beautification

Stage 5: Long-Term management

Stage 1: Clearing of pollution and Preventive measures

Pollution in the canal is either 'point source' such as residential garbage, which enters the river in high volumes from few locations or 'non-point source' such as agricultural run-off, which can enter from various locations along its course. Since these canals are adjacent to various agricultural fields, the run-off from these farms is harmful as chemicals are used for cultivation. Encouraging farmers to practice organic farming which uses organic content as manure and dependence on chemical inputs will be decreased, further advocating the healthy way of eating.

Proper disposal of residential garbage and minimizing the use of single use plastic bags is the first step towards a cleaner water body. Educating residents on proper ways to dispose off different types of garbage by providing containers to segregate said waste. Imposing penalties on households dumping garbage in open land/ water body. Stringent rules are needed for sanitary workers who are responsible for picking up door-to-door garbage. Also, with the use of trash collecting boats, garbage from the canal can be easily collected and transported to an appropriate dumping ground. 


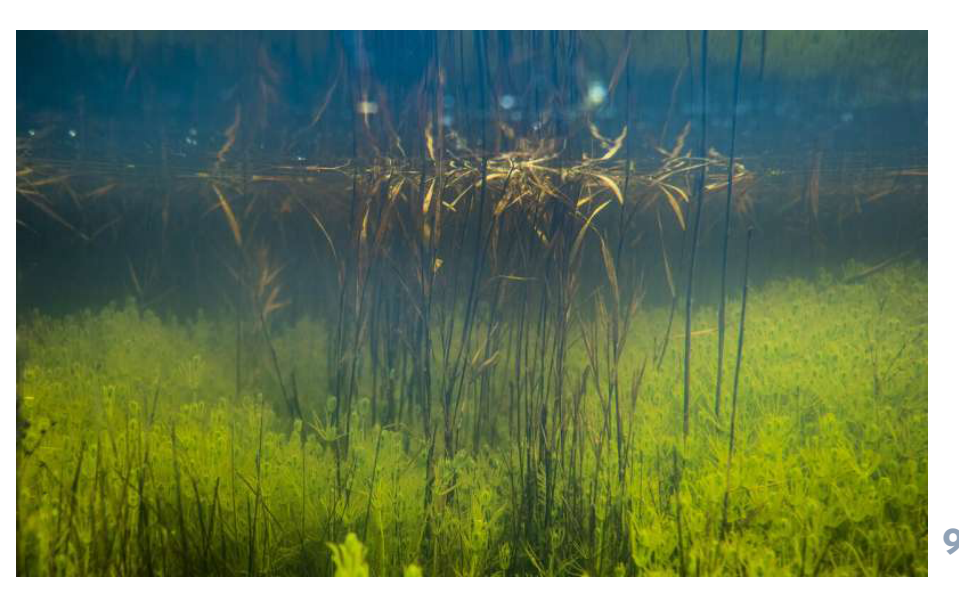

Aquatic vegetation with root system that help in controlling the water $\mathrm{pH}$ levels.

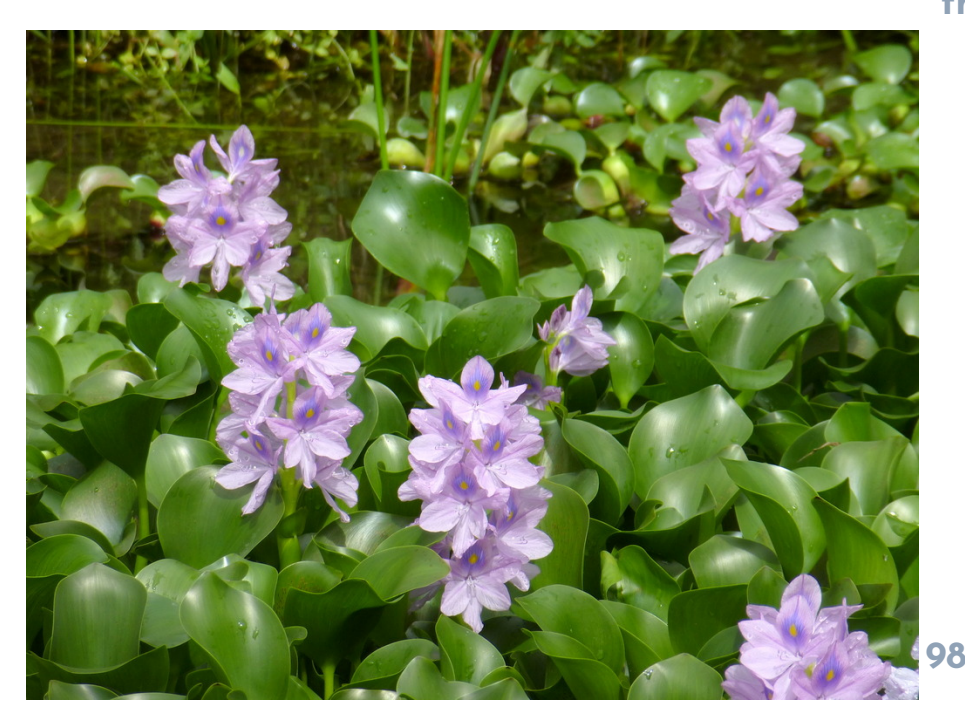

Water hyacinth, a weed that multiplies rapidly, hindering the flow of water

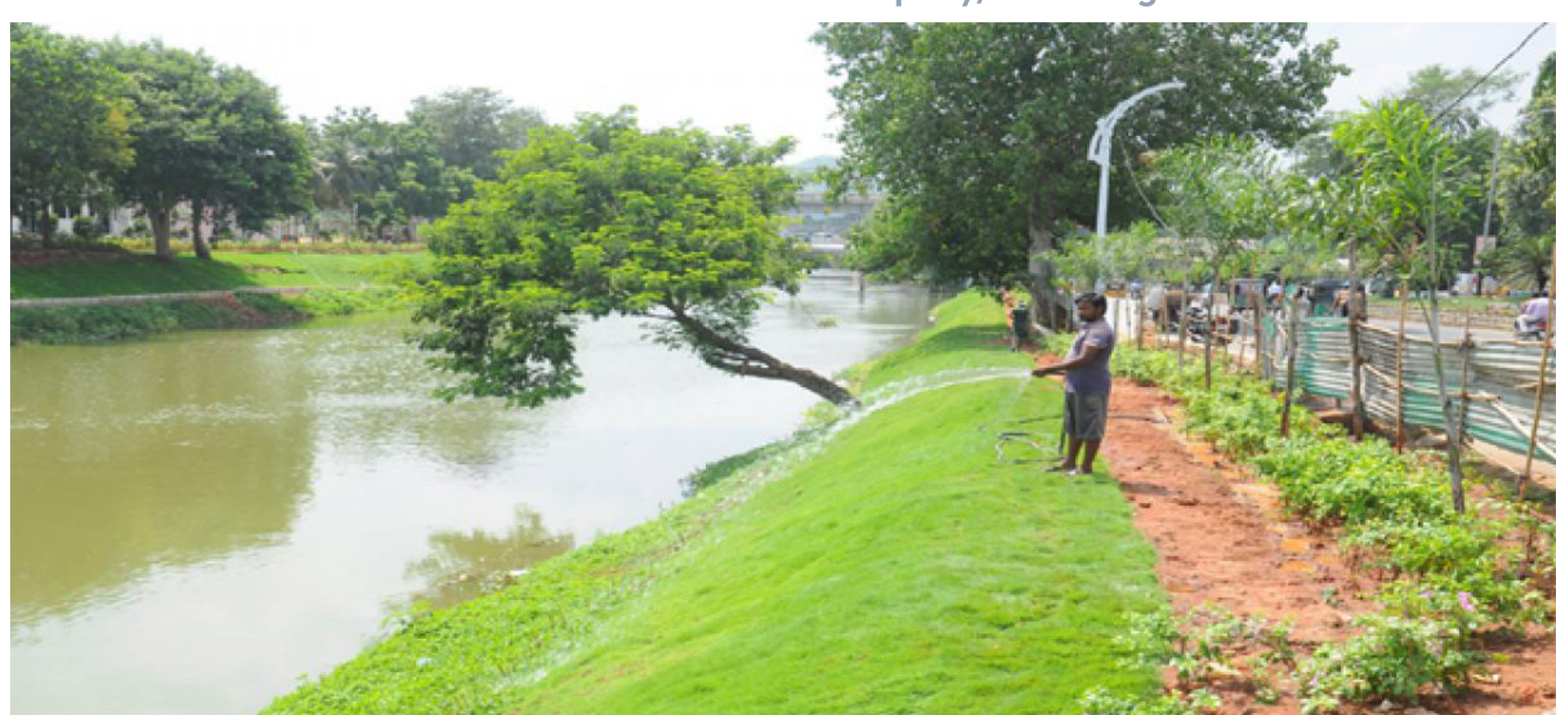

A volunteer helps in watering the banks of the river. Also seen is the dirt walkway that can easily erode during monsoon.
Additionally, treating sewage with the help of aquatic plants, the wa ter hyacinth, were found to possess the ability of purifying the organic pollutants and taking up inorganic nutrient salts such as nitrogen and phosphorus compounds.

Generally, open land garbage dumping can be seen at bus-stations where people wait, converting these dumps into mini pockets for public leisure and comfortable waiting spaces while providing pub lic garbage bins that segregate waste into solid, metal, plastic and miscellaneous. This measure can prevent garbage flowing into canals during monsoon and promotes the public to follow rules and avoid paying fines.

The city's municipal corporation has proposed an on-site water treatment plant, that is cost-effective and eliminates the need of long-distance transporting of wastewater to treatment plants. It is a cleans ing process that can be tailored to the existing need in a timely and cost-effective manner. Wastewater is recycled within the watershed making environmental management, planning and protection easier 


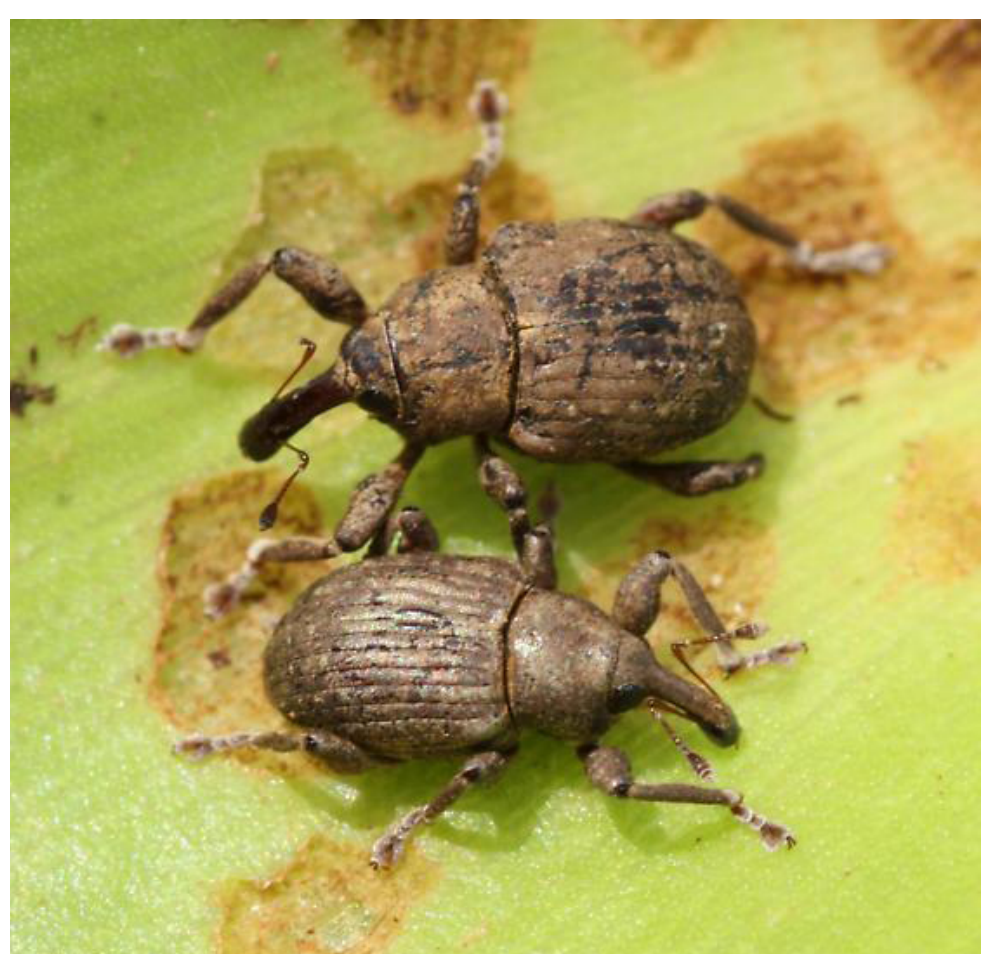

103 Neochetina eichchornae Warner, insect used

to prevent the spread of Water hyacinth

\section{BIOMATRIX}

WATER

\section{Floating Ecosystem}

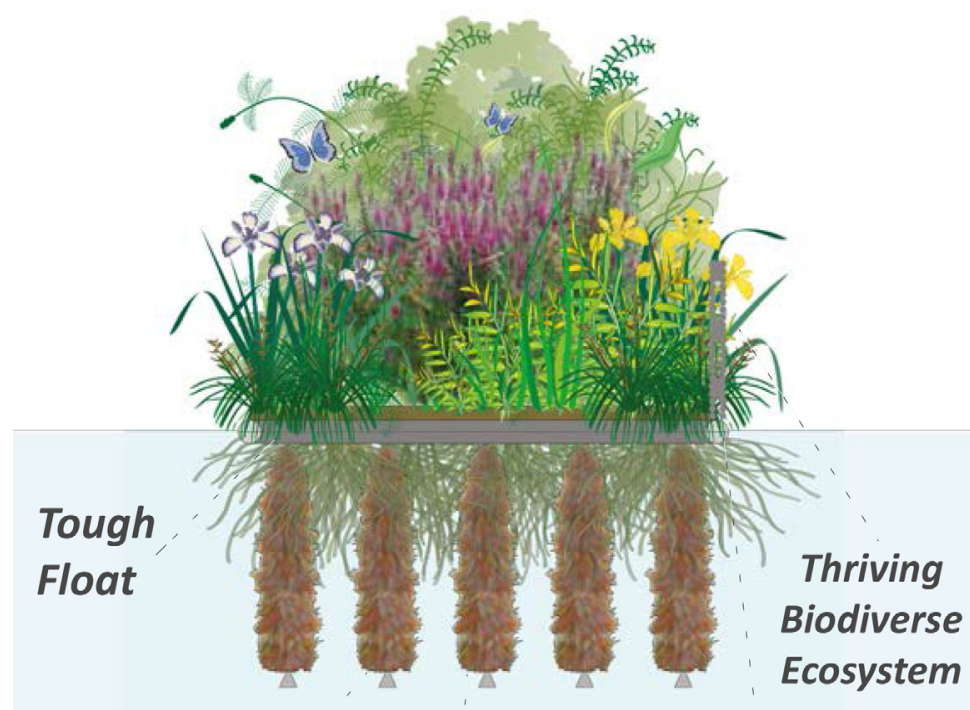

$\begin{gathered}\text { Dynamic Media } \\ \text { Column }\end{gathered}$
Biofilms $\begin{gathered}\text { Stainless Steel } \\ \text { Connection } \\ \text { Flange }\end{gathered}$

104. Artificial ecosystem as illustrated by Bioma-

trix Water Company.
Although clearing of Water hyacinth would not guarantee its low chances of comeback altogether. While using the technique of releasing insects can be seen as an easy option, it would also be a complication for other aquatic vegetation. Therefore, a combination of aforementioned techniques can be used to tackle this issue. Also, allowing local crafts to prosper with the help of invasive weed is a commendable idea that should be further encouraged.

Stage 3: Floating ecosystem

This unique ecosystem is dominated by a variety of grasses and forbs, which can create a buoyant mat that floats on a layer of water. Artificial Floating Islands (AFIs) are human-made floating structures capable of supporting aquatic vegetation. Previous studies pointed out that most AFIs use aquatic plants to carry out improvement of water quality and ecological conservation. In addition to environmental conservation, AFI can be effective at improving water quality. Nakamura and Mueller and Wen pointed out that the plant root system and floating structures of AFI can intercept contaminants, reduce water velocity, abate the dispersal of pollution, and absorb waves to protect the banks of bodies of water from erosion. It can also effectively reduce organic contaminants in the water. AFI is an effective method to treat eutrophic water, as water pollutants can be transformed and degraded by the combination of plants and microorganisms on the floating island, thus, increasing the efficiency of the natural water quality improving process. Also, studies proved that when using just plants to purify wastewater on a floating island, the ammonia nitrogen removal rate is higher than $56 \%$, and the total phosphorus removal rate is higher than $52 \%$; thus, the effect is significant. [25] [27] 


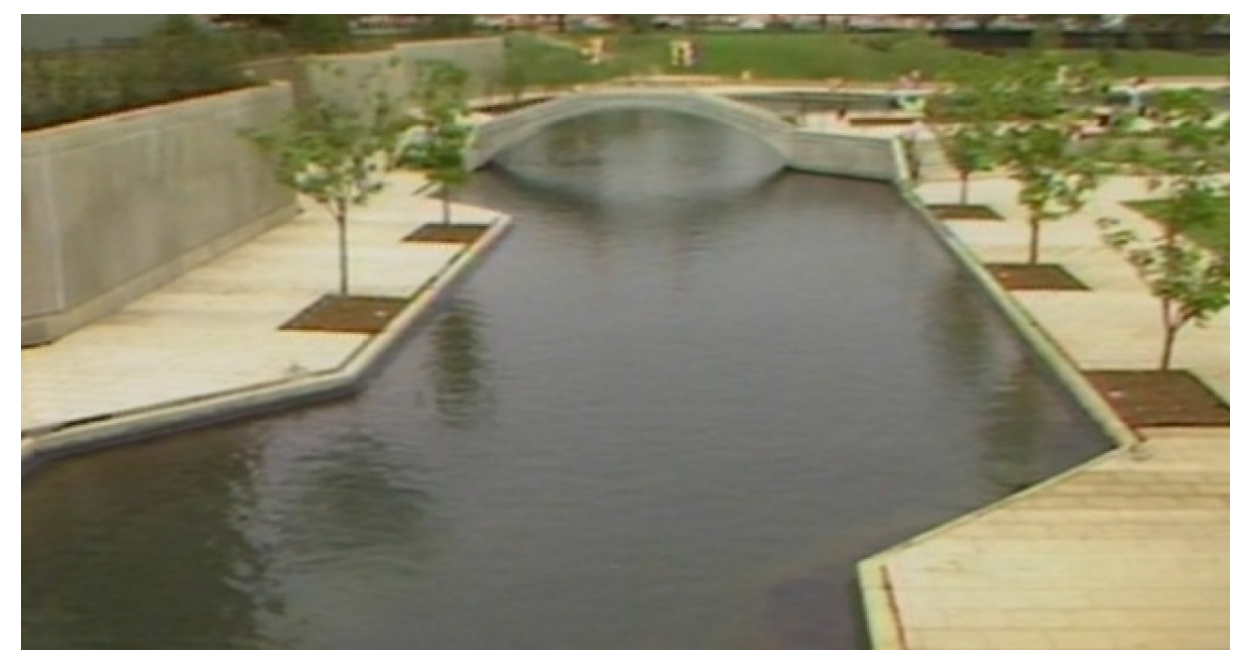

105 An example of Canal beautification with walkways and overpass.

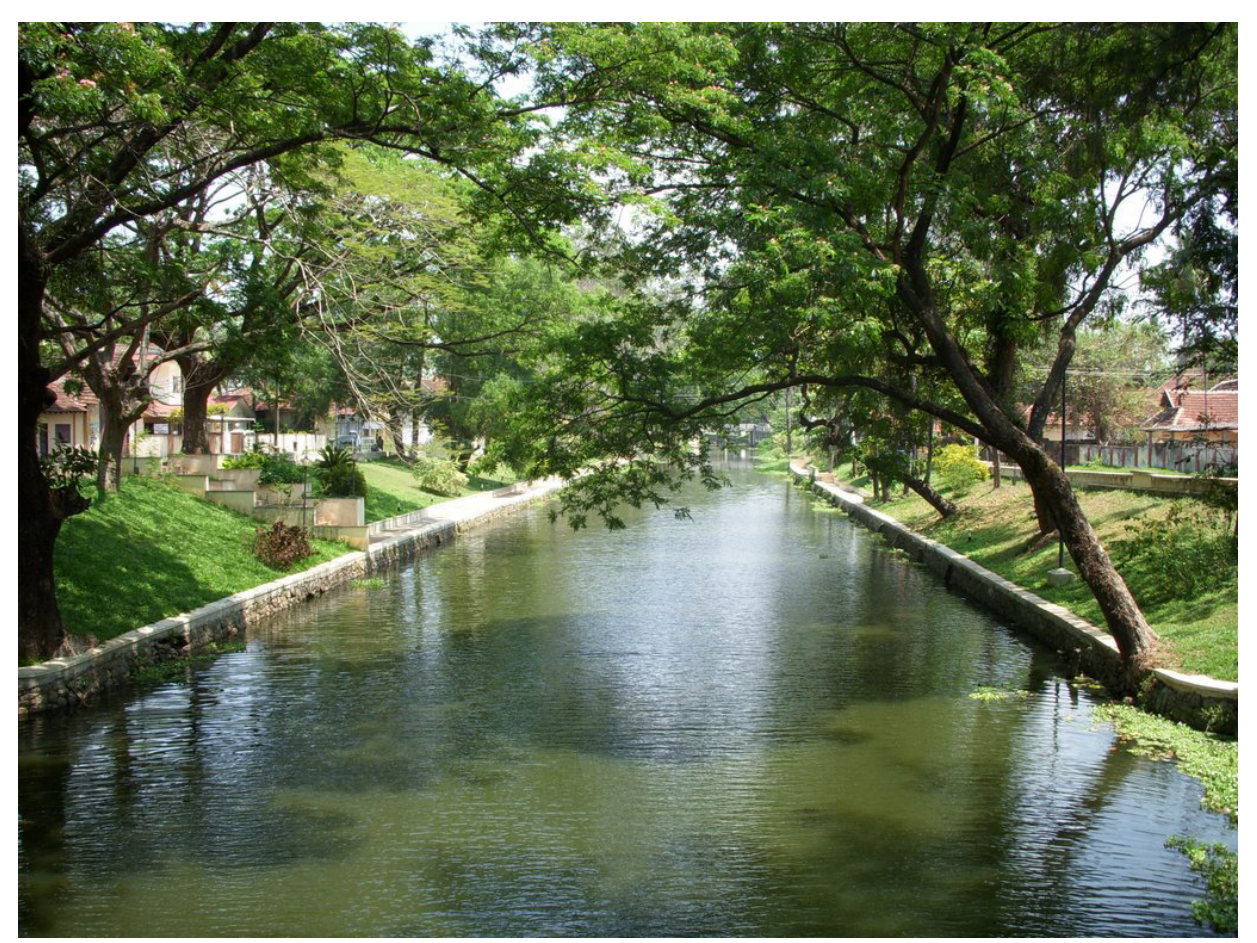

106 A canal waterway in Alleppey, Kerala, India.

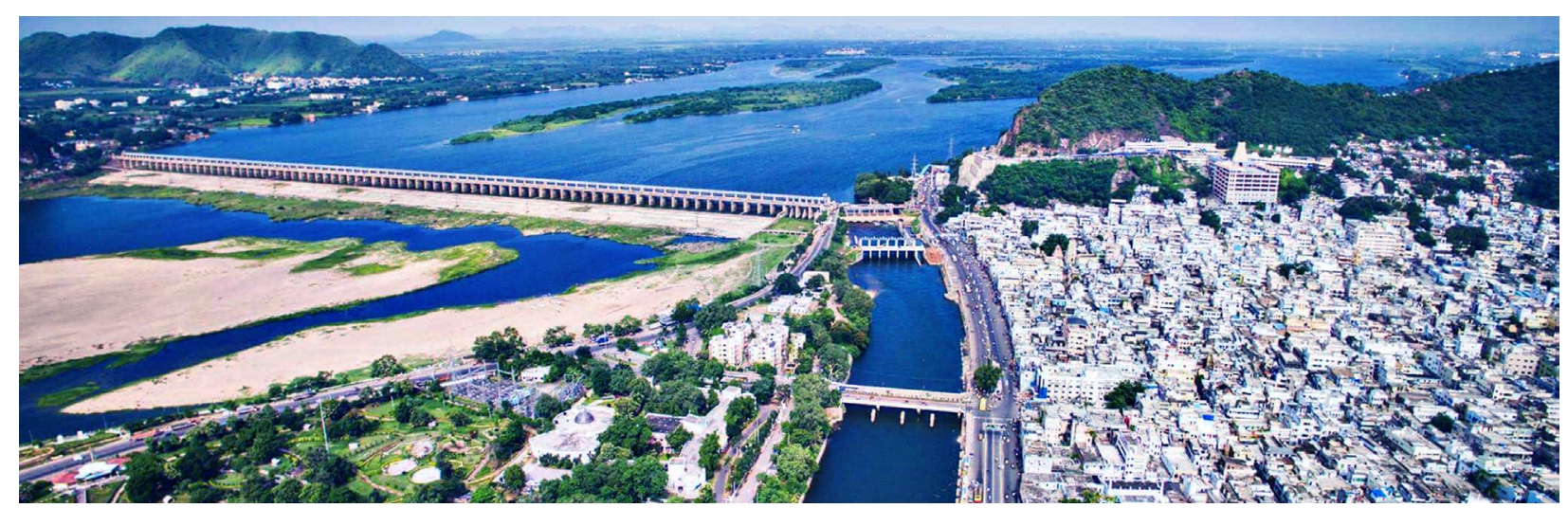

Stage 4: Beautification

A $3 \mathrm{~km}$ stretch has been identified for beautification along the canal to prevent indiscriminate dumping of waste. Due to the ill maintenance of this beautification, the grass and trees have dried out and the canal banks have returned to their original positions. Also, the construction debris that was being dumped at the site, was initially thought to be used for construction of recreational platforms along the canal.

Stage 5: Long-term management

A committee can be formed for the sole purpose of maintaining the canals and should be responsible for putting together proper regulations that the residents must abide to. Also, they should be held accountable to any future encroachments, polluting, or garbage disposal activities. Their mission should include: Educating residents, bringing in volunteers for tree planting, conducting various workshops and creating awareness of the problems caused by dumping. 
The fine grain urban fabric of this city has adapted to the religious structures and its many functions often overlapping to residential or other mixed-use core of the city. A single temple was the center of the city in ancient times, but with rapid urbanization and comfort of the user, temples have multiplied in number and are scattered around the dense urban layout. Presence of temples and other religious structures adds to the character of the city, also provides many options of discovery and exploration.

Gradually religious structures have found their way into the city, but never found a way to blend itself into its surroundings. Temples are viewed as a sacred space and an entity of itself.

By creating a connection between temples and other mixed-use sectors of the city, then can seamlessly blend together and evolve over time with any new developments. This way then can be integrated as with the ever expanding urban space.

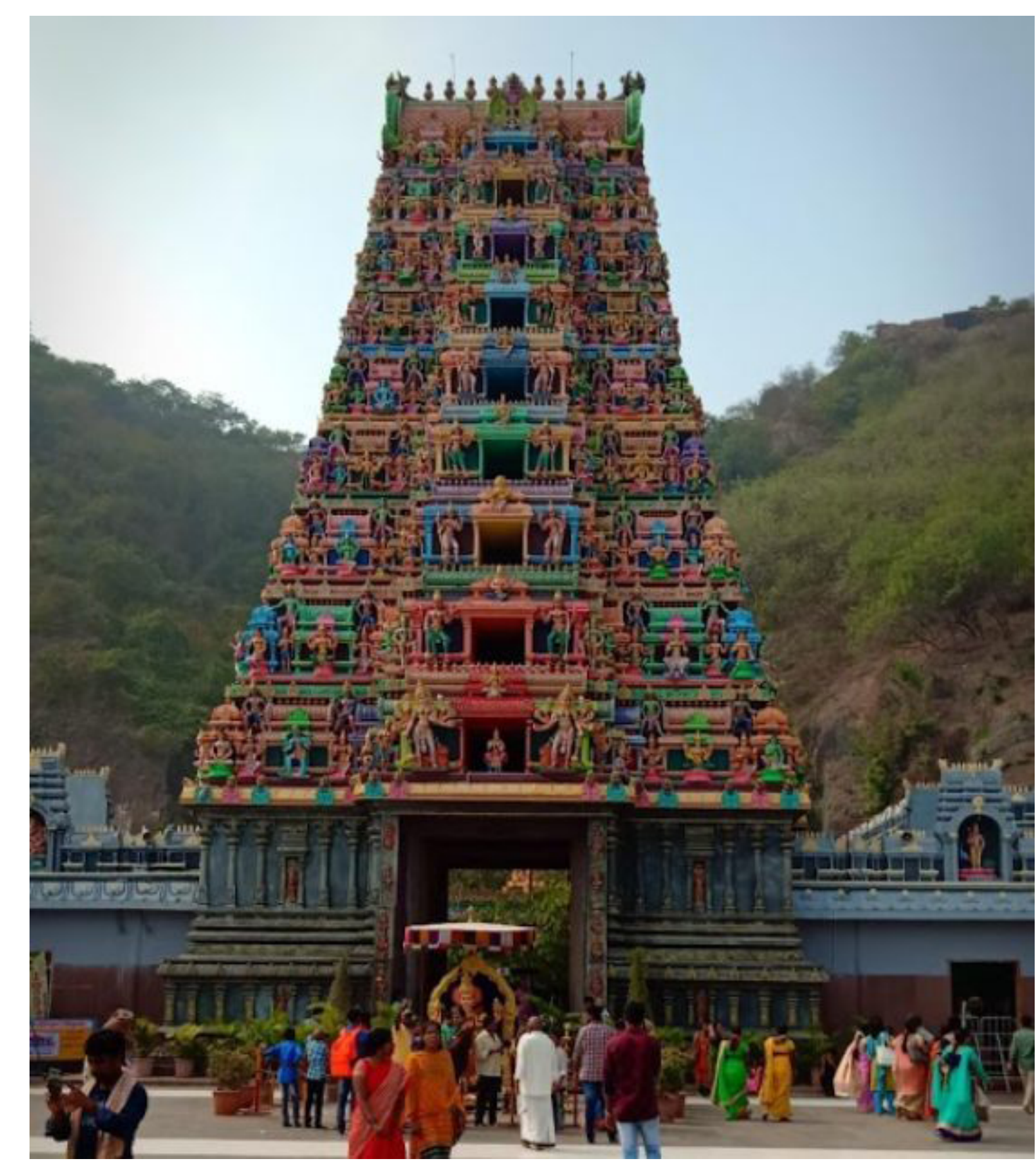


1) Singh, V. (2015, January 23). Census: Hindu and Muslims share in India. The Indian Express. https://indianexpress.com/article/india/india-others/census-hindushare-dips-below-80-muslim-share-grows-but-slower/

2) Hindu Calendar - Indian Calendar. (n.d.). Hindu Calendar. https://www.timeanddate.com/calendar/hindu-calendar.html

3) India TV News Desk. (2015, October 8). 5 reasons why women are not allowed at shamshan ghat. India TV. https://www.indiatvnews.com/news/india/why-womenare-not-allowed-at-shamshan-ghat-55126.html

4) Indian Plate. (n.d.). Eurasian Tectonics. http://eurasiatectonics.weebly.com/indian-plate.html

5) UNESCO World Heritage Centre. (2003). Western Ghats. https://whc.unesco. org/en/list/1342

6) Wikipedia contributors. (n.d.). South India. Wikipedia. https://en.wikipedia. org/wiki/South_India\#:\%7E:text=Religion,-Religion\%2Oin\%20South\&text=Hinduism\%2Ois\%2Othe\%20major\%2Oreligion,Islam\%20and\%208\%25\%20follow\%20 Christianity.

A. (n.d.). Hindu Symbols and their meaning. Welcome to East Asian Cultures. https://east-asian-cultures.com/hindu-symbols/\#1_Hindu_symbol_Aum___Pronounced_as_Om)

7) Behari Dutt, B. (2009). Town Planning in Ancient India. Gyan Publishing House. 8) Venkataramana Reddy, G. (2010). Alayam, the Hindu Temple - An Epitome of Hindu Culture. Ramakrishna Math.

9) Bharath, K. (2010). Puja Room. BK.http://bharathkidilse.blogspot.com/2009/10/ puja-room.html

10) Pooram festivals of Kerala. (n.d.). Kerala Tourism. https://www.keralatourism. org/event/pooram/

11) Sinha, Amita. (2017). Living Ghats of Varanasi.

12) Surendar, T. (2019, August 16). Highway to heaven. ST. https://www.fortuneindia.com/ideas/highway-to-heaven/103518

13) Vishwanath Corridor will be ready by June 2021: CEO of Kashi temple trust. (2019, May 18). The Sunday Guardian Live. https://www.sundayguardianlive.com/ news/vishwanath-corridor-will-ready-june-2021-ceo-kashi-temple-trust
14) Current Status of Soil Management in Andhra Pradesh. (2012). Dr. A. Sreenivasa Raju. http://birds-spacc.org/consultants\%2Oreport/ Current\%20\%20Status\%20Soil\%20Mgt.pdf

15) DETAILS OF ROADS IN EACH ULB OF ANDHRA PRADESH. (2016). Andhra Pradesh Govt. https://web.archive.org/ web/20160801101300/http://centralapp.cdma.ap.gov.in:8080/CD.

MAAPTaxesInfo/RoadDetails.jsp

16) Lynch, K., \& Joint Center for Urban Studies. (1960). The Image of the City. Amsterdam University Press.

17) Average weather in Vijayawada, India. (n.d.). Weather Spark. https://weatherspark.com/y/110141/Average-Weather-in-Vijayawada-India-Year-Round

18) Official website for Kanaka Durga Temple. (2017). Sri Durga Malleswara Swamy Varla Devasthanam. http://kanakadurgamma org/DarshanPlanner

19) Josh, J. (2015, December 7). Common Plant Species of India. Jagranjosh.Com. https://www.jagranjosh.com/general-knowledge/ common-plant-species-of-india-1440146954-1

20) Herbarium JCB. (n.d.). Flora of Peninsular India. http://flora-peninsula-indica.ces.iisc.ac.in/herbsheet.php?id $=4082 \&$ cat $=7$

21) Kumar, N. (2013, March 30). Thesis report Nitish Kumar. Generating Public Space through Canalfront Development. https://www. slideshare.net/nitish12/thesis-report-nitish-kumar

22) Air pollution tolerance index of selected plants in Vijayawada city, Andhra Pradesh. (2017). G. Krishnaveni, K. Kiran Kumar. https:// www.greenpharmacy.info/index.php/ijgp/article/view/1419/797

23) Lanka, V. (2019, April 28). Finally, Vijayawada civic body takes to cleaning city's three choked irrigation canals. The Times of India. https://timesofindia.indiatimes.com/city/vijayawada/finally-civicbody-takes-to-cleaning-citys-three-choked-irrigation-canals/articleshow/69076419.cms 
1. Map of India highlighted southern states. (n.d.). [Map]. https://www.mapsofindia. com/maps/india/outlinemapofindia.htm

2. Ravi, K. (n.d.). Godavari Pushkaraalu. [Image]. https://pro2-bar-s3-cdn-cfl.myportfolio.com/b2d804e904c05a8010ead4dbecc852bl/96cc233dec398cc9b7180094_rw_1920. jpg?h=27ee9a5b84a3699a09b37f58463c5599

3. Daswamedha Ghat, Varanasi, India. (n.d.). [Image]. https://upload.wikimedia.org/ wikipedia/commons/6/6a/Dashashwamedha_ghat_on_the_Ganga\%2C_Varanasi.jpg

4. Map of India, highlighted eastern Ghats, western ghats and major rivers. (n.d.). [Map]. https://www.mapsofindia.com/maps/india/outlinemapofindia.htm

5. Vaishno Devi temple, Himalayan mountain ranges. (n.d.). [Image]. https://hinduexistence.files.wordpress.com/2011/11/465928852_368c273559.jpg?w=300\& $\mathrm{h}=225$

6. Tirumala Hills, Tirupati,India. (n.d.). [Image]. https://www.teluguone.com/tonecmsuserfiles/Tirumala_Hills-Sapthagiri-1.png

Gopuram of Meenakshi Temple. (n.d.). [Image]. https://uasatish.com/wp-content/uploads/2020/02/Sculptures-on-Gopuram.jpg

8. Ganesh idol procession in Mumbai,India. (2019, September 12). [lmage]. https:// indianexpress.com/article/lifestyle/life-style/ganesh-visarjan-2019-live-updates-india-bidsadieu-lord-ganesh-anant-chaturdashi-5988214/

9. Aum or Om symbol. (n.d.). [lcon]. https://upload.wikimedia.org/wikipedia/commons/ thumb/6/67/Aum_Om_red.svg/1200px-Aum_Om_red.svg.png

10. Swastika symbol. (n.d.). [lcon]. https://i.pinimg.com/originals/78/b9/1b/78b9lbcaea013da74c8bofle8ffe9fd3.png

11. Sri Yantra. (n.d.). [Icon]. https://en.wikipedia.org/wiki/File:The_Sri_Yantra_in_diagrammatic_form.svg

12. Gopuram style in Dravidian Architecture. (n.d.). [Image]. https://upload.wikimedia. org/wikipedia/commons/d/dd/Dravidian_Architecture.jpg

13. Evening Aarti at Varanasi. (n.d.). [Image]. https://images.squarespace-cdn. com/content/vl/5ad327ef7e3c3a5bb2b975e2/1531033055138-7TTAQOSPT7RVVSJKYO2Q/kel7ZwdGBToddl8pDm48kFmfxoboNKufWj-55Bgmc-J7gQa3H78H3YOtxjaiv_OfDoOvxcdMmMKkDsyUqMSsMWxHk725yiiHCCLfrh8Olz4YTzHvnKhyp6Da-NYroOW3ZGjoBKy3azqku80C78910iXS6XmVv7bUJ418E8YoclhjuviiiZmrL38wlymUdqq4JaGeFUxjM-HeS7Oc-SSFcg/Varanasi-29.jpg
14. Evening aarti at Krishna River. (n.d.). [Image]. https://1.bp.blogspot.com/-7600I2W$\mathrm{PcK} 8 / \mathrm{V} 40 \mathrm{O} \mathrm{z} Z \mathrm{ZqVel} / \mathrm{AAAAAAAAASE} / \mathrm{elg}$-cl5c-9g2cBqiNOfCY5gfKq3YrTrMACLcB/ s1600/k22rishna_pushkaralu_Haarathi.jpg

15. Devotee lighting fire as an offering. (n.d.). [Image]. https://www.sbs.com.au/food/ sites/sbs.com.au.food/files/styles/full/public/gettyimages-92318260.jpg?itok=n9qiPww5

16. Festival procession in Kerala, India. (n.d.). [Image]. https://www.eastcoastdaily.in/ wp-content/uploads/2020/04/maxresdefault-5.jpg

17. Festival procession in Kerala, India. (n.d.-b). [Image]. https://pml.narvii. com/6455/25373a8be83713bdcd3060e140eb9adee5aebd6a_hq.jpg

18. Ganges river, Varanasi,India. (n.d.). [Image]. https://www.planetware.com/wpimages/2020/02/india-varanasi-best-places-to-visit-ganges-river.jpg

19. Kasi Vishwanathtemple, Varanasi,India.(n.d.).[Image].https://www.deccanherald.com/ sites/dh/files/article_images/2020/05/19/file78dyvtvft2btvgg7aqu-431705513-1576246883. jpg

20. Artificial floating ecosystem. (n.d.). [Image].

21. Cremation ghat on banks of River Ganga. (n.d.). [Image]. https://i.dailymail.co.uk/i/ pix/2015/09/25/12/2CB9D6AB00000578-3248208-Tourists_are_able_to_experience_ the_Burning_Ghat_from_a_boat_on_-a-6_1443179995377.jpg

22. Cremation ghats on bank of River Ganga. (n.d.). [Image]. https://assets.atlasobscura. com/media/W1siZilsInVwbG9hZHMvcGxhY2VfaWlhZ2VzL2lyZWFhMjYyLWVhNDAt-

NDM4ZSO5YmYzLTFIZGQIMWM2ZTgzODhjYmRjYjU2NmFkMWJiMjgzYl9WYXJhbm-

FzaV9jemVtYXRpb24uanBnllOsWyJwliwidGhlbWliLCJ4MzkwPiJdLFsicClsImNvbnZlcnQiLCItcXVhbGlOeSA4MSAtYXVObylvcmllbnQiXVo/Varanasi_cremation.jpg

23. Alam Khan, M. D. N. (2016, August 27). Activity mapping of River Ganga, Allahabad, India [Image]. https://www.coroflot.com/nooralam90/Thesis-MArch-Urban-Regeneration-2016-REGENERATION-OF-WATERFRONT-ALLAHABAD

24. Shah, P. (2015, April 14). Introducing sacred tanks along holy ghats [lmage]. https:// issuu.com/palakshah55/docs/palak_shah_architecture_portfolio

25. Temple corridor. (n.d.). [lmage]. https://images.assettype.com/fortuneindia\%2 F2019-07\%2F845128b4-bbb0-4384-a444-adfd8a79c5db\%2FNB_00191_FF_copy.jp-

$g ? w=668 \& q=95$ 
26. Before and After images of Kasi Vishwanath temple corridor. (n.d.). [Image]. https:// images.assettype.com/fortuneindia\%2F2019-07\%2Fd494678c-cce4-465d-ada5-75e542le6a52\%2F01_Drone_Survey_High_Res_450x810___750_copy.jpg?w=668\&q=95

27. Perspective images of design proposal. (n.d.). [Image]. https://www.thehindu.com/ news/9pruh2/article26618935.ece/BINARY/VaranasiJPG

28. Meenakshi temple gopuram. (n.d.). [Image]. https://www.thehindu.com/society/history-and-culture/article19896086.ece/alternates/FREE_615/2OFRMEENAKSHI4

29. Telangana and Andhra Pradesh, India. (n.d.). [Map]. https://mapstyle.withgoogle. $\mathrm{com} /$

30. Vijayawada, Andhra Pradesh, India. (n.d.). [Map]. https://mapstyle.withgoogle.com/ 31. Old photographs of Vijayawada,India. (n.d.). [Image]. https://chaibisket.com/rarevja-pics/

32. Vijayawada through the years. (n.d.). [Map]. https://www.google.com/earth/

33. Old photographs of Vijayawada,India. (n.d.). [Image]. https://chaibisket.com/rarevja-pics/

34. Devotees in queue. (n.d.). [Image]. https://images.newindianexpress.com/uploads/ user/imagelibrary/2019/10/7/w900X450/Durgasss.jpg

35. Ramireddy, Y. (2011, September 4). Undavalli caves [Image]. https://en.wikipedia. org/wiki/Undavalli_Caves\#/media/File:Ananta_Padmanabha_Swami_Temple.jpg

36. Kanaka Durga temple view. (n.d.). [Image]. https://www.oneindia.com/india/vijayawada-kanaka-durga-temple-management-to-implement-dress-code-for-devotees- 2829754 html

37. Krishna river and ghats. (n.d.). [Image]. https://www.google.com/maps

38. Niharika, A. (n.d.). Urban facade of Vijayawada [Image]. In NA.

39. Temple as seen from neighboring residential area. (n.d.). [Image]. https://www.google.com/maps

40. Wind direction and Summer temperature. (n.d.). [Graph]. https://weatherspark.com

41. View from temple. (n.d.). [Image]. https://www.google.com/maps

42. Entry road to temple. (n.d.). [Image]. https://www.google.com/maps

43. Residential neighborhood as seen from temple. (n.d.). [Image]. https://www.google. $\mathrm{com} / \mathrm{maps}$

44. Old photographs of Vijayawada,India. (n.d.). [Image]. https://chaibisket.com/rarevja-pics/
45. Old photographs of Vijayawada,India. (n.d.). [Image]. https://chaibisket.com/rarevja-pics/

46. Night view of the temple. (n.d.). [Image]. https://youtube.com

47. Gopuram during night. (n.d.). [Image]. https://tourmyindia.com

48. Niharika, A. (n.d.-a). Logo for this thesis [Logo]. In NA.

49. Sri Yantra. (n.d.). [Icon]. https://en.wikipedia.org/wiki/File:The_Sri_Yantra_in_diagrammatic_form.svg

50. Avatars of Goddess Durga. (n.d.). [Image]. https://floweraura.com

51. Decorated temple and goddess during Sakhambari festival. (n.d.). [Image]. https:// indiatimes.com

52. Old photographs of Vijayawada,India. (n.d.). [Image]. https://chaibisket.com/rarevja-pics/

53. Aerial view of the ghats. (n.d.). [Image]. https://www.google.com/maps

54. Panoramic view of the ghats. (n.d.). [Image]. https://www.google.com/maps

55. Site boundary. (n.d.). [Map]. https://studio.mapbox.com

56. Aerial view of Vijayawada. (n.d.). [Image]. https://indiatimes.com

57. Niharika, A. (n.d.-b). Street character on the way to temple [Images]. In NA

58. View of the temple retaining wall as seen from ghats. (n.d.). [Image]. https://www. google.com/maps

59. Map showing surroundings of temple. (n.d.). [Map]. https://studio.mapbox.com

60. Map showing bubble diagram for design proposal. (n.d.). [Map]. https://studio.mapbox.com

61. Temporary queues held in place for devotees. (n.d.). [Image]. https://indiatimes.com 62. View of the ghat during a festival. (n.d.). [lmage]. https://www.google.com/maps

63. Map showing temporary queues. (n.d.). [Map]. https://studio.mapbox.com

64. Map showing activity mapping of everyday life. (n.d.). [Map]. https://studio.mapbox. com

65. Map showing route taken by devotees. (n.d.). [Map]. https://studio.mapbox.com

66. Traffic on the national highway in Vijayawada. (n.d.). [Image]. https://indiatimes.

com

67. Before and After design proposal. (n.d.). [Map]. https://www.google.com/earth/

68. Farmers ploughing fields. (n.d.). [lmage]. https://deccanherald.com

69. Farmers ploughing fields. (n.d.). [Image]. https://deccanherald.com

70. Map showing canals. (n.d.). [Map]. https://studio.mapbox.com 
71. Farmers irrigating fields. (n.d.). [Image]. https://deccanherald.com

72. Aerial view of Vijayawada. (n.d.). [Image]. https://amaravativoice.com

73. Garbage thrown on the banks of canal. (n.d.). [Image]. https://deccanherald.com

74. Canal pollution due to dumping of waste. (n.d.). [Image]. https://deccanherald.com

75. Beautification of the canal. (n.d.). [Image]. https://deccanherald.com

76. Canal during monsoon. (n.d.). [Image]. https://deccanherald.com

77. Aquatic plant and Water Hyacinth. (n.d.). [Image]. https://indiatimes.com

78. Beautification of the canal. (n.d.). [Image]. https://deccanherald.com

79. Drying and weaving of Water Hyacinth stems. (n.d.). [Image]. https://yourstory.com

80. Neochetina eichhorniae insect. (n.d.). [Image]. https://invasive.org

81. Artificial floating island. (n.d.). [lmage]. https://biomatrixwater.com

82. Canal walkway. (n.d.). [Image]. https://ewscripps.brightspotcdn.com/dims4/ default/a914efa/2147483647/strip/true/crop/640×336+0+50/resize/1200×630!/

quality/90/?url=https\%3A\%2F\%2Fmediaassets.theindychannel.com\%2Fpho-

to\%2F2O18\%2F09\%2F19\%2Fcanal\%2Ol_1537367931975.png_97970921_ver1.O_640_480.

ipg

(n) 83.

net

84. Aerial view of Vijayawada. (n.d.). [Image]. https://amaravativoice.com

85. View of Prakasam Barrage Vijayawada. (n.d.). [Image]. https://amaravativoice.com 86. View of Prakasam Barrage. (n.d.). [Image]. Prakasam Barrage. https://www.agoda. com/en-gb/city/vijayawada-in.html?cid=1844104

\section{TABLES}

1. Pillai, L.D.S. (1 December 1996). Panchang and Horoscope. Asian Educational Services

2. Varanasi: About the city". Official website of Uttar Pradesh Tourism.

[A] Tree Calculator. (2000). Tree Spacing Calculator. https://treeplantation.com/tree-spacing-calculator.html 